\section{Regio- and Stereoselective Synthesis of Acetallic Tetrahydropyrans as Building Blocks for Natural Products Preparation, via a Tandem [4+3]-Cycloaddition/Ozonolysis Process}

\author{
[a] Industrial and Applied Organic Chemistry Research Unity, Department of Organic Chemistry, \\ University of Barcelona, Martí Franquès 1-11, 08028 Barcelona, Spain \\ E-mail: angel.montana@ub.edu \\ [b] X-ray Diffraction Unit. Scientific and Technologic Centers of the University of Barcelona \\ (CCiTUB), University of Barcelona, Solé i Sabarís 1-3, 08028 Barcelona, Spain \\ E-mail: angel.montana@ub.edu
}


36 ABSTRACT:

37

38 A highly versatile synthetic pathway is presented for the preparation of polyfunctionalized acetallic

39 tetrahydropyrans from conveniently substituted 1-methoxy-8-oxabicyclo[3.2.1]-oct-6-en-3-one

40 derivatives, as intermediates in the total synthesis of natural and unnatural products with structural,

41 functional and/or biological importance. This synthetic methodology involves two key steps: a [4 + 3]

42 cycloaddition reaction between an oxyallyl cation and 2-methoxyfuran as a diene, followed by oxidative

43 and/or reductive ozonolysis of the cycloheptenonesubunit. This sequence renders polyfunctionalized 2-

44 methoxytetrahydropyranic products capable of being easily opened under acidic conditions. The key

45 steps, cycloaddition and subsequent ozonolysis were both fully studied under different reaction

46 conditions and using several substrates in order to optimize yields and stereoselectivities and to study

47 the scope of the methodology. It is noteworthy that both reactions proceed with high diastereoselectivity

48 and, in the case of the oxidative ozonolysis, outstanding regioselectivity as well. A chemical library of

4914 polyfunctionalized tetrahydrofurans, having five or seven stereocenters, has been prepared using the

50 detailed approach. 
54 Tetrahydropyran (THP) substructures are present in many wellknown natural products with antiproliferative, antitumor or antibiotic activities. For instance, phorboxazoles,[1] trehazolins,[2] allosamidins,[3] lasonolides,[4] spongistatins,[5] ambruticin,[6] bistramide A,[7] sorangicins,[8] monensins,[9] nigericin,[10] and the antibiotic Ro-21-6150,[11] all bear this structural feature as well as fascinating and important bioactivities (Figure 1). Driven, in part by this realization, the synthesis of THP scaffolds has been widely studied by organic chemists[12] and many different approaches have been developed to obtain the scaffold; the Prins cyclisation,[13] hetero-Diels-Alder cycloadditions,[14] Petasis-Ferrier rearrangement,[15] and the intramolecular oxy-Michael addition,[16] figure prominently among the routes devised to provide facile access to the THP scaffold.

Our interest is focused on the development of a versatile synthetic pathway leading to THP subunits with the desired degrees of functionalization. The key intermediates in this methodology are the C1 difunctionalized 8-oxabicyclo[3.2.1]-oct-6-en-3-one products obtained via a [4 + 3] cycloaddition reaction[17] studied previously in our research group.[18] Furthermore, the 8-oxabicyclo[3.2.1]oct-6-en3 -one framework has been used by others as a key precursor for many different reactions in organic synthesis.[17,19] The synthetic methodology developed herein starts with the [4+3] cycloaddition reaction between C2-functionalized furans III and oxyallyl cation II derived from a dihaloketone I to generate polyfunctionalized 8-oxabicyclo[3.2.1] oct-6-en-3-one products (IV) (Scheme 1). Moreover, we have studied the chemical modification of the ketone group at the $\mathrm{C} 3$ position. Thus, 8oxabicyclo[3.2.1] oct-6-en-3-one products (IV) can be reduced in a diastereoselective way to 8oxabicyclo[3.2.1] oct-6-en-3-ol products (V), which were protected to generate products VI. These products were converted via ozonolysis into final acetallic tetrahydropyranic products VII and VIII (Scheme 1). Both oxidative and reductive ozonolysis conditions have been widely studied to obtain, in a regioselective and stereoselective manner, many different functionalized THP products for use as building blocks in natural products synthesis. Using these methodologies, a chemical library of THP compounds with high molecular diversity has been obtained. The added value of these THP synthons is based on the fact that they are conveniently functionalized at $\mathrm{C} 2$ in such a way as to enable facile hydrolytic ring-opening to generate polyfunctionalized linear building blocks with several stereocenters. Alternatively, these synthons have at $\mathrm{C} 2$ and $\mathrm{C} 6$ positions, hydroxymethyl groups, formyl groups and/or acetal or epoxide functions, useful for anchoring this synthon or subunit to more complex structures or substructures from a natural product.

A similar synthetic approach has also been used by the Pons group[20] in their study of enantioselective enzymatic desymmetrizations of functionalized THP products. However, Pons and co-workers used cycloadducts devoid of $\mathrm{C} 1$ functionalization. compatibility of the method. In our research group we have carried out a systematic study of $[4 \mathrm{C}(4 \pi)+$ 
$893 \mathrm{C}(2 \pi)]$ cycloaddition reactions as relates to our interest in the preparation of polyfunctionalized 90 cycloheptanes from C2-functionalized furans as dienes.[18] This study afforded a wide range of 91 oxabicyclo[3.2.1] oct-6-en-3-ones IV from polyfunctionalized and/or substituted furans III and oxyallyl 92 cations II (derived from dihaloketones I) (Scheme 1 and Table S1, Supporting Information).

93 Examples of 8-oxabicyclo[3.2.1] oct-6-en-3-one derivatives that we and others have synthesized via [4+ 94 3] cycloadditions with $\mathrm{C} 2$ and/or $\mathrm{C} 3$ substituted furans as dienes, are illustrated in Table S1 (Supporting 95 Information). These cycloadducts are excellent precursors from which to prepare polyfunctionalized 96 tetrahydropyrans.

97 


\section{RESULTS AND DISCUSSION}

\subsection{The $[4+3]$ Cycloaddition Step}

The first key step in the synthesis of cycloadduct IV (8-oxabicyclo[ 3.2.1]oct-6-en-3-one), precursor of the tetrahydropyran structures VII and VIII (Scheme 1), was the [4+3] cycloaddition reaction between an oxyallyl cation II generated in situ and a C2-functionalized furan III. This resulting oxabicyclic structure represents a readily accessible scaffold widely used as a polyoxygenated building block for the synthesis of natural products.[17-20]

The cycloaddition reaction $[4 C(4 \pi)+3 C(2 \pi)]$ involving an oxyallyl cation and a furan "diene" has been demonstrated to be a straightforward and scalable means of generating a wide variety of versatile bicyclic intermediates. It also is noteworthy as a facile way of generating four stereocenters in only one step (Scheme 2).[21]

The versatility and the functional group compatibility of the reaction allows the use of different oxyallyl polysubstituted cations with different functionalized furans as well as with pyrroles. The reaction is carried out using a stoichiometric amount of reducing metal, normally activated $\mathrm{Cu}$ or $\mathrm{Zn}$, along with aprotic solvents such as THF or ACN, for $4-9 \mathrm{~h}$ at $-10{ }^{\circ} \mathrm{C}$ or $60^{\circ} \mathrm{C}$, depending on the kinetic or thermodynamic control desired for the cycloaddition reaction.

From the previously synthesized cycloadducts (Table S1, Supporting Information) we selected as a key starting material for this work furan 1 (Scheme 2). We had previously studied and described this key step[18] using different oxyallyl cations and functionalized dienes, in order to demonstrate the versatility of the reaction (Table S1, Supporting Information). Theoretically, the cycloaddition affords four possible diastereoisomers (IVa, IVb, IVc and IVd, see Scheme 2 and Figure 2). However, high diastereoselectivity was observed and thus, when using methoxyfuran 1 as the diene, only cycloadducts $2 \mathrm{a}$ and $2 \mathrm{c}$ were formed in a $97 \%$ yield, with a diastereoisomeric ratio $2 \mathrm{a} / 2 \mathrm{c}=30: 70$. This diastereoselectivity was induced principally by: a) the nature and electrophilic character of the oxyallyl cation, generated in situ, b) the steric hindrance of the diene (depends on the degree of furan substitution), and c) possible coordination effects involving the metallic counterion of the oxyallyl species and the furan substituents.[22] These interactions likely dictate that the $[4+3]$ cycloaddition takes place using either a) a multi-step mechanism which can afford any of the four diastereoisomers, or b) a concerted mechanism that allows only formation of cis-endo adduct IVa or cis-exo product IVc (Figure 2).

The formation of the cis products instead of the trans products is achieved with excellent diastereoselectivity under Hoffmann conditions:[23,17a,17c] $\mathrm{Cu} / \mathrm{NaI}, 50-60{ }^{\circ} \mathrm{C}$ and $\mathrm{CAN}$. When using these reaction conditions no formation of the trans products was observed. This is attributable to the fact that the oxyallyl cation maintains a $\mathrm{W}$ conformation in its approach to the diene (Figure 2). The transition state, proposed for the concerted mechanism, can be compacted or extended, depending on the 
is determined by multiple factors such as the solvent or the nature of substituents at the $\mathrm{C} 2$ and $\mathrm{C} 3$ positions of the furan diene, among others.

Oxyallyl cations II were generated in situ during the cycloaddition reaction from corresponding dihaloketones I (Scheme 1). In the synthesis of the final THP products, the type of oxyallyl cation used in this work originated from 2,4-dibromo-3-pentanone, which can be easily obtained by halogenation of the corresponding aliphatic ketone, following well described procedures.[24] Diastereoisomers 2a and 2c obtained in the [4 +3$]$-cycloaddition reactions were isolated by flash column chromatography and fully characterized. According to the physical and spectroscopic properties of cycloadducts and application of the structural assignment model previously developed in our group,[25] (based on correlations of shielding and deshielding effects of NMR signals), it was possible to unequivocally determine the relative stereochemistry of diastereoisomeric cycloadducts $2 \mathrm{a}$ and $2 \mathrm{c}$. To obtain other THP scaffolds VII and VIII, it was necessary to reduce the carbonyl group of species IV to intermediate alcohols V. Protection of transient alcohol V enabled access to products VI. By virtue of the C6-C7 double bond in VI, final products VII and VIII were easily generated via reductive or oxidative ozonolyses of VI, respectively (Scheme 1).

\subsection{Stereoselective Reduction of the C3 Carbonyl Group}

Different reaction conditions were attempted to optimize the yields and diastereomeric ratios for reduction of the carbonyl group at $\mathrm{C} 3$. For the substrates indicated in Table 1, the method employing $\mathrm{NaBH} 4$ as the reducing agent, in $\mathrm{MeOH}$, at $0{ }^{\circ} \mathrm{C}$ for $7 \mathrm{~h}$ was, in all cases, optimal [called in this article method (a)]. Other methods that were evaluated gave lower yields and worse diastereomeric ratios. These approaches included: Method (b) DIBAL, THF, $-24{ }^{\circ} \mathrm{C}, 6 \mathrm{~h}$, Method (c) NaBH4/MgBr, $\mathrm{MeOH}$, room temp. $6 \mathrm{~h}$, and Method (d) $\mathrm{NaBH} 4 / \mathrm{CeCl} 3, \mathrm{MeOH},-78^{\circ} \mathrm{C}, 4.5 \mathrm{~h}$. among others. The results highlighted in Table 1 confirm the approach of the hydride $\mathrm{H}$ - ion, predicted for the reaction, as described in Figure 3. When methyl substituents at the $\mathrm{C} 2$ and $\mathrm{C} 4$ positions are in a cis-exo configuration (Table 1, Entry 2), the hydride attack takes place on the most accessible face (Si face) giving excellent diastereomeric ratios. Alternatively, when the methyl groups adopt a cis-endo configuration, hydride the attack takes place on the Re face (Table 1, Entry 1). Thus, we may conclude that the stereoselectivity observed in the reduction of the carbonyl group is dictated by the configurations of the $\mathrm{C} 2$ and $\mathrm{C} 4$ substituents in cycloadducts $2 \mathrm{a}$ and 2c (Figure 3).

In order to determine the relative configuration of the reduction products, NMR correlations were used. This method is based on; a) a complete and unequivocal assignment of signals from 1H and 13C NMR spectra, by performing DEPT, selective irradiations and 2D COSY and HSQC experiments, b) careful analyses of $1 \mathrm{H}$ and 13C NMR spectroscopic data and the use of 2D-NOESY experiments, c) the correlation of shielding or deshielding effects exerted by the $\mathrm{C} 3 \mathrm{OH}$ as a function of $\mathrm{C} 1, \mathrm{C} 2$ and $\mathrm{C} 4$ substituent configurations, and d) the application of the Karplus equation, on the basis of coupling 
constants, to find consistency among the dihedral angles between vicinal hydrogen atoms, in the energy minimized conformation, for each relative configuration.

\subsection{Protection of the C3 Alcohol}

In order to prevent the partial or complete oxidation of the alcohol at C3 during the oxidative ozonolysis, this $\mathrm{OH}$ was conveniently protected. Thus, the next step in THP synthesis entailed protection of alcohol V to generate intermediate VI (Scheme 1). Both benzyl and acetyl protecting groups were used for this purpose and substrates 3 and 4 were used as substrates; the corresponding O-protected derivatives were obtained in high to excellent yields (Table 2). Acetylated products 7 and 9 were obtained using acetyl chloride and MeLi (Table 2, Entries 1 and 3 ), and were purified by flash column chromatographic on silica gel. Notably, acetylation of these substrates using Ac2 $\mathrm{O}$ and pyridine, under different reaction conditions also was attempted but gave rise to lower yields potentially due to steric hindrance imposed by the neighboring methyl groups. On the other hand, benzylation of alcohols 3 and 4 to afford products 8 and 10, respectively, was accomplished in high yield using $\mathrm{BnBr} / \mathrm{NaH}$ in the presence of Bu4NI, (Table 2, Entries 2 and 4).

\subsection{Oxidative Ozonolysis}

The final step in the synthesis of the tetrahydropyran products was ozonolysis of the C6-C7 double bond. Both reductive and oxidative ozonolyses were applied to different protected 8oxabicyclo[3.2.1] oct-6-en-3-ol products affording a wide variety of final acetallic THP products enabling us to evaluate the versatility and functional group tolerance of this step. Many different reaction conditions were tried in order to obtain THP scaffolds by an oxidative ozonolysis reaction. Thus, four different oxidizing agents were used: a) $\mathrm{H} 2 \mathrm{O} 2-$ urea complex (UHP), b) $\mathrm{H} 2 \mathrm{O} 2$, c) pyridinium dichromate Furthermore, diazomethane was added at the end of each reaction to convert resulting carboxylic acids to their methyl esters. This approach facilitated the separation and purification of dicarboxylated THPs. Depending on the oxidizing agents and the reaction conditions, more than one product was typically obtained; formyl, epoxide and hydroperoxide acetallic functions were formed on the side chains. This important result is discussed below.

200 Cycloheptenone 11 (Table 3, Entry 3) was also evaluated as a substrate. This compound was obtained by cleavage of the oxygen bridge of intermediate 9 . Cleavage of the cyclic ketal in 9 was carried out with trifluoroacetic acid/water, 1:1, in chloroform, to generate, in excellent yield, cycloheptenone 11 substrates in order to generate polyfunctionalized cycloheptenones as synthons, which can be used as precursors in the synthesis of natural and unnatural products with biological activity.[16-20] The oxidative ozonolysis, using the H2O2-urea complex[26] (UHP) as the oxidizing agent, was studied for three different bicyclic substrates (Table 3, Entries 1-3), using two different "nucleophilic" solvents, 
$\mathrm{MeOH}$ and EtOH (see below), and also different molar ratios of UHP:substrate. The results demonstrated the importance of the type of solvent used, because both $\mathrm{MeOH}$ and $\mathrm{EtOH}$ act as nucleophiles and attack one of the faces of the sp2 reactive center of the Criegee intermediate, in a regioselective manner (Scheme 4). The formation of compounds 12 and 13 could be explained by the mechanism illustrated in Scheme 4. This mechanism involves de stereoselective formation of the exo ozonide because the endo isomer could not be formed due to the steric hindrance exerted by the methyl groups at $\mathrm{C} 2$ and $\mathrm{C} 4$ and the acetate group at $\mathrm{C} 3$. This exo ozonide $9 \mathrm{a}$ rearranges to generate Criegee intermediate (carbonyl oxide) 9b, in a regioselective manner.

216 This regioselectivity may be rationalized by taking into account that ozonolysis involves a [3+2] 1,3-

217 dipolar cycloaddition reaction of ozone with the $\mathrm{C} 6-\mathrm{C} 7$ double bond of 9, leading to the formation of

218 primary ozonide (1,2,3-trioxolane) 9a. A second step is an electrocyclic cycloreversion process of 9a to

219 afford the transient carbonyl oxide (Criegee intermediate) and a stable formyl group. This cycloreversion may proceed in two different ways since the C6-C7 double bond of 9 is unsymmetrically substituted.[27] There are three principal factors affecting the regioselectivity of the cleavage of the unsymmetrically substituted ozonide.[28] These include: a) the electronic effect (inductive effect) of the substituents attached directly to the $\mathrm{C}=\mathrm{C}$ double bond;[29] b) the electronic effect of the heteroatoms attached at the allylic position (oxygen bridge and $\mathrm{MeO}$ group),[30] and c) the steric effects of the substituents directly attached to the $\mathrm{C}=\mathrm{C}$ bond and at the allylic position.[31] The relative importance of these effects depends on the nature and intensity of the electronic or inductive effect $(+\mathrm{I}$ or $-\mathrm{I})$ and the steric bulkiness of substituents on both the original double bond and the allylic position. Usually the electronic effects are more important than the steric ones but in some cases, if the substituent presents a large steric hindrance, it may compensate or decrease the inductive influences.[30a] Thus, electron-withdrawing substituents can have a strong directing effect on the generation of the carbonyl oxide (Criegee intermediate) from the ozonide to favour the fragmentation mode. This leads to generation of the carbonyl oxide at the alkene carbon most remote from the substituent (OMe).[32] In this sense, it is well-established, for example, that ozonolysis of vinyl chlorides takes place with high regioselectivity to afford the carbonyl oxide on the fragment remote from the halogen atom.[33] The electron-subtracting effect $(-\mathrm{I})$ and the steric hindrance exerted by the methoxy group on $\mathrm{C} 1$ was found to be a determinant, conditioning the direction of rearrangement of $9 \mathrm{a}$, leading to exclusive formation of the transient carbonyl oxide $9 b$. Carbonyl oxide $9 b$ is sterically less-congested than $9 b^{\prime}$ and also more assisted electronically, allowing the stabilization of the resonance forms of the former regioisomer (see Figure 4). In this case, both the electronic and steric factors act synergistically favoring

242 To rationalize the difference of paths (a) and (b) (Figure 4, A) in the cycloreversion of ozonide 9a, 243 QM/MM calculations [DFT B3LYP/6-31++G(d,p)] using Gaussian and semiempirical calculations 244 (PM7) by MOPAC-2012 on the structures of 9a, 9b and 9b' were carried out (Figure 4, A). The 
minimum energy conformations, the formation enthalpies and total steric energies were calculated for these three species. Also, Mulliken atomic charges on the 1,2,3-trioxaciclopentane subunit were obtained. From the resulting data we consider that $9 b$ is thermodynamically more stable than $9 b^{\prime}$, which has a lower formation enthalpy (in absolute value) and higher inner energy (steric energy). On the other hand, carbon atom $\mathrm{C} 7$ in 9a has a positive charge $(+0.5506$ e) whereas $\mathrm{C} 6$ possesses a negative charge ($0.2206 \mathrm{e}$ ). This electron charge distribution is consistent with the previously mentioned factors influencing the regioselectivity, favouring pathway (a) with the carbonyl oxide group away from the methoxy substituent (strain relief) and attached to carbon C6 with higher electron density, which stabilizes the resonant forms by an electron-donating effect. Moreover, in pathway (b), the carbonyl oxide group and the methoxy group are placed in close proximity (rendering steric congestion), and the electron distribution is unfavorable.

256 The carbonyl oxide (Criegee intermediate) is very reactive and, in the absence of a protic nucleophile, a

257 1,3-dipolar cycloaddition reaction of the carbonyl oxide and the co-generated formyl group will take place, leading to formation of a secondary ozonide (molozonide). Ozonolysis in the presence of methanol, ethanol or a similar nucleophile results in their addition to the carbonyl oxide to afford a hydroperoxy-acetal together with the formyl group formed during fragmentation of the primary ozonide.[34,27d] According to our mechanistic proposal, the Criegee intermediate undergoes a stereoselective nucleophilic attack by the nucleophilic solvent through the more accessible site Re face) (Figure 4, B), resulting in formation of 9c, with a hydroperoxide acetal moiety on one side (C6) and a formyl group on the other side (C2). This nucleophilic attack generates a new stereocenter in a stereoselective manner as confirmed by X-ray diffraction analysis on a single crystal of major product 12, which has an S relative configuration on the newly formed asymmetric center. As mentioned previously, this stereoselectivity is a consequence of the preferential attack of the R-OH nucleophile upon the Re face of the sp2 reactive center due to hindrance imposed upon the Si face by the C5 methyl group in the minimum energy conformation of $9 \mathrm{~b}$ (Figure 4, B).[35] In addition, the formyl group of the other side-chain reacts with diazomethane, by a carbene insertion,[36] affording the corresponding epoxide in a stereoselective manner. This stereoselectivity may be explained by the formation of a H-bond between the hydrogen atom of the hydroperoxide group and the oxygen of the pyran ring in the most stable conformation of the molecule as preoptimized by dynamic minimization (Figure 4, C) using the MM2 molecular mechanics algorithm, followed by a semiempirical quantum mechanical PM7 algorithm, implemented using MOPAC software. This H-bond decreases the conformational freedom of the side chain and hinders, together with the methoxy group on

$278 \mathrm{C} 1$, the Re face of the formyl group, in such a way that preferential attack takes place through the Si

279 face, affording the epoxide with the S configuration at the newly formed stereocenter.[37]

280 On the other hand, the easily oxidizable formyl group is, in part, oxidized to the carboxylic acid, under 
methyl esters 13 and 15 . The structure of these compounds was established on the basis of their spectroscopic data and confirmed by X-ray diffraction analysis of single crystals for the case of compound 12 (see Table 5 and Figure S1 from the Supporting Information).

The formation of these acetallic hydroperoxides during ozonolysis is widely described in the literature as the origin of the presence of hydroperoxides and peroxides in the troposphere, due to the reaction of tropospheric ozone with the olefinic VOC (volatile organic compounds) that contaminate the atmospheres of polluted cities.[38] Apart from these studies on environmental chemistry, interesting references dealing with synthetic chemistry have appeared in the bibliography.[39] These compounds having hydroperoxide and epoxide functions could be very useful and versatile in organic synthesis. Their applications as synthons are currently being studied in our laboratory.

292 Comparing entries 1 and 2 (Table 3), it is possible to observe that the global yields of products 12 and

29313 (generated by the action of UHP) are slightly higher than those of products 14 and 15 . The reason for 294 this result may have to do with the use of a molar ratio (oxidant/substrate) that is 2-fold in entry 2 vs. entry 1 . On the other hand, the ratio $12 / 13$ vs. $14 / 15$ changes when increasing the amount of oxidizing agent UHP, to favour ester formation. Besides the H2O2-urea complex, other oxidizing systems were used in this final step of acetallic THP synthesis. In the case of the oxidation with PDC[40] (Table 3, Entry 5), the use of a non-nucleophilic solvent as DCM, led to formation of only the dialdehyde product; solvent attack upon the molozonide intermediate was not evident. Then, the addition of PDC to the reaction medium oxidized both aldehyde groups to the corresponding carboxylic acids, which were efficiently methylated with diazomethane (Scheme 5).

303 The formation of lactone 19 could be explained by the opening of the cyclic acetal of the initial cycloadduct (substrate) and subsequent decarboxylation, under the oxidative conditions. This acetal cleavage generates an $\alpha$-ketocarboxylic system, which decarboxylates (at the original C7 position) and forms a $\gamma$-lactone between the free hydroxyl group and the carboxylic acid, to afford final product 19 after esterification of the free carboxylic acid with diazomethane.

308 Another oxidizing agent used for the oxidative ozonolysis was potassium permanganate[41] (Table 3, 309 Entry 6), which involved the use of aqueous medium at a $\mathrm{pH}$ of 4.4. This method led to over-oxidation of the final product (Scheme 6). On one hand, the benzyl protecting group was oxidized to a benzoyl group (20) and, on the other hand, a partial hydrolysis of the protecting group took place to afford the free hydroxyl group at the $\mathrm{C} 3$ position (21).

\subsection{Reductive Ozonolysis}

A large number of procedures and reagents $(\mathrm{Pt} / \mathrm{H} 2, \mathrm{BH} 3, \mathrm{Mg} / \mathrm{MeOH}, \mathrm{Zn} / \mathrm{HOAc}$, LiAlH4, NaBH4, $\mathrm{PPh} 3, \mathrm{Me} 2 \mathrm{~S}, \mathrm{DMSO} / \mathrm{Et} 3 \mathrm{~N}$, etc.) have been described for reduction of ozonides to carbonyl or alcohol groups.[42] We have used two reduction methods: a) successive use of $\mathrm{SMe} 2$ and $\mathrm{NaBH} 4$ as reducing 
compounds was the reductive ozonolysis of 8-oxabicyclo[3.2.1] oct-6-en-3-ol derivatives VI (Scheme 1), having the $\mathrm{C} 3 \mathrm{OH}$ group protected with either acetyl or benzyl. The same reaction conditions and solvent were used in all cases.[43] The successive addition of SMe2 and NaBH4 as reducing agents, within an interval of $20 \mathrm{~min}$, in a solvent system of DCM/methanol (4:1), gave very good results, always affording the desired final products with good to excellent yields. (Table 4). The use of two consecutive reducing agents led to complete reduction of the ozonide intermediate and the formation of two hydroxylmethyl side chains at original positions C6 and C7 (Scheme 7). In the case of THP compound 25 (Table 4, Entry 3) only dimethyl sulfide was used as reducing agent and, in this case, the reduction of the ozonide group afforded the dialdehyde compound without any dialcohol formation. The yield obtained in this case was the lowest of all reductive ozonolyses carried out. On the other hand, in entry 1 it was observed that only a very small amount of transacetallization product 23 was isolated ( $1 \%$ yield). We think of this byproduct as an artifact generated during silica gel column chromatography of compound 22. The structure of 23 was confirmed by X-ray diffraction analysis (see Table 5 and Figure S2 from the Supporting Information). Notably, this transesterification is feasible in the case of a $4 \mathrm{R}^{*}$ configuration with the $\mathrm{OBn}$ group at $\mathrm{C} 4$ and the $\mathrm{HOCH} 2$ group at $\mathrm{C} 6$ in a trans relationship. In the case of the epimer with a $4 \mathrm{~S}^{*}$ configuration, attack of the hydroxide group may be more difficult due to stereo-electronic reasons. To confirm this idea, 22 and 24 were independently reacted for $3 \mathrm{~d}$ at room temp. with catalytic amounts of aqueous $\mathrm{HCl}$ in $\mathrm{CHCl} 3$ (see Experimental Section and bottom of Scheme 7). We observed formation of 23 from 22 in a $70 \%$ yield but could find no evidence for formation of the corresponding dioxabicycle derived from 24 . We envision however, that under stronger acidic conditions, it may be possible to effect such transacetallization.

340 It is worth noting that very high yields were obtained when using SMe2 and NaBH4 and that great functional group compatibility was observed. All functional groups present on the substrates (benzyl, acetyl or methoxy groups, in general) remained unchanged during the course of these reactions The synthesized THP compounds, having a $\mathrm{C} 2$ acetallic function, enable preparation of a chemical library of cyclic and linear building blocks for the synthesis of strategic subunits of complex natural products. The acetal function may be easily opened, and in a chemoselective manner, under moderate acidic conditions, afford access to polysubstituted and/or polyfunctionalized linear synthons. This methodology is very versatile, in such a way that the degree of functionalization may be designed from the beginning, starting from the conveniently substituted $\alpha, \alpha^{\prime}$-dihaloketones and $\mathrm{C} 2$-functionalized furans, as substrates for the initial [4+3]-cycloaddition reaction. The stereochemistry of all asymmetric centers may be also conveniently controlled. Important efforts to develop this last step in the THP production sequence are currently being carried out in our lab and the results will be published in due 


\section{3. CONCLUSIONS}

355

356 In this work, we report a synthetic methodology to prepare a chemical library of polysubstituted

357 acetallic THP synthons. These synthons are subunits present in a wide variety of natural products with

358 interesting structural, functional and/or biological activities. A key step in this synthesis is the final

359 ozonolysis reaction, which has been widely studied, by using different oxidizing and reducing agents,

360 leading to, in a regioselective and diastereoselective manner, the final desired products in medium to

361 excellent yields, depending on the method used. These two key steps, cycloaddition and ozonolysis,

362 were both fully studied under different reaction conditions and using several substrates in order to

363 improve their yields and stereoselectivities and also to understand the scope of the methodology. It is

364 noteworthy that both reactions showed high diastereoselectivity and, in the case of the oxidative

365 ozonolysis, outstanding regioselectivity as well. A chemical library of 14 polyfunctionalized

366 tetrahydrofurans, having five or seven stereocenters, has been prepared using this approach. These C2-

367 functionalized THP products, as acetallic derivatives, could be potentially ringopened under mild

368 conditions to afford linear polyfunctionalized synthons with five stereocenters whose stereochemistry

369 can be designed and controlled. 


\section{Experimental Section}

7.1. General procedures: NMR spectra were recorded with Varian Inova 200 or 300 MHz, Varian Mercury $400 \mathrm{MHz}$ and/or with Bruker DMX $500 \mathrm{MHz}$ instruments. Chemical shifts $(\delta)$ are expressed in ppm vs. tetramethylsilane as an internal standard. IR spectra were recorded with a NICOLET 6700 FTIR by film, KBr pellet or ATR (Attenuated Total Reflectance) methods. Mass spectrometry was performed with a Hewlett-Packard 5890 apparatus, generally under a CI (Chemical Ionization) method by using $\mathrm{NH} 3$ or $\mathrm{CH} 4$ or by direct insertion under Electron Impact a $70 \mathrm{eV}$ and $150^{\circ} \mathrm{C}$. The elemental analyses were obtained using a FISONS Elemental Analyser, Model Na-1500. The samples were previously pyrolyzed at $1000^{\circ} \mathrm{C}$, under an oxygen atmosphere, and the content of carbon, hydrogen and nitrogen determined by evaluating the combustion gases by gas chromatography using a FID detector. Solvents were dried, according to standard procedures, and distilled prior to use. All other major chemicals were obtained from commercial sources and used without further purification. Gas chromatography was performed using a Shimadzu AOC-20i apparatus with a capillary column (HP-5 Crosslinked $5 \%$ Phe-Me-Siloxane, $0.25 \mu \mathrm{m}$ film thickness, $30 \mathrm{~cm}$ length and $0.32 \mathrm{~mm}$ diameter). Used carrier gas brands and pressures were: $\mathrm{He}=5.5 \mathrm{bar}$ (Linde, Helium 5.0), Air $=3$ bar (Linde, synthetic air), H2 = 3 bar (Linde, Hydrogen 5.0). The experimental conditions are specified in each case. Ozonolysis reactions were carried out using an ozone-generator Fischer Ozone-500 apparatus, under the following conditions: Intensity $=0.25-0.40 \mathrm{~A}, \mathrm{PO} 2=0.25 \mathrm{bar}, \mathrm{O} 3 \mathrm{flow}=50-100 \mathrm{~mL} / \mathrm{min}$.

7.2. Molecular Computer Calculations: Geometry and energy calculations were preoptimized by molecular mechanics MM2 followed by semiempirical quantum mechanical PM7 algorithm,[45] implemented using MOPAC-2016 software.[46] This software was also used to calculate the formation enthalpy. Density functional theory (DFT) based methods at the B3LYP functional level, $[47,48]$ were used for subsequent full refinements, within the Gaussian-03W (Revision E.01, version 6.1) software package.[49] For carbon, hydrogen and oxygen atoms, the 6-31++G(d, p) basis set was used,[50] All calculations were performed on the isolated molecules (gas phase), as consideration of solvation by the molecules of the solvent by a polarizable continuum model (PCM)[51] produced a loss in computational performance (increase of $\mathrm{CPU}$ calculation time and change of convergence behavior), but did not result in significant changes of the calculation results.

7.3. X-ray Experimental Data Acquisition for Compounds 12 and 23: Prismatic crystals $(0.1 \times 0.1 \times$ $0.2 \mathrm{~mm}$ ) of both 12 and 23 were selected and independently mounted on an Enraf-Nonius CAD4 fourcircle diffractometer. Unit-cell parameters were determined from automatic centering of 25 reflections $\left(12<\theta<21^{\circ}\right)$ and refined by least-squares method. Intensities were collected with graphite 
monochromatic Mo K $\alpha$ radiation, using $\omega / 2 \theta$ scan-technique. 2664 and 4185 reflections, respectively, were measured in the range $2.22 \leq \theta \leq 29.98$ (for 12) and in the range $2.10 \leq \theta \leq 29.98$ (for 23). 1095 and 1580 reflections, respectively, were assumed as observed applying the condition I $>2 \sigma(\mathrm{I})$. Three reflections were measured every $2 \mathrm{~h}$ as orientation and intensity control, significant intensity decay was not observed. Lorentz-polarization and absorption corrections were made.

413 The structure was solved by direct methods, using SHELXS computer program and refined by fullmatrix least-squares method with SHELX97 computer program,[52] using 2664 reflections, (very negative intensities were not assumed). The function minimized was $\Sigma \mathrm{w} \| \mathrm{Fo}|2-| \mathrm{Fc}|2| 2$, where $\mathrm{w}=$ $416[\sigma 2(\mathrm{I})+(0.0929 \mathrm{P}) 2]-1$, and $\mathrm{P}=(|\mathrm{Fo}| 2+2|\mathrm{Fc}| 2) / 3, \mathrm{f}^{\prime} \mathrm{f}^{\prime}$ and $\mathrm{f}^{\prime \prime}$ were taken from International Tables of 417 X-ray Crystallography.[53] All hydrogen atoms were computed and refined, using a riding model, with an isotropic temperature factor equal to 1.2 times the equivalent temperature factor of the atom to which are linked. The final $\mathrm{R}($ on $\mathrm{F}$ ) factors were: $0.053, \mathrm{wR}(\mathrm{on}|\mathrm{F}| 2)=0.178$ and goodness of fit $=0.867$ for all observed reflections, corresponding to 12 and 0.065 , $w R($ on $|F| 2)=0.115$ and goodness of fit $=0.992$ for all observed reflections, corresponding to 23 . The number of refined parameters was 215 for 12 and 262 for 23. Maximum shift/esd $=0.00$ and mean shift/esd $=0.00$. Maximum and minimum peaks in final difference synthesis was 0.253 and -0.240 e $\AA-3$, respectively, for 12 and 0.186 and -0.188 e $\AA-3$, respectively, for 23. Heteroatom and hydrogen atoms were located in the difference Fourier map and were isotropically refined; all others were placed onto calculated positions. The crystal data and a summary of the data collection for 12 and 23 are summarized in Table 5.

\subsection{Synthetic Procedures}

Synthesis of 2,4-Dibromopentan-3-one: 2,4-Dibromopentan-3-one was prepared according to a previously described procedure.[18] See the Supporting Information for a detailed preparation method.

Synthesis of 1-Methoxy-2,4-dimethyl-8-oxabicyclo[3.2.1] oct-6-en-3-one (2a and 2c)

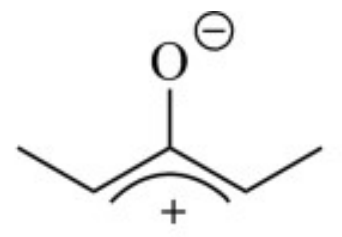<smiles>COc1ccco1</smiles>

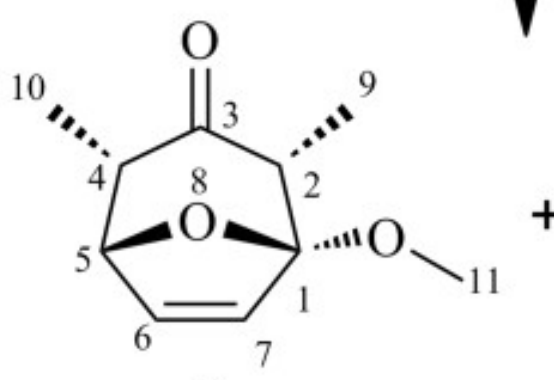

$2 \mathbf{a}$

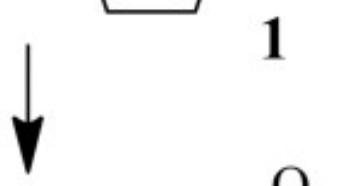

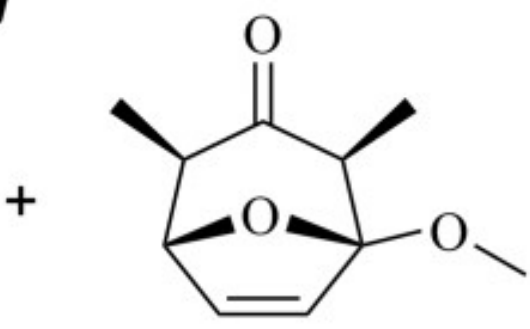

2c 
Copper Powder Activation: In a $250 \mathrm{~mL}$ round-bottomed flask equipped with a stirring bar, a solution of iodine in acetone $(100 \mathrm{~mL}, 2 \% \mathrm{w} / \mathrm{w})$ and copper powder $(10 \mathrm{~g})$ were placed. The mixture was stirred at room temperature for $15 \mathrm{~min}$ and then filtered through a Büchner funnel. The obtained solid was successively washed with $2 \mathrm{M}$ aqueous $\mathrm{HCl}$, distilled water and acetone. Finally, the solid was dried under vacuum obtaining a shiny reddish metallic powder that was stored into a desiccator, pumped out and filled back with argon, and in the dark.

440

[4 +3] Cycloaddition Reaction Procedure: In a two-necked roundbottomed flask equipped with a stirring bar and a Dimroth condenser, commercially available 2-methoxyfuran 1 (4.51 g, $46 \mathrm{mmol})$, activated copper powder (10.17 g, $160 \mathrm{mmol})$, oven-dried $\mathrm{NaI}(45.38 \mathrm{~g}, 303 \mathrm{mmol})$ and anhydrous acetonitrile $(27 \mathrm{~mL})$ were placed, under nitrogen atmosphere. 2,4-Dibromo-3-pentanone $(6.6 \mathrm{~mL}, 48$ $\mathrm{mmol}$ ), freshly percolated through a short pad of anhydrous alumina, was added slowly to the reaction mixture. The system was heated at $55{ }^{\circ} \mathrm{C}$ for $6 \mathrm{~h}$ (monitored by GC and/or TLC). Once conversion was complete, the solvent was removed in vacuo. The resulting crude product was dissolved in cold DCM $(100 \mathrm{~mL})$ and was poured over a mixture of water and crushed ice $(1: 1,100 \mathrm{~mL})$, maintaining the magnetic stirring for $15 \mathrm{~min}$. During this short period, the copper salts precipitated and were filtered out through a Büchner funnel. The filtered liquid was cooled by an icewater bath and transferred to a separation funnel. The organic layer was decanted and kept cold. The aqueous layer was washed with DCM $(6 \times 20 \mathrm{~mL})$ and all organic phases were combined together and successively washed with a cold solution of aqueous NH3 $(25 \%, 2 \times 50 \mathrm{~mL})$ and distilled water $(2 \times 50 \mathrm{~mL})$ until the blue colour due to the $\mathrm{Cu}(\mathrm{NH} 3) 42+$ complex disappeared. The resulting organic phase was dried with anhydrous $\mathrm{MgSO} 4$, filtered and concentrated to dryness. The obtained crude product was submitted to flash column chromatography on silica gel, eluting with mixtures of hexane and ethyl acetate of increasing polarity. The elution with hexane/EtOAc (7:3), afforded first, cis-exo diastereoisomer 2c (2.44 g, $29.1 \%)$ and secondly, cis-endo diastereoisomer 2a (5.69 g, $67.9 \%)$, both as white solids. The global reaction yield was $97 \%$ and the diastereoisomeric ratio $2 \mathrm{a} / 2 \mathrm{c}$ was $70: 30$.

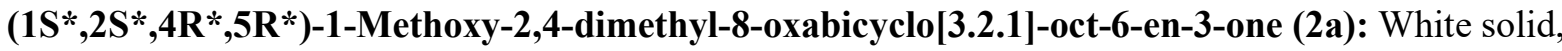
m.p. $=60-61{ }^{\circ} \mathrm{C}$ (diethyl ether). IR (film): $v^{\sim}=3105$ (H-Csp2), 3005, 2960, 2920, 2860 (H-Csp3), 1710 $(\mathrm{C}=\mathrm{O}), 1615(\mathrm{C}=\mathrm{C}), 1460,1450$ (C-C, deform.), 1390, 1380, 1360, 1340, 1310, 1280 (C-H, deform.), 1200, 1170, 1130, 1110 (C-O), 1010, 990, 910, 830, 820, 770, 660 cm-1. 1H NMR (500 MHz, CDCl3): $\delta=0.84(\mathrm{~d}, \mathrm{~J}=7.0 \mathrm{~Hz}, 3 \mathrm{H}, \mathrm{H} 10), 0.91(\mathrm{~d}, \mathrm{~J}=7.0 \mathrm{~Hz}, 3 \mathrm{H}, \mathrm{H} 9), 2.60$ (q, J = 7.0 Hz, $1 \mathrm{H}, \mathrm{H} 2), 2.62$ (dq, $\mathrm{J} 1=4.8, \mathrm{~J} 2=7.0 \mathrm{~Hz}, 1 \mathrm{H}, \mathrm{H} 4), 3.28$ (s, $3 \mathrm{H}, \mathrm{OMe}$ ), 4.73 (dd, J1 = 4.8, J2 = 1.9 Hz, 1 H, H5), 6.06 (d, J $=6.1 \mathrm{~Hz}, 1 \mathrm{H}, \mathrm{H} 7), 6.28$ (dd, J1 = 6.1, J2 = 1.9 Hz, $1 \mathrm{H}, \mathrm{H} 6)$ ppm. 13C NMR (50MHz, CDCl3): $\delta=$ 8.64 (C10), 10.18 (C9), 48.01 (C4), 51.14 (OMe), 54.68 (C2), 79.00 (C5), 112.16 (C1), 132.42 (C7), 136.10 (C6), 208.11 (C3) ppm. MS (DIP-CI, CH4, $\left.70 \mathrm{eV}, 150{ }^{\circ} \mathrm{C}\right): \mathrm{m} / \mathrm{z}(\%)=211(10)$ [M + C2H5], 183 (100) [M + H], 182 (9) [M], 167 (2) [M - CH3], 151 (5) [M - CH3O], 127 (2) [M - C4H7 or 
$\mathrm{C} 3 \mathrm{H} 4 \mathrm{O}], 125$ (2) [M - C4H9 or C3H5O], 95 (7) [M - C5H11O or $\mathrm{C} 4 \mathrm{H} 7 \mathrm{O} 2] . \mathrm{GC}\left(\mathrm{Ti}=50{ }^{\circ} \mathrm{C}, \mathrm{ti}=1\right.$ $\left.\min , \mathrm{r}=10^{\circ} \mathrm{C} / \mathrm{min}, \mathrm{Tf}=250^{\circ} \mathrm{C}, \mathrm{tf}=15 \mathrm{~min}\right): \mathrm{tR}=13.4 \mathrm{~min} . \mathrm{C} 10 \mathrm{H} 14 \mathrm{O} 3(182.22 \mathrm{~g}$ mol-1): calcd. $\mathrm{C}$ 65.92, H 7.74; found C 65.87, H 7.69.

$\left(1 \mathrm{~S}^{*}, 2 \mathrm{R} *, 4 \mathrm{~S}^{*}, 5 \mathrm{R}^{*}\right)-1-$ Methoxy-2,4-dimethyl-8-oxabicyclo-[3.2.1] oct-6-en-3-one (2c): White solid, m.p. $61-62{ }^{\circ} \mathrm{C}$ (diethyl ether). IR (film): $v^{\sim}=3100$ (H-Csp2), 3000, 2970, 2895, 2850 (H-Csp3), 1730, $1715(\mathrm{C}=\mathrm{O}), 1615(\mathrm{C}=\mathrm{C}), 1470(\mathrm{C}-\mathrm{C}$, deform. $), 1340,1310,1300,1280(\mathrm{C}-\mathrm{H}$, deform. $), 1200,1130$, 1100 (C-O), 970, 910, 820, $740 \mathrm{~cm}-1$. 1H NMR (500 MHz, CDCl3): $\delta=1.27$ (d, J = 7.5 Hz, $3 \mathrm{H}, \mathrm{H} 9$ ), 1.36 (d, J = 7.5 Hz, 3 H, H10), 2.23 (q, J = 7.5 Hz, 1 H, H4), 2.54 (q, J = 7.5 Hz, 1 H, H2), 3.42 (s, 3 H, OMe), 4.67 (d, J = 1.4 Hz, 1 H, H5), 6.09 (d, J = 6.2 Hz, 1 H, H7), 6.33 (dd, J1 = 6.2, J2 = 1.4 Hz, 1 H, H6) ppm. 13C NMR (50MHz, CDCl3): $\delta=13.14$ (C9), 17.83 (C10), 47.82 (C4), 51.39 (OMe), 54.05 (C2), 79.72 (C5), 110.27 (C1), 133.39 (C7), 137.01 (C6), 213.74 (C3) ppm. MS (DIP-IE, 70 eV, 150 $\left.{ }^{\circ} \mathrm{C}\right): \mathrm{m} / \mathrm{z}(\%)=182(3)[\mathrm{M}], 167$ (8) [M - CH3], 153 (6) [M - CHO], 125 (37) [M - C4H9 or C3H5O],

[C4H4O]. GC ( $\left.\mathrm{Ti}=50^{\circ} \mathrm{C}, \mathrm{ti}=1 \mathrm{~min}, \mathrm{r}=10^{\circ} \mathrm{C} / \mathrm{min}, \mathrm{Tf}=250^{\circ} \mathrm{C}, \mathrm{tf}=15 \mathrm{~min}.\right): \mathrm{tR}=13.1 \mathrm{~min}$.

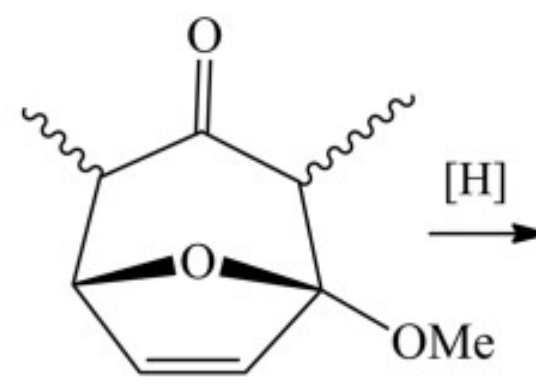

2a (2c)

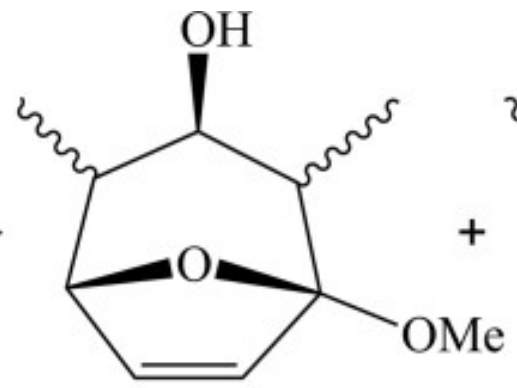

$3(5)$

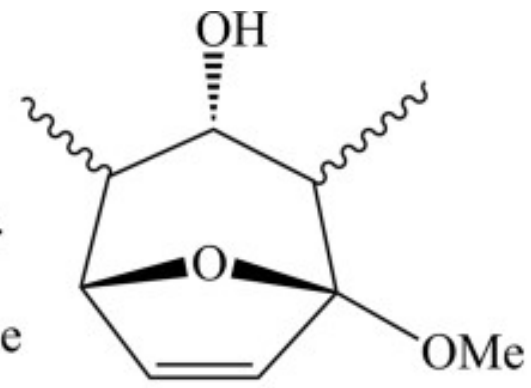

4 (6)

492

493

494

495

496

497

498

499

500

501

In a $50 \mathrm{~mL}$ round-bottomed flask, equipped with a stirring bar and fitted with septa, NaBH4 (1.149 g, $30.4 \mathrm{mmol})$ and anhydrous $\mathrm{MeOH}(5 \mathrm{~mL})$ were placed, under nitrogen atmosphere. The system was cooled by an ice-water bath and the cycloadduct $2 \mathrm{a}$ or $2 \mathrm{c}(7.42 \mathrm{mmol})$, dissolved in anhydrous $\mathrm{MeOH}(7$ $\mathrm{mL}$ ), was slowly added to the reaction flask via syringe. Once the reaction was complete (as determined by TLC and/or GC), excess of $\mathrm{NaBH} 4$ was quenched with distilled water $(2.2 \mathrm{~mL})$ and the resulting mixture was stirred at room temperature for $15 \mathrm{~min}$ at $0{ }^{\circ} \mathrm{C}$. Then, the reaction mixture was concentrated to dryness in vacuo. The resulting crude product was dissolved in anhydrous $\mathrm{CHCl} 3(20 \mathrm{~mL})$ and the organic solution was filtered out via cannula, washing the solid residue $(3 \times 5 \mathrm{~mL}$ of $\mathrm{CHCl3})$. The organic solution was concentrated to dryness and the resulting crude oil was submitted to flash column 
505

506 507

508

509

510

511

512

513

514

515

516

517

518

519

520

521

522

523

524

525

526

527 chromatography on silica gel, eluting with mixtures of hexane and ethyl acetate of increasing polarity. The elution with hexane/EtOAc (7:3), afforded the two diastereomeric alcohols, as white solids, in excellent yields (93-97\%).

$\left(1 S^{*}, 2 S^{*}, 3 R^{*}, 4 R^{*}, 5 R^{*}\right)-1-M e t h o x y-2,4-d i m e t h y l-8-o x a b i c y c l o-[3.2 .1]$ oct-6-en-3-ol (3)

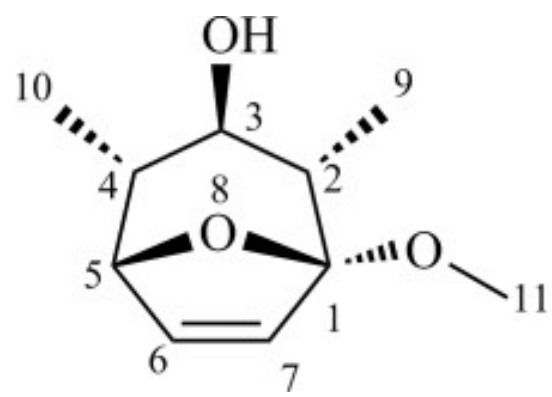

White solid, m.p. $=94-96{ }^{\circ} \mathrm{C}(\mathrm{CHCl} 3) . \mathrm{TLC}: \mathrm{Rf}=0.25(\mathrm{SiO} 2$, hexane/EtOAc, 8:2, developed with anisaldehyde reagent). IR (film): $v^{\sim}=3417$ O-H), 3081 (Csp2-H), 2964, 2935 (Csp3-H), 2877, 2838, $1599(\mathrm{C}=\mathrm{C}), 1457,1374,1341,1300,1256,1221,1189,1164,1117,1088,1034,1007,994,976,959$, $895 \mathrm{~cm}-1.1 \mathrm{H} \mathrm{NMR}(200 \mathrm{MHz}, \mathrm{CDCl} 3): \delta=0.97$ (d, J = 7.0 Hz, $3 \mathrm{H}, \mathrm{H} 10), 1.02$ (d, J = 7.0 Hz, $3 \mathrm{H}$, H9), 1.60-1.80 (m, 2 H, H2, H4), 2.78 (dd, J1 = 8.8, J2 = 8.8 Hz, 1 H, H3), 3.36 (s, 3 H, OMe), 4.60 $(\mathrm{dd}, \mathrm{J} 1=3.6, \mathrm{~J} 2=1.8 \mathrm{~Hz}, 1 \mathrm{H}, \mathrm{H} 5), 6.09$ (d, J = 6.0 Hz, $1 \mathrm{H}, \mathrm{H} 7), 6.30(\mathrm{dd}, \mathrm{J} 1=6.0, \mathrm{~J} 2=1.8 \mathrm{~Hz}, 1 \mathrm{H}$, H6) ppm. 13C NMR (75 MHz, CDCl3): $\delta=12.84$ (C9), 14.20 (C10), 40.89 (C4), 44.69 (C2), 50.69 (OMe), 78.89 (C3), 80.85 (C5), 112.10 (C1), 131.13 (C7), 134.09 (C6) ppm. MS (DIP-CI, NH3, 70 eV, $\left.150{ }^{\circ} \mathrm{C}\right): \mathrm{m} / \mathrm{z}(\%)=219(2)[\mathrm{M}+\mathrm{N} 2 \mathrm{H} 5], 202(100)[\mathrm{M}+\mathrm{NH} 3], 185(42)[\mathrm{M}+\mathrm{H}], 184(7)[\mathrm{M}], 167$ (15) $[\mathrm{M}-\mathrm{OH}], 166(1)[\mathrm{M}-\mathrm{H} 2 \mathrm{O}], 153$ (2) $[\mathrm{M}-\mathrm{OMe}], 152[\mathrm{M}-\mathrm{MeOH}] . \mathrm{GC}\left(\mathrm{Ti}=50^{\circ} \mathrm{C}, \mathrm{ti}=1 \mathrm{~min}, \mathrm{r}\right.$ $\left.=10^{\circ} \mathrm{C} / \mathrm{min}, \mathrm{Tf}=250^{\circ} \mathrm{C}, \mathrm{tf}=30 \mathrm{~min}\right): \mathrm{tR}=9.13 \mathrm{~min} . \mathrm{C} 10 \mathrm{H} 16 \mathrm{O} 3(184.235 \mathrm{~g}$ mol-1): calcd. $\mathrm{C} 65.19$, H 8.75; found C 65.23, H 8.67.

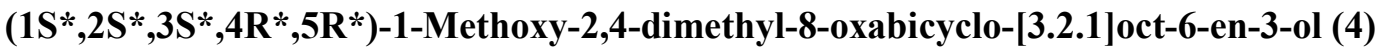

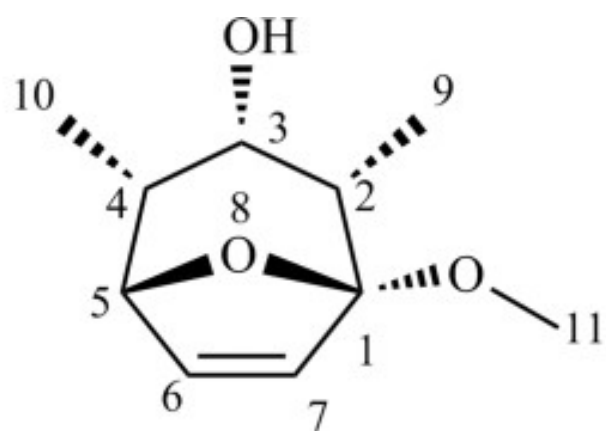


White solid, m.p. $=44-45{ }^{\circ} \mathrm{C}(\mathrm{CHCl} 3) . \mathrm{TLC}: \mathrm{Rf}=0.42(\mathrm{SiO} 2$ eluted with hexane/EtOAc, 8:2, developed with anisaldehyde reagent). IR (film): $v^{\sim}=3494$ (O-H, st), 3081 (H-Csp2, st), 2965, 2934, 2838 (H-Csp3, st), 1663 (C=C, st), 1454, 1406 (C-C, deform.), 1375, 1346 (C-H, deform.), 1190, 1163, 1119, 1080, 1038, 1014, 989 (C-O, st), 966, 879, 853, 807, 762, 740 cm-1. 1H NMR (200 MHz, CDCl3): $\delta=0.98$ (d, J = 7.4 Hz, 3 H, H10), 1.05 (d, J = 7.4 Hz, 3 H, H9), 2.05-2-2 (m, 2 H, H2, H4), $3.34(\mathrm{~s}, 3 \mathrm{H}, \mathrm{OMe}), 3.75(\mathrm{dd}, \mathrm{J} 1=5.5, \mathrm{~J} 2=5.5 \mathrm{~Hz}, 1 \mathrm{H}, \mathrm{H} 3), 4.60(\mathrm{dd}, \mathrm{J} 1=1.5, \mathrm{~J} 2=1.5 \mathrm{~Hz}, 1 \mathrm{H}, \mathrm{H} 5)$, $6.31(\mathrm{~d}, \mathrm{~J}=6.4 \mathrm{~Hz}, 1 \mathrm{H}, \mathrm{H} 7), 6.60$ (dd, J1 = 6.4, J2 = 1.8 Hz, $1 \mathrm{H}, \mathrm{H} 6)$ ppm. 13C NMR (75 MHz, CDCl3): $\delta=11.50$ (C9), 12.62 (C10), 38.92 (C4), 42.09 (C2), 50.52 (OMe), 72.77 (C3), 82.03 (C5), 111.38 (C1), 134.94 (C7), 138.81 (C6) ppm. MS (DIPCI, CH4, $\left.70 \mathrm{eV}, 150{ }^{\circ} \mathrm{C}\right): \mathrm{m} / \mathrm{z}(\%)=213(1)[\mathrm{M}+$ C2H5], 185 (100) [M + H], 183 (18) [M - H], 169 (22) [M - CH3], 167 (79) [M - OH], 153 (24) [M CH3O], 139 (15) [M - C2H5O], 107 (7) [M - C3H9O], 95 (19) [M - C4H9O2]. GC (Ti = 50 ${ }^{\circ} \mathrm{C}, \mathrm{ti}=1$ $\left.\min , \mathrm{r}=10{ }^{\circ} \mathrm{C} / \mathrm{min}, \mathrm{Tf}=250{ }^{\circ} \mathrm{C}, \mathrm{tf}=30 \mathrm{~min}\right): \mathrm{tR}=9.06 \mathrm{~min} . \mathrm{C} 10 \mathrm{H} 16 \mathrm{O} 3(184.235 \mathrm{~g} \mathrm{~mol}-1)$ : calcd. $\mathrm{C}$ 65.19, H 8.75; found C 65.16, H 8.82.

541

White solid, m.p. $=49.5-51.5^{\circ} \mathrm{C}$ (hexane). IR (KBr): $v^{\sim}=3473(\mathrm{O}-\mathrm{H}), 3077(\mathrm{H}-\mathrm{Csp} 2, \mathrm{st}), 2940(\mathrm{H}-$

Csp3, st), 2838, 1605 (C=C), 1466, 1379, 1325, 1286, 1223, 1178, 1134, 1103 (C-O), 1084, 1007, 984, 964, $931 \mathrm{~cm}-1$. 1H NMR (300 MHz, CDCl3): $\delta=1.10$ (d, J = 6.9 Hz, $3 \mathrm{H}, \mathrm{H} 9), 1.16$ (d, J = 7.5 Hz, 3 H, H10), 1.80 (dq, J1 = 6.9, J2 = 7.5 Hz, 1 H, H4), 2.09 (dq, J1 = 6.9, J2 = 6.9 Hz, 1 H, H2), 3.37 (s, 3 H, OMe), 4.01 (m, 1 H, H3), 4.62 (d, J = 1.8 Hz, 1 H, H5), 5.97 (d, J = 6.0 Hz, 1 H, H7), 6.24 (dd, J1 = 6.0, J2 = 1.8 Hz, 1 H, H6) ppm. 13C NMR (75 MHz, CDCl3): $\delta=8.49$ (C10), 13.65 (C9), 34.37 (C4), 39.96 (C2), 50.87 (OMe), 68.35 (C3), 81.75 (C5), 111.27 (C1), 131.61 (C7), 134.53 (C6) ppm. MS (DIP-CI, NH3, $\left.70 \mathrm{eV}, 150{ }^{\circ} \mathrm{C}\right): \mathrm{m} / \mathrm{z}(\%)=219$ [M + N2H7], $202(100)[\mathrm{M}+\mathrm{NH} 4], 185(27)[\mathrm{M}+\mathrm{H}]$, 184 (2) [M], 169 (1) [M - CH3], 167 (8) [M - OH], 153 (2) [M - CH3O], 152 (1) [M - CH4O], 151 (1) [M - CH5O], 136 (9) [M - CH4O2], 134 (1) [M - CH6O2]. C10H16O3 (184.235 g mol-1): calcd. C 65.19, H 8.75; found C 65.21, H 8.78. 


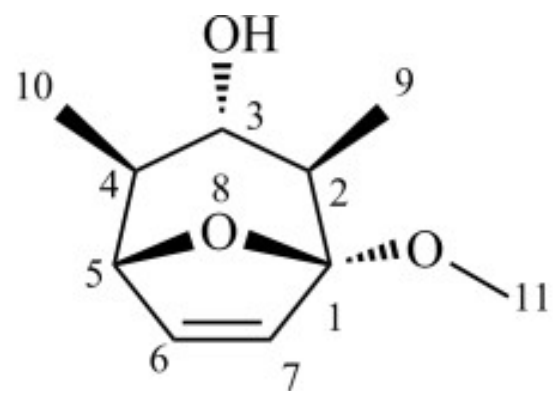

Colourless oil. IR (film): $v^{\sim}=3477(\mathrm{O}-\mathrm{H}), 3077,2936,2836,1653(\mathrm{C}=\mathrm{C}), 1468,1402,1377,1325$,
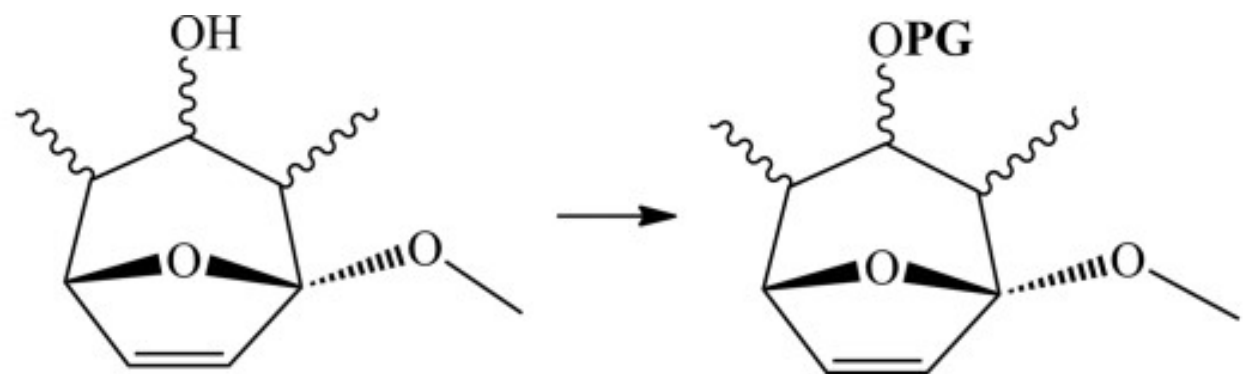

\section{Method (a): Protection of Cycloadducts 3 and 4 with $\mathrm{CH} 3 \mathrm{COCl} / \mathrm{MeLi}$}

In a $50 \mathrm{~mL}$ round-bottomed flask equipped with a stirring bar and an ice-water bath and fitted with septa, the corresponding cycloadduct 3 (4) (1 g, $5.43 \mathrm{mmol})$ was placed, dissolved in anhydrous THF $(16 \mathrm{~mL})$, under nitrogen atmosphere. Once the solution was cooled to $0{ }^{\circ} \mathrm{C}$, MeLi in hexane $(1.6 \mathrm{M}, 3.6$ $\mathrm{mL}, 5.7 \mathrm{mmol}$ ) were added by syringe; $15 \mathrm{~min}$ later, $\mathrm{CH} 3 \mathrm{COCl}(448 \mu \mathrm{L}, 5.7 \mathrm{mmol})$ was added and the reaction mixture was stirred for $1.5 \mathrm{~h}$. Once the reaction was complete (as determined by TLC), the 
via cannula to remove solid $\mathrm{LiCl}$. The solution was concentrated to dryness and the resulting residue was submitted to flash column chromatography on silica gel, eluting with mixtures of hexane and EtOAc of increasing polarity. The elution with hexane/ EtOAc (7:3), afforded the corresponding final products as white solids 7 (920 mg, $75 \%$ ) and (9) (944.5 mg, $77 \%$ ), respectively.

\section{Method (b): Protection of Cycloadducts 3 and 4 with $\mathrm{BnBr} / \mathrm{NaH}$}

In a round-bottomed flask equipped with a stirring bar and a Liebig condenser, the corresponding cycloadduct 3 (4) (100 mg, $0.548 \mathrm{mmol}), \mathrm{NaH}$ (60\% on paraffin, $80.5 \mathrm{mg}, 2.01 \mathrm{mmol}$ ), and anhydrous THF $(2 \mathrm{~mL})$ were placed under nitrogen atmosphere. The mixture was heated to reflux and stirred for 30 min. Then, benzyl bromide ( $98 \%$, $0.2 \mathrm{~mL}, 1.68 \mathrm{mmol})$, and Bu4NI (26 mg, $0.07 \mathrm{mmol}$ ) dissolved in anhydrous THF $(2 \mathrm{~mL})$ were added. The mixture was then stirred under reflux for $5 \mathrm{~h}$. After reaction completion (as determined by TLC), the reaction mixture was cooled with a water/ice bath and the excess of $\mathrm{NaH}$ was quenched by adding distilled water $(0.1 \mathrm{~mL})$ and stirring the mixture for $15 \mathrm{~min}$. The mixture was dried with anhydrous $\mathrm{MgSO} 4$, filtered, and concentrated to dryness. The resulting crude was submitted to flash column chromatography on silica gel, eluting with mixtures of hexane and EtOAc of increasing polarity. The elution with hexane/EtOAc (7:3), afforded the corresponding final

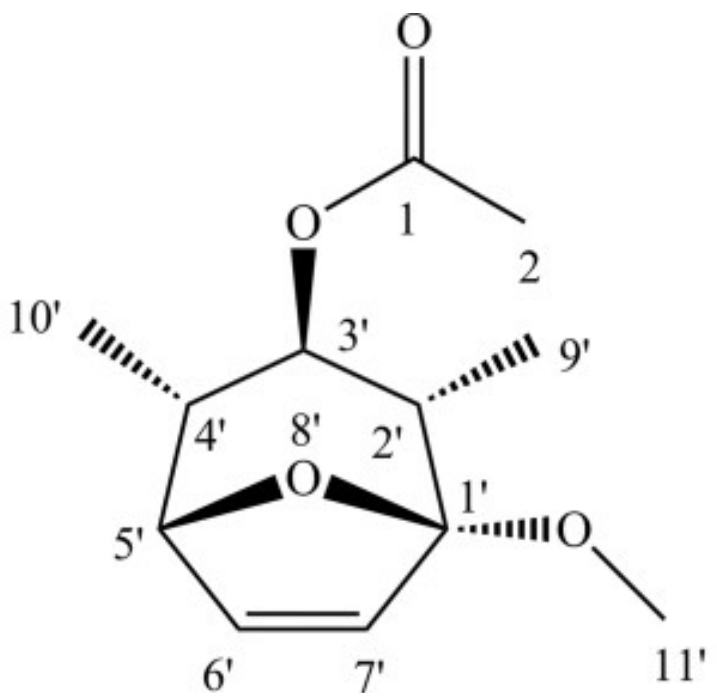

610 White solid, m.p. $=35-37^{\circ} \mathrm{C}$ (ethyl acetate). TLC: $\mathrm{Rf}=0.91(\mathrm{SiO} 2$, hexane/EtOAc, 7:3, developed with 611 anisaldehyde reagent). IR (film): $v^{\sim}=3081$ (H-Csp2), 2966 (H-Csp3, st), 1739 (C=O, st), 1457, 1376, 612 1341, 1247 (C-O), 1191, 1117, 1090, 1032, 999, 913 cm-1. 1H NMR (200 MHz, CDCl3): $\delta=0.82$ (d, J $\left.613=7.0 \mathrm{~Hz}, 3 \mathrm{H}, \mathrm{H} 10^{\prime}\right), 0.86\left(\mathrm{~d}, \mathrm{~J}=7.0 \mathrm{~Hz}, 3 \mathrm{H}, \mathrm{H} 9^{\prime}\right), 1.8-2.0$ (m, $2 \mathrm{H}, \mathrm{H} 2^{\prime}$ and H4'), 2.08 (s, $3 \mathrm{H}, \mathrm{H} 2$ ), 
3.36 (s, $3 \mathrm{H}, \mathrm{H} 11^{\prime}$ ), 4.41 (br. t, J = $\left.8.8 \mathrm{~Hz}, 1 \mathrm{H}, \mathrm{H3}{ }^{\prime}\right), 4.61$ (dd, J1 = 4.2, J2 = 2.2 Hz, 1 H, H5'), 6.14 (d, J

625

626 $\left.=5.8 \mathrm{~Hz}, 1 \mathrm{H}, \mathrm{H}^{\prime}\right), 6.38\left(\mathrm{dd}, \mathrm{J} 1=6.1, \mathrm{~J} 2=2.0 \mathrm{~Hz}, 1 \mathrm{H}, \mathrm{H}^{\prime}\right)$ ppm. 13C NMR (50 MHz, CDCl3): $\delta=$ 12.7 (C9' ), 14.0 (C10), 21.1 (C2), 38.4 (C4'), 41.9 (C2'), 50.8 (C11'), 79.2 (C3'), 80.7 (C5'), 111.9

(C1'), $131.3\left(\mathrm{C}^{\prime}\right), 134.2\left(\mathrm{C} 66^{\prime}\right), 171.0(\mathrm{C} 1) \mathrm{ppm}$. MS (DIP-CI, NH3, $\left.70 \mathrm{eV}, 150{ }^{\circ} \mathrm{C}\right): \mathrm{m} / \mathrm{z}(\%)=227(7)$ $[\mathrm{M}+\mathrm{H}], 228(6)[\mathrm{M}+\mathrm{H}], 244$ (100) [M + NH4], 245 (13) [M + NH4], 167 (51) [M + H - C2H4O2]. C12H18O4 (226.27 g mol-1): calcd. C 63.70, H 8.02; found C 63.67, H 8.10.

$\left(1 S^{*}, 2 S^{*}, 3 S^{*}, 4 S^{*}, 5 R^{*}\right)-1-M e t h o x y-2,4-d i m e t h y l-8-o x a b i c y c l o-[3.2 .1] o c t-6-e n-3-y l$ Acetate (9)

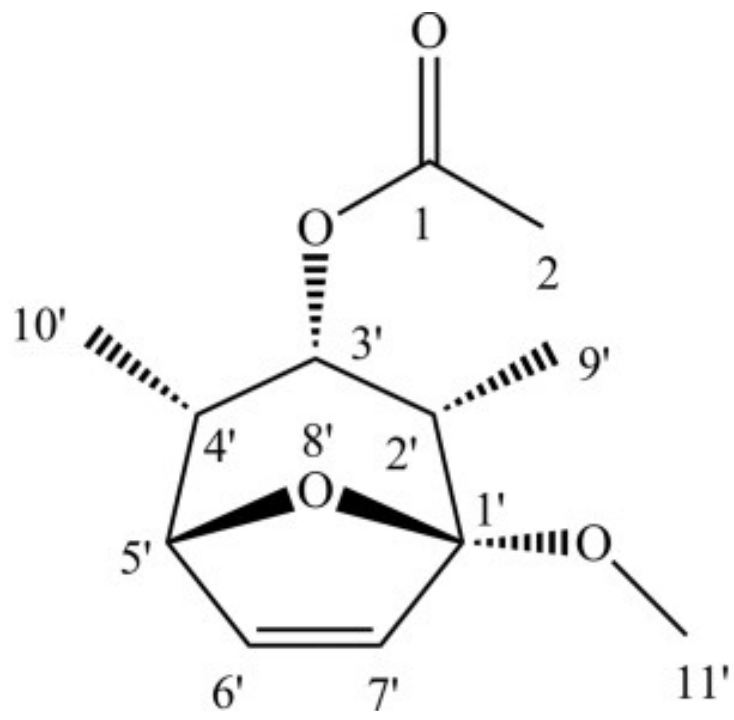

White solid, m.p. $=40-42{ }^{\circ} \mathrm{C}$ (hexane). TLC: $\mathrm{Rf}=0.59(\mathrm{SiO} 2$, hexane/EtOAc, 1:1, developed with anisaldehyde reagent). IR (film): $v^{\sim}=2970,2939,2838$ (H-Csp3, st), $1719(\mathrm{C}=\mathrm{O}, \mathrm{st}), 1673(\mathrm{C}=\mathrm{C})$, 1559, 1541, 1459, 1372, 1335, 1250 (C-O), 1080, 1040, 1014, 995, 941, 879 cm-1. 1H NMR (200 $\mathrm{MHz}, \mathrm{CDCl} 3$ ): $\delta=0.76\left(\mathrm{~d}, \mathrm{~J}=7.4 \mathrm{~Hz}, 3 \mathrm{H}, \mathrm{H10}\right.$ ), 0.83 (d, J = 7.2 Hz, $\left.3 \mathrm{H}, \mathrm{H} 9^{\prime}\right), 2.02$ (s, $\left.3 \mathrm{H}, \mathrm{H} 2\right), 2.2-$ 2.3 (m, 1 H, H2'), 2.3-2.45 (m, 1 H, H4'), 3.34 (s, 3 H, H11'), 4.54 (dd, J1 = 4.5, J2 = 2.4 Hz, 1 H, H5'), 5.32 (br. t, J = 5.5 Hz, $\left.1 \mathrm{H}, \mathrm{H} 3^{\prime}\right), 6.15\left(\mathrm{~d}, \mathrm{~J}=6.0 \mathrm{~Hz}, 1 \mathrm{H}, \mathrm{H} 7^{\prime}\right), 6.41$ (dd, J1 = 6.4, J2 = 1.8 Hz, $1 \mathrm{H}, \mathrm{H} 6^{\prime}$ ) ppm. 13C NMR (50 MHz, CDC13): $\delta=11.24$ (C9'), 12.39 (C10'), 21.07 (C2), 37.85 (C4'), 40.92 (C2'), 51.08 (C11'), $73.11\left(\mathrm{C}^{\prime}\right), 82.12\left(\mathrm{C}^{\prime}\right), 111.86\left(\mathrm{C1}^{\prime}\right), 133.31\left(\mathrm{C} 7^{\prime}\right), 137.17$ (C6'), $171.43(\mathrm{C} 1)$ ppm. MS (DIP-CI, NH3, $\left.70 \mathrm{eV}, 150{ }^{\circ} \mathrm{C}\right): \mathrm{m} / \mathrm{z}(\%)=261$ (9) [M + N2H7], 244 (100) [M + NH4], 227 (76) [M + $\mathrm{H}], 226$ (2) [M], 183 (1) [M- COCH3], 167 [M - OCOCH3].

C12H18O4 (226.27 g mol-1): calcd. C 63.70, H 8.02; found C 63.64, H 8.10. 


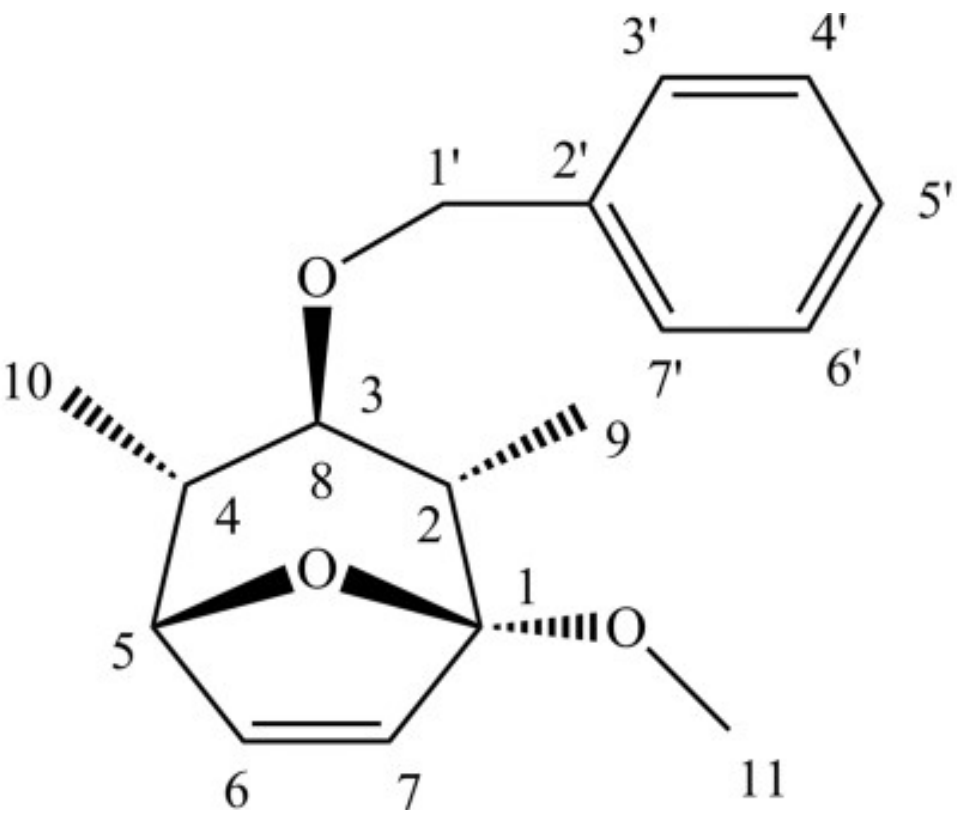

644

645

646

647

663

664

665

Colourless oil. TLC: $\mathrm{Rf}=0.81$ ( $\mathrm{SiO} 2$, hexane/EtOAc, 8:2, developed with anisaldehyde reagent). IR (film): $v^{\sim}=3075$ (H-Csp2), 2935 (H-Csp3, st), 1654 (C=C), 1559, 1497, 1457 (C-C), 1339, 1189, 1075, 1034, 996, 741, 697 cm-1. 1H NMR (200 MHz, CDCl3): $\delta=0.98$ (d, J = 7.0 Hz, 3 H, H10), 1.04 (d, J = 6.8 Hz, 3 H, H9), 1.9-2.1 (m, 2 H, H2 and H4), 2.79 (t, J = 9.2 Hz, 1 H, H3), 3.36 (s, 3 H, H11), 4.57 (s, 3 H, H5 and H1'), 6.11 (d, J = 5.8 Hz, 1 H, H7), 6.34 (dd, J1 = 6.6, J2 = 2.2 Hz, 1 H, H6), 7.37.4 (m, 5 H, H3', H4', H5', H6', H7') ppm. 13C NMR (50 MHz, CDCl3): $\delta=13.2$ (C9), 14.7 (C10), 38.5 (C4), 42.2 (C2), 50.6 (C11), 73.5 (C1'), 80.9 (C3), 87.3 (C5), 112.1 (C1), 127.5 (C4', C6' ), 128.3 (C3', C5', C7'), 131.3 (C7), 133.9 (C6), 138.7 (C2') ppm. MS (DIP-CI, NH3, $70 \mathrm{eV}, 150{ }^{\circ} \mathrm{C}$ ): m/z (\%) = 275 (13) $[\mathrm{M}+\mathrm{H}], 276(3)[\mathrm{M}+\mathrm{H}+1], 292(100)[\mathrm{M}+\mathrm{NH} 4], 293$ (18) $[\mathrm{M}+\mathrm{NH} 4+1] . \mathrm{C} 17 \mathrm{H} 22 \mathrm{O} 3(274.36$ g mol-1): calcd. C 74.42, H 8.08; found C 74.51, H 8.15. 


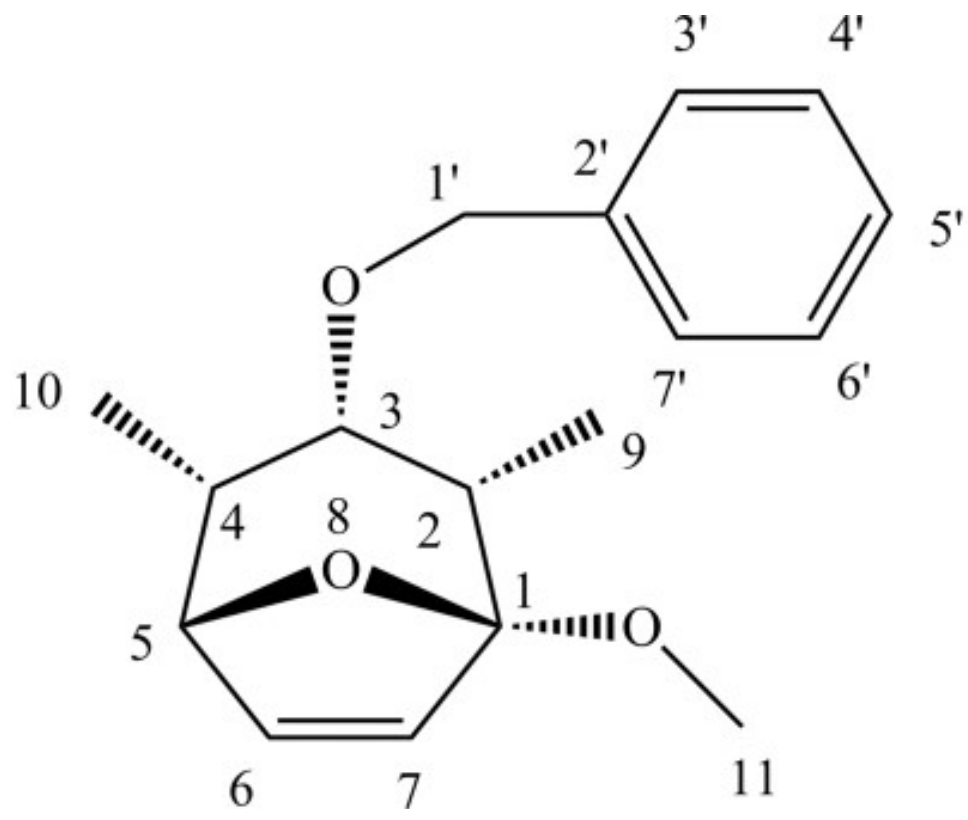

669

670

671 Colourless oil. TLC: $\mathrm{Rf}=0.78$ ( $\mathrm{SiO} 2$, hexane/EtOAc, 7:3, developed with anisaldehyde reagent). IR 672 (film): $v^{\sim}=2935$, (H-Csp3, st), 1603 (C=C), 1497, 1457 (C-C), 1341, 1248, 1191, 1084 (C-O), 1042, 989, 944, 880 cm-1. 1H NMR (200 MHz, CDCl3): $\delta=0.94$ (d, J = 7.5 Hz, 3 H, H10), 1.03 (d, J = 6.9 Hz, 3 H, H9), 2.17-2.26 (m, 1 H, H4), 2.28-2.38 (m, 1 H, H2), 3.33 (s, 3 H, H1 1), 3.57 (dd, J1 = 4.2, J2 $=4.8 \mathrm{~Hz}, 1 \mathrm{H}, \mathrm{H} 3), 4.42\left(\mathrm{~s}, 2 \mathrm{H}, \mathrm{H1} 1^{\prime}\right), 4.50(\mathrm{dd}, \mathrm{J} 1=1.5, \mathrm{~J} 2=1.8 \mathrm{~Hz}, 1 \mathrm{H}, \mathrm{H} 5), 6.13(\mathrm{~d}, \mathrm{~J}=6.0 \mathrm{~Hz}, 1 \mathrm{H}$, H7), 6.39 (dd, J1 = 6.0, J2 = 1.8 Hz, 1 H, H6), 7.3 (m, 5 H, H3', H4', H5', H6', H7') ppm. 13C NMR (50 MHz, CDCl3): $\delta=11.3$ (C9), 12.6 (C10), 39.9 (C4), 43.0 (C2), 50.5 (C11), 76.1 (C1'), 80.7 (C3), 82.0 (C5), $111.6(\mathrm{C} 1), 126.8,127.0$ (C7', C3'), 128.1 (C4', C6'), 132.8 (C7), 137.0 (C6), 139.1 (C2') ppm. MS (DIP-CI, NH3, $\left.70 \mathrm{eV}, 150{ }^{\circ} \mathrm{C}\right): \mathrm{m} / \mathrm{z}(\%)=275$ (100) [M + NH4], 256-257 (13) [M - H2O], 267 (18) [M - C7H7O], 243 (3) [M - MeO]. C17H22O3 (274.36 g mol-1): calcd. C 74.42, H 8.08; found C 74.37, H 7.96. 


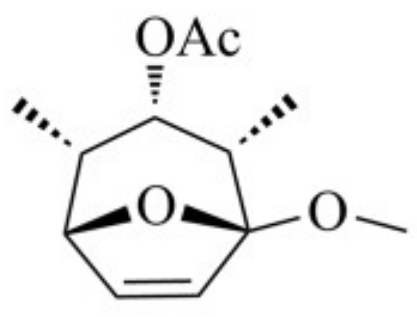

9

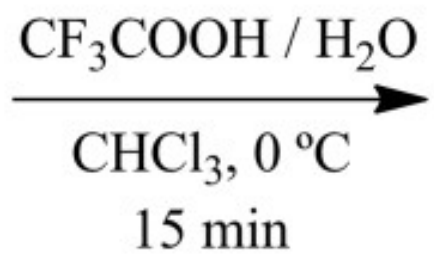

$15 \mathrm{~min}$
693

694

695

696

697

698

699

700

701

702

703

704

705

706

707

708

709

710

711

712

713

714

715

716

717

718

719

In a round-bottomed flask equipped with magnetic stirring, 9 (49.5 $\mathrm{mg}, 0.219 \mathrm{mmol})$ dissolved in

$\mathrm{CHCl} 3(0.66 \mathrm{~mL})$ was placed, under nitrogen atmosphere. The mixture was cooled with a water/ice bath and then trifluoroacetic acid $(0.09 \mathrm{~mL}, 1.16 \mathrm{mmol})$ and distilled water $(0.02 \mathrm{~mL}, 1.1 \mathrm{mmol})$ were added at once. The reaction mixture was stirred for $15 \mathrm{~min}$ and once the reaction was complete (as determined by TLC) the solvent was evaporated under high vacuum at $0{ }^{\circ} \mathrm{C}$. The resulting oil was dissolved in EtOAc and percolated through a shot pad of neutral alumina to afford final product 11 as a white solid. (92\% $42.8 \mathrm{mg})$.

Colourless oil. TLC: $\mathrm{Rf}=0.44$ ( $\mathrm{SiO} 2$, hexane/EtOAc, 1:1, developed with anisaldehyde reagent). IR (film): $v^{\sim}=3405(\mathrm{O}-\mathrm{H}), 2921(\mathrm{H}-\mathrm{Csp} 3, \mathrm{st}), 1746(\mathrm{C}=\mathrm{O}), 1663(\mathrm{C}=\mathrm{O}), 1560(\mathrm{C}=\mathrm{C}), 1542,1453,1380$, 1296, 1227 (C-O), 1177, 1158, 1113, 1072, 1022, 960, 914, 845 cm-1. 1H NMR (200 MHz, CDCl3): $\delta$ $=1.11(\mathrm{~d}, \mathrm{~J}=7.0 \mathrm{~Hz}, 3 \mathrm{H}, \mathrm{H} 9), 1.21(\mathrm{~d}, \mathrm{~J}=6.6 \mathrm{~Hz}, 3 \mathrm{H}, \mathrm{H} 8), 2.05$ (s, $3 \mathrm{H}, \mathrm{H} 2$ ) $), 2.35$ (ddq, J1 = 10.0, J2 $=6.8 \mathrm{~Hz}, \mathrm{~J} 3=1.8 \mathrm{~Hz}, 1 \mathrm{H}, \mathrm{H} 2), 2.96(\mathrm{dq}, \mathrm{J} 1=7.0, \mathrm{~J} 2=1.8 \mathrm{~Hz}, 1 \mathrm{H}, \mathrm{H} 7), 4.27$ (ddd, J1 = 10.0, J2 = 2.2 $\mathrm{Hz}, \mathrm{J} 3=2.2 \mathrm{~Hz}, 1 \mathrm{H}, \mathrm{H} 3), 5.35$ (dd, J1 = 1.8, J2 = 1.8 Hz, $1 \mathrm{H}, \mathrm{H1}$ ), 5.98 (dd, J1 = 2.2, J2 = $13.2 \mathrm{~Hz}, 1$ $\mathrm{H}, \mathrm{H} 4$ or H5), 6.42 (dd, J1 = 2.6, J2 = 13.2 Hz, $1 \mathrm{H}, \mathrm{H} 4$ or H5) ppm. 13C NMR (50 MHz, CDCl3): $\delta=$ 14.70 (C8), 18.30 (C9), 21.12 (C2'), 44.89 (C2), 51.80 (C7), 72.29 (C1), 78.26 (C3), 129.67 (C5), 145.76 (C4), $171.25\left(\mathrm{Cl}^{\prime}\right), 201.22$ (C6) ppm. MS (DIP-CI, NH3, $\left.70 \mathrm{eV}, 150^{\circ} \mathrm{C}\right): \mathrm{m} / \mathrm{z}(\%)=247$ (3) [M $+\mathrm{N} 2 \mathrm{H} 7], 230(100)[\mathrm{M}+\mathrm{NH} 4], 213(4)[\mathrm{M}+\mathrm{H}] . \mathrm{GC}\left(\mathrm{Ti}=50^{\circ} \mathrm{C}, \mathrm{ti}=1 \mathrm{~min}, \mathrm{r}=10^{\circ} \mathrm{C} / \mathrm{min}, \mathrm{Tf}=250\right.$ $\left.{ }^{\circ} \mathrm{C}, \mathrm{tf}=30 \mathrm{~min}\right): \mathrm{tR}=9.36 \mathrm{~min} . \mathrm{C} 11 \mathrm{H} 16 \mathrm{O} 4(212.10 \mathrm{~g}$ mol-1): calcd. $\mathrm{C} 62.25, \mathrm{H} 7.60$; found $\mathrm{C} 62.31, \mathrm{H}$ 7.58 .

General Method for the Oxidative Ozonolysis, Using Ozone-UHP. Synthesis of THP Products: In a two neck round-bottomed flask, equipped with a Dimroth condenser connected to an anhydrous $\mathrm{CaCl} 2$ trap and a magnetic stirring bar, the corresponding cycloadduct $(9,10$ or 11) (104.6 mg, $0.46 \mathrm{mmol})$ 
dissolved in anhydrous $\mathrm{MeOH}(10 \mathrm{~mL})$ was placed. The mixture was cooled with a $\mathrm{CO} 2 /$ acetone bath. Once the system reached $-78^{\circ} \mathrm{C}, \mathrm{O} 3$ was bubbled inside the solution through a diffusor fitted to sideneck of the reaction flask, until the reaction mixture was saturated by ozone and adopted a blue colour. Once the reaction was complete (as determined by TLC), the Dimroth condenser was removed and two

724

725

726

732

733 . septum were fitted to flask necks. Then, the system was purged with nitrogen and the UHP (H2O2-Urea complex) (179.8 mg, $1.87 \mathrm{mmol}, 4.1$ equiv. In the case of substrate 10, 8 equiv. of UHP were used) was added at once under magnetic stirring at $-20{ }^{\circ} \mathrm{C}$. After the addition, the reaction mixture was warmed up to room temperature and stirred for $1.5 \mathrm{~h}$. After $1.5 \mathrm{~h}$, a diazomethane solution in diethyl ether $(15 \mathrm{~mL}$, $4.6 \mathrm{mmol}$ ) was added. The reaction mixture was stirred for $30 \mathrm{~min}$ in the dark and after reaction completion (as determined by TLC), the solvent was evaporated in vacuo. The resulting residue was submitted to flash column chromatography on silica gel, eluting with mixtures of hexane and EtOAc of increasing polarity to afford final THP products $12-16$.

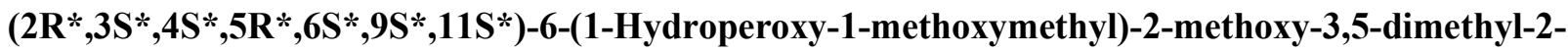
(oxiran-2-yl)tetrahydropyran-4-yl Acetate (12)

\section{(oxiran-2-yl)tetrahydropyran-4-yl Acetate (12)}

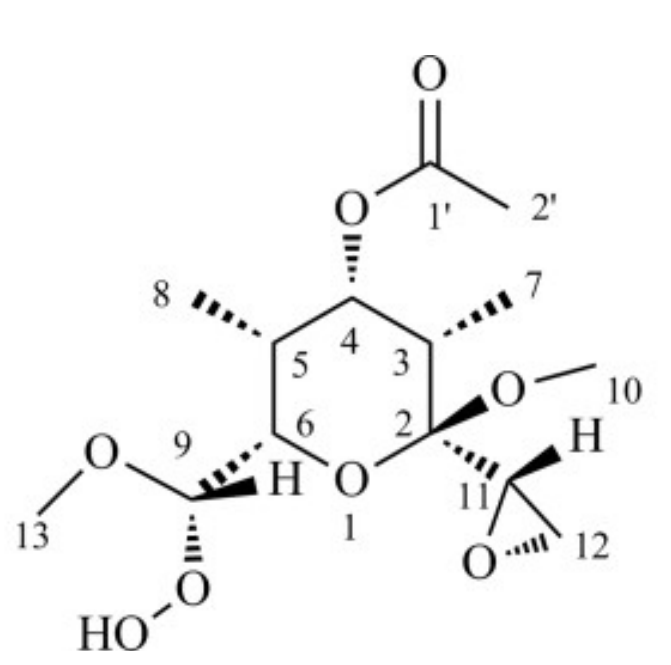

White solid, m.p. $45-47^{\circ} \mathrm{C}$ (ethyl acetate). TLC: $\mathrm{Rf}=0.72$ (SiO2, hexane/ EtOAc, 1:1, developed with anisaldehyde reagent). IR (film): $v^{\sim}=3374(\mathrm{O}-\mathrm{H}), 2984,2950,2842(\mathrm{H}-\mathrm{Csp} 3, \mathrm{st}), 2155,1742(\mathrm{C}=\mathrm{O})$, 1654, 1559, 1541, 1457 (CH3, asym cm-1. def.), 1385, 1250 (C-O, acetate), 1243, 1175 (C-O), 1140, 1115, 1032, 1009, $976 \mathrm{~cm}-1$. 1H NMR (500 MHz, CDCl3): $\delta=0.99$ (d, J = 2.5 Hz, $3 \mathrm{H}, \mathrm{H} 7$ or H8), 1.01 (d, J = 2.5 Hz, 3 H, H7 or H8), 2.07 (s, 3 H, H2'), 2.20-2.25 (m, 1 H, H5), 2.25-2.30 (m, 1 H, H3), $2.67(\mathrm{dd}, \mathrm{J} 1=4.5, \mathrm{~J} 2=6.0 \mathrm{~Hz}, 1 \mathrm{H}, \mathrm{H} 12 \mathrm{a}), 2.72(\mathrm{dd}, \mathrm{J} 1=3.0, \mathrm{~J} 2=6.0 \mathrm{~Hz}, 1 \mathrm{H}, \mathrm{H} 12 \mathrm{~b}), 2.92(\mathrm{dd}, \mathrm{J} 1=$ 3.0, J2 = 4.5 Hz, $1 \mathrm{H}, \mathrm{H} 11$ ), 3.36 (s, $3 \mathrm{H}, \mathrm{H} 10), 3.55$ (s, $3 \mathrm{H}, \mathrm{H} 2$ '), 3.88 (dd, J1 = 3.0, J2 = 7.5 Hz, $1 \mathrm{H}$, H6), 4.65 (d, J = 7.5 Hz, 1 H, H9), 5.31 (dd, J1 = 5.5, J2 = $11.0 \mathrm{~Hz}, 1 \mathrm{H}, \mathrm{H} 4), 8.25$ (br. s, $1 \mathrm{H}, \mathrm{OH}$ ) ppm. 13C NMR (75 MHz, CDCl3): $\delta=8.95$ (C7 or C8), 11.06 (C7 or C8), 21.12 (C2'), 32.24 (C5), 38.30 (C3), 42.95 (C12), 50.20 (C10), 53.72 (C13), 57.63 (C11), 70.64 (C6), 70.87 (C4), 99.24 (C2), 107.05 
(C9), $169.99\left(\mathrm{C1}^{\prime}\right)$ ppm. MS (DIP-CI, NH3, $\left.70 \mathrm{eV}, 150{ }^{\circ} \mathrm{C}\right): \mathrm{m} / \mathrm{z}(\%)=338$ (2) [M + NH4], $320(100)$ [M], 306 (3) [M + H - CH3], 290 (34) [M - OMe + H], 289 (3) [M - OMe], 278 (15), 271 (12) [M OCH3 - H2O], 260 (19) [M - AcOH], 246 (50) [M - C2H2O3], 243 (9) [M - C2H5O3]. (DIP-CI, CH4, $\left.70 \mathrm{eV}, 150^{\circ} \mathrm{C}\right): \mathrm{m} / \mathrm{z}(\%)=320(8)[\mathrm{M}], 303(24)[\mathrm{M}-\mathrm{OH}], 289$ (4) [M - OMe], 271 (100) [M - OCH3 - H2O], 259 (7) [M - C2H5O2], 243 (34) [M - C2H5O3], 212 (21) [M - C2H5O3 - OMe], 183 (13) [M

753

$-\mathrm{C} 2 \mathrm{H} 5 \mathrm{O} 3-\mathrm{AcOH}]$. [Electrospray, $\mathrm{ESP}(+), 1 \mathrm{HCOOH}$ in $\mathrm{ACN} / \mathrm{H} 2 \mathrm{O}, 1: 1]: \mathrm{m} / \mathrm{z}(\%)=338(25)[\mathrm{M}+$ H2O], 307 (30) [M - OMe + H2O], 289 (100) [M - OMe], 271 (85) [M - OMe - H2O], 243 (27) [M C2H5O3]. C14H24O8 (320.34 g mol-1): calcd. C 52.49, H 7.55; found C 52.52, H 7.50.

756

Methyl (2R*,3S*,4S*,5R*,6S*,9S*)-4-Acetoxy-6-(1-hydroperoxy-1-methoxymethyl)-2-methoxy758 3,5-dimethyltetrahydropyran-2-carboxylate (13)

759

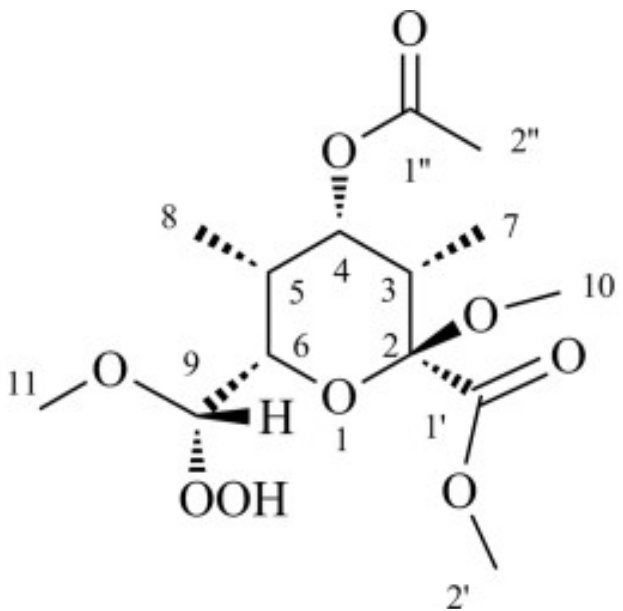

761

762

Colourless oil. TLC: $\mathrm{Rf}=0.55$ ( $\mathrm{SiO} 2$, hexane/EtOAc, 1:1, developed with anisaldehyde reagent). IR (film): $v^{\sim}=3392$ (O-H st), 2936 (H- Csp3, st), 2851, 1744 (C=O), 1654, 1457 (CH3 def asym), 1375 (CH3 def sym), 1239 (C-O st acetate), 1193 (C-O), 1152, 1094, 1067, 1028 (C-O-C st asym cm-1. or C-O st) cm-1. 1H NMR (500 MHz, CDCl3): $\delta=0.90$ (d, J = 7.5 Hz, 3 H, H8 or H9), 1.05 (d, J = 7.0 Hz, 3 H, H8 or H9), 2.07 (s, 3 H, H2"), 2.30-2.34 (m, 1 H, H5), 2.34-2.40 (m, 1 H, H3), 3.18 (s, 3 H, H10), 3.59 (s, 3 H, H11), 3.78 (s, 3 H, H2'), 3.96 (dd, J1 = 3.0, J2 = 7.5 Hz, 1 H, H6), 4.82 (d, J = 7.5 $\mathrm{Hz}, 1 \mathrm{H}, \mathrm{H} 7), 5.29$ (dd, J1 = 6.0, J2 = 11.5 Hz, $1 \mathrm{H}, \mathrm{H} 4), 8.40$ (br. s, $1 \mathrm{H}, \mathrm{OH})$ ppm. 13C NMR (75 MHz, CDCl3): $\delta=8.91$ (C8 or C9), 11.10 (C8 or C9), 21.08 (C2"), 31.91 (C5), 37.66 (C3), 50.91 (C10 or C11), 52.22 (C10 or C11), 57.44 (C2'), 70.31 (C4), 71.27 (C6), 102.77 (C2), 106.66 (C7), 168.18 (C1' or $\left.\mathrm{C} 1^{\prime \prime}\right), 169.77\left(\mathrm{Cl}^{\prime}\right.$ or $\left.\mathrm{C} 1^{\prime \prime}\right)$ ppm. MS (DIP-CI, NH3, $\left.70 \mathrm{eV}, 150^{\circ} \mathrm{C}\right): \mathrm{m} / \mathrm{z}(\%)=320$ (27) [M], $321(5)[\mathrm{M}+\mathrm{H}], 339$ (2) [M + NH4 + H], 338 (13) [M + NH4], 306 (37) [M - MeOH + NH4], 307 (6) $[\mathrm{M}-\mathrm{MeO}+\mathrm{NH} 4], 278$ (6) [M - C2H4O2 + NH4], 262 (25) [M - C2H4O2 + 2 H]. C14H24O9 (336.34 


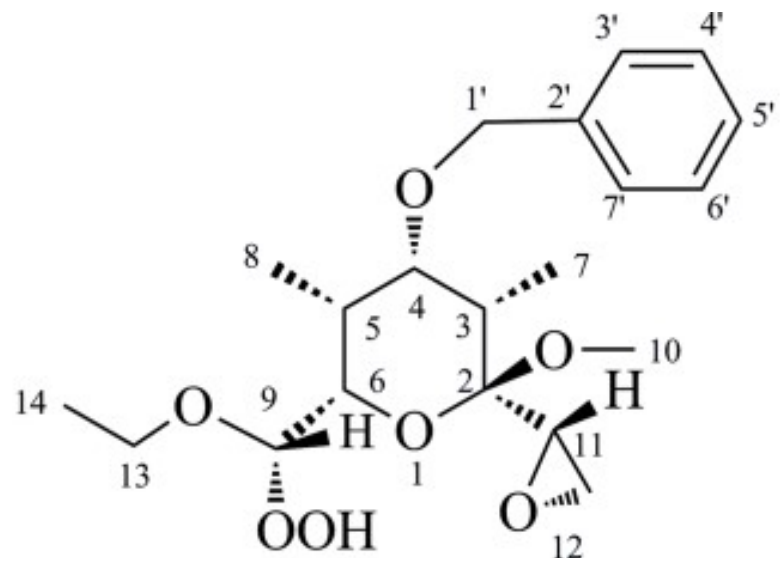

780

781

Colourless oil. TLC: $\mathrm{Rf}=0.71$ (SiO2, EtOAc, developed with anisaldehyde reagent). IR (film): $v^{\sim}=$ 3381 (O-H), 2981, 2931 (H-Csp3, st), 1723, 1654, 1559, 1457 (CH3 def asym), 1357, 1272, 1209, 1115, 1069 (C-O), 1007, 893, 739, 699 cm-1. 1H NMR (500 MHz, CDCl3): $\delta=1.00$ (d, J = 1.5 Hz, 3 H, H7 or H8), 1.02 (d, J = 1.5 Hz, 3 H, H7 or H8), 1.25 (t, J = 6 Hz, 3 H, H14), 2.23-2.40 (m, 2 H, H3 and H5), $2.67(\mathrm{dd}, \mathrm{J} 1=4.0, \mathrm{~J} 2=6.0 \mathrm{~Hz}, 1 \mathrm{H}, \mathrm{H} 12 \mathrm{a}), 2.70(\mathrm{dd}, \mathrm{J} 1=3.0, \mathrm{~J} 2=6.0 \mathrm{~Hz}, 1 \mathrm{H}, \mathrm{H} 12 \mathrm{~b}), 2.93$ $(\mathrm{dd}, \mathrm{J} 1=3.0, \mathrm{~J} 2=4.0 \mathrm{~Hz}, 1 \mathrm{H}, \mathrm{H} 11), 3.35$ (s, $3 \mathrm{H}, \mathrm{H} 10), 3.73$ (dd, J1 = 3.0, J2 = $7.5 \mathrm{~Hz}, 1 \mathrm{H}, \mathrm{H} 6), 3.76$ (m, 1 H, H13), 3.94-3.96 (m, 2 H, H4 and H13), 4.49 (q, J = 12.0 Hz, 2 H, H1'), 4.77 (d, J = 8.0 Hz, 1 H, H9), 7.32-7.33 (m, 5 H, H3', H4', H5', H6' and H7'), 8.40 (br. s, $1 \mathrm{H}, \mathrm{OH})$ ppm. 13C NMR (75 MHz, CDC13): $\delta=8.43$ (C7 or C8), 10.66 (C7 or C8), 15.31 (C14), 32.12 (C5), 38.61 (C3), 42.77 (C12), 50.10 (C10), 53.92 (C11), 66.35 (C13), 69.49 (C1'), 71.24 (C6), 74.74 (C4), 99.05 (C2), 106.05 (C9), 127.10 (C3'), $127.14\left(\mathrm{C}^{\prime}\right), 127.25$ (C4'), 128.22 (C6'), 129.36 (C5'), 138.66 (C2') ppm. MS (DIP-CI, NH3, 70 $\left.\mathrm{eV}, 150{ }^{\circ} \mathrm{C}\right): \mathrm{m} / \mathrm{z}(\%)=294(100)[\mathrm{M}-\mathrm{C} 7 \mathrm{H} 7+\mathrm{NH} 4+\mathrm{H}], 295$ (22) $[\mathrm{M}-\mathrm{C} 7 \mathrm{H} 7+\mathrm{NH} 4+2 \mathrm{H}], 278(7)$ $[\mathrm{M}-\mathrm{C} 2 \mathrm{H} 5 \mathrm{O}-\mathrm{C} 2 \mathrm{H} 3 \mathrm{O}], 367$ (6) $[\mathrm{M}+\mathrm{H}], 349$ (5) [M - H2O + H], 259 (4) [M - BnO]. C20H30O7 
807

808

809

810

811

812

813

814

815

816

817

818

819

820

821

822

823

824

825

826

827

828

829

830

831

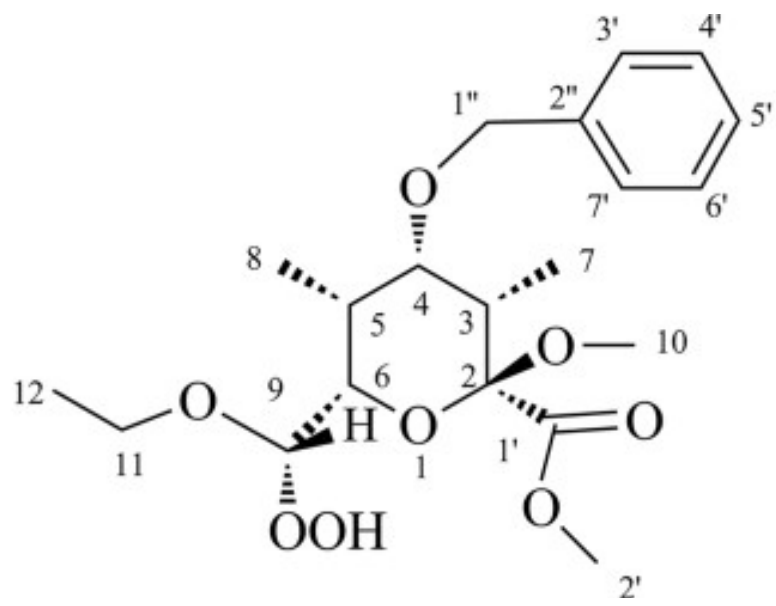

Colourless oil. TLC: $\mathrm{Rf}=0.69$ ( $\mathrm{SiO} 2$, EtOAc, developed with anisaldehyde reagent). IR (film): $v^{\sim}=$ 3396 (O-H st), 2979, 2937 (H- Csp3, st), 1742 (C=O), 1457 (CH3 def asym), 1384 (CH3 def sym), 1275, 1196, 1156 (C-O), 1061, 1027, 787, $699 \mathrm{~cm}-1.1 \mathrm{H} \mathrm{NMR} \mathrm{(500} \mathrm{MHz,} \mathrm{CDCl3):} \delta=0.92$ (d, J = 7.0 Hz, 3 H, H8), 1.07 (d, J = 7.0 Hz, 3 H, H7), 1.26 (t, J = 7.0 Hz, 3 H, H12), 2.34 (ddq, J1 = 3.0, J2 = 5.0 $\mathrm{Hz}, \mathrm{J} 3=7.5 \mathrm{~Hz}, 1 \mathrm{H}, \mathrm{H} 5), 2.40$ (dq, J1 = 2.0, J2 = 7.5 Hz, $1 \mathrm{H}, \mathrm{H} 3), 3.18$ (s, $3 \mathrm{H}, \mathrm{H} 10), 3.79$ (s, $3 \mathrm{H}$, H2'), 3.80-3.83 (m, 2 H, H6 and H1 1), 3.91-3.95 (m, 2 H, H4 and H11), 4.50 (q, J = 13 Hz, 2 H, H1'), 4.95 (d, J = 7.5 Hz, 1 H, H9), 7.20-7.26 (m, 2 H, H4"and H6"), 7.31-7.33 (m, 3 H, H3", H5" and H 7"), 8.75 (br. s, $1 \mathrm{H}, \mathrm{OH}$ ) ppm. 13C NMR (75 MHz, CDCl3): $\delta=8.45$ (C7), 10.80 (C8), 15.39 (C12), 31.94 (C5), 37.91 (C3), 50.74 (C10 or C2'), 52.18 (C10 or C2'), 66.27 (C11), 69.52 (C1"), 71.76 (C6), 74.54 (C4), 103.04 (C2), 105.89 (C9), 127.18 (C3"), 127.36 (C7"), 128.30 (C4" ), 128.42 (C6"), 129.55 (C5"), $138.66\left(\mathrm{C2}^{\prime \prime}\right), 168.61\left(\mathrm{C}^{\prime}\right)$ ppm. MS (DIP-CI, NH3, $\left.70 \mathrm{eV}, 150{ }^{\circ} \mathrm{C}\right): \mathrm{m} / \mathrm{z}(\%)=310$ (95) [M - C7H7 + NH4], 294 (40) [M - BnO + NH4 + H], 341 (26) [M - C2H3O2 + NH4], 324 (25) [M - C2H3O2 + H], 381 (21) [M - H], 291 (21) [M - C7H7], 292 (11) [M - C7H7 + H], 337 (9) [M - EtO], 355 (7) [M $\mathrm{EtO}+\mathrm{NH} 4], 382$ (6) [M], 383 (6) [M + H]. C20H30O8 (398.19 g mol-1): calcd. C 60.29, H 7.59; found C 60.33, H 7.62 . 
835

836

837

838

839

840

841

842

843

844

845

846

847

848

849

850

851

852

853

854

855

856

857

858

859

860

861

(1)

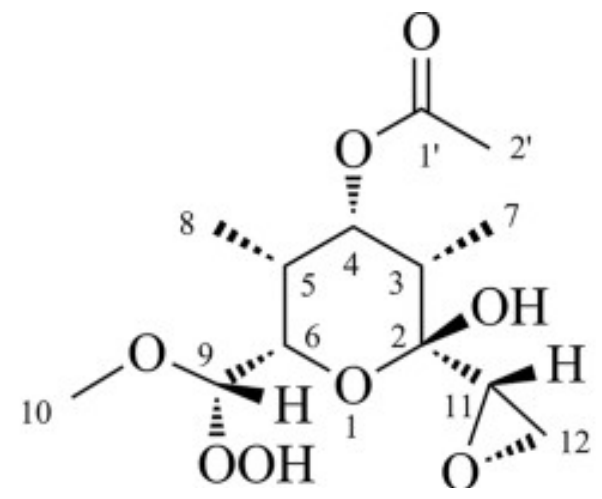

Colourless oil. TLC: $\mathrm{Rf}=0.53(\mathrm{SiO} 2$, hexane/EtOAc, $3: 7$, developed with anisaldehyde reagent). IR (film): $v^{\sim}=3368(\mathrm{O}-\mathrm{H}), 2935$ (H-Csp3, st), $1737(\mathrm{C}=\mathrm{O}), 1652,1561,1459$ (CH3 def asym), 1378, 1243 (C-O, acetate), 1078 (C-O, st), $1026 \mathrm{~cm}-1$. 1H NMR (500 MHz, CDCl3): $\delta=1.01$ (d, J = $7.0 \mathrm{~Hz}$, 3 H, H8), 1.07 (d, J = 7.0 Hz, 3 H, H7), 2.08 (s, 3 H, H2'), 2.09 (dq, J1 = 4.5, J2 = 8.0 Hz, 1 H, H3), 2.32 $(\mathrm{ddq}, \mathrm{J} 1=5.0, \mathrm{~J} 2=8.0 \mathrm{~Hz}, \mathrm{~J} 3=10.0 \mathrm{~Hz}, 1 \mathrm{H}, \mathrm{H} 5), 2.82$ (dd, J1 = 4.0, J2 = 5.5 Hz, $1 \mathrm{H}, \mathrm{H} 11), 3.04$ (dd, $\mathrm{J} 1=2.5, \mathrm{~J} 2=5.5 \mathrm{~Hz}, 1 \mathrm{H}, \mathrm{H} 12), 3.11(\mathrm{dd}, \mathrm{J} 1=3.0, \mathrm{~J} 2=4.0 \mathrm{~Hz}, 1 \mathrm{H}, \mathrm{H} 12), 3.51(\mathrm{~s}, 3 \mathrm{H}, \mathrm{H} 10), 4.32(\mathrm{dd}$, $\mathrm{J} 1=3.0, \mathrm{~J} 2=7.5 \mathrm{~Hz}, 1 \mathrm{H}, \mathrm{H} 6), 4.65$ (d, J = 7.5 Hz, $1 \mathrm{H}, \mathrm{H} 9), 5.35(\mathrm{dd}, \mathrm{J} 1=5.5, \mathrm{~J} 2=11.0 \mathrm{~Hz}, 1 \mathrm{H}, \mathrm{H} 4)$, 8.80 (br. s, $1 \mathrm{H}, \mathrm{OOH})$ ppm. 13C NMR (75 MHz, CDCl3): $\delta=9.02$ (C7 or C8), 10.98 (C7 or C8), 21.05 (C2'), 32.44 (C5), 38.33 (C3), 42.97 (C12), 53.72 (C10), 59.59 (C11), 70.61 (C6), 70.90 (C4), 98.65 (C2), 107.10 (C9), $170.11\left(\mathrm{Cl}^{\prime}\right)$ ppm. MS (DIP-CI, NH3, $\left.70 \mathrm{eV}, 150{ }^{\circ} \mathrm{C}\right): \mathrm{m} / \mathrm{z}(\%)=291(1)[\mathrm{M}+\mathrm{H}]$, 308 (4) [M + NH4], 246 (100) [M - C2H4O], 247 (14) [M - C2H3O], 276 (24) [M - MeOH + NH4], 229 (10) [M - C2H3O - H2O]. C13H22O8 (306.13 g mol-1): calcd. C 50.98, H 7.24; found C 51.03, H 7.31.

2

853

854

85




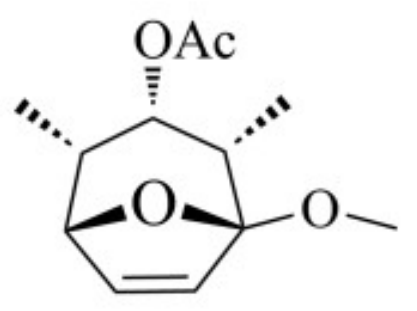

9

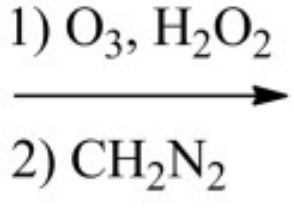

2) $\mathrm{CH}_{2} \mathrm{~N}_{2}$

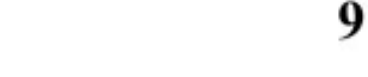

(1)

In a two neck round-bottomed flask, compound $9(100 \mathrm{mg}, 0.44 \mathrm{mmol})$ dissolved in EtOAc $(5 \mathrm{~mL})$ was placed. The mixture was cooled by a solid $\mathrm{CO} 2 /$ acetone bath. Then, $\mathrm{O} 3$ was bubbled inside the solution through a diffusor until the reaction mixture was saturated adopting a blue colour. Afterwards, the system was purged with $\mathrm{N} 2$, in order to remove the excess of ozone, and $\mathrm{H} 2 \mathrm{O} 2(30 \%)(100 \mu \mathrm{L}, 0.88$ mmol) was added at $0{ }^{\circ} \mathrm{C}$. The reaction was stirred for $21 \mathrm{~h}$, and once the reaction was complete (as determined by TLC) the crude was diluted with EtOAc $(10 \mathrm{~mL})$ and the organic phase was washed with a saturated aqueous solution of $\mathrm{Na} 2 \mathrm{CO} 3$. The aqueous phase was acidified with $\mathrm{HCl}$ to $\mathrm{pH} 2-3$ and washed with EtOAc, the organic phases were combined together, dried with anhydrous $\mathrm{MgSO} 4$ and concentrated to dryness. Then, a diazomethane solution in diethyl ether $(15 \mathrm{~mL}, 4.6 \mathrm{mmol})$ and methanol $(5 \mathrm{~mL})$ were added. The reaction solution was stirred for $30 \mathrm{~min}$ in the dark. After reaction completion (as determined by TLC), the solvent was evaporated. The resulting residue was submitted to flash column chromatography on silica gel, eluting with mixtures of hexane and EtOAc of increasing polarity. The elution with hexane/EtOAc, 7:3 gave final product 17 as a colourless oil (34 mg, $25 \%$ ).

TLC: $\mathrm{Rf}=0.28$ ( $\mathrm{SiO} 2$, hexane/EtOAc, 3:7, two elutions, developed with anisaldehyde reagent). IR (film): $v^{\sim}=2956,2850(\mathrm{H}-\mathrm{Csp} 3), 1746(\mathrm{C}=\mathrm{O}), 1767(\mathrm{C}=\mathrm{O}), 1457,1439,1376,1237$ (C-O, acetate), 1196, 1162, 1127, 1082, 1032, 918, $861 \mathrm{~cm}-1$. 1H NMR (200 MHz, CDCl3): $\delta=0.97$ (d, J = $7.2 \mathrm{~Hz}, 3$ H, H7 or H8), 0.98 (d, J = 7.4 Hz, 3 H, H7 or H8), 2.10 (s, 3 H, H2'), 2.43 (dq, J1 = 5.6, J2 = 7.4 Hz, 1 H, H3), 2.56 (m, 1 H, H5), 3.21 (s, 3 H, H9), 3.80 (s, 3 H, H2" or H2"'), 3.83 (s, 3 H, H2" or H2"'), 4.49 $(\mathrm{d}, \mathrm{J}=3.2 \mathrm{~Hz}, 1 \mathrm{H}, \mathrm{H} 6), 5.41$ (dd, J1 = 5.8, J2 = 5.8 Hz, $1 \mathrm{H}, \mathrm{H} 4)$ ppm. 13C NMR (75 MHz, CDCl3): $\delta$ $=9.38(\mathrm{C} 7), 10.96(\mathrm{C} 8), 20.98(\mathrm{C} 2$ '), 33.09 (C5), 37.54 (C3), 51.26 (C9), 52.09 (C2" or C2"'), 52.38 (C2" or C2"'), 69.72 (C4), 71.06 (C6), 103.04 (C2), 167.56 (C1'), 169.47 (C1" or C1"'), 169.71 (C1" or $\left.\mathrm{C}^{\prime \prime \prime}\right)$ ppm. MS (DIP-CI, NH3, $\left.70 \mathrm{eV}, 150{ }^{\circ} \mathrm{C}\right): \mathrm{m} / \mathrm{z}(\%)=336(100)[\mathrm{M}+\mathrm{NH} 4], 318$ (1) [M], 287 (2) 


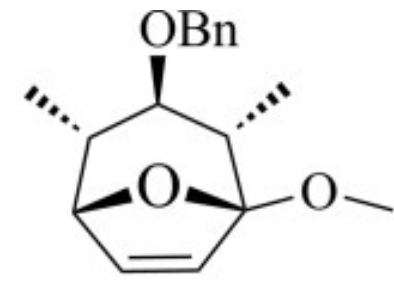

8

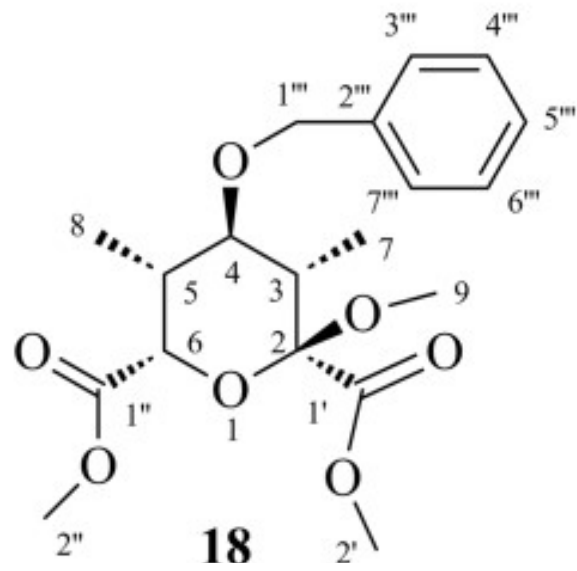

1) $\mathrm{O}_{3}, \mathrm{SMe}_{2}$, PDC

\section{2) $\mathrm{CH}_{2} \mathrm{~N}_{2}$}

899

900

901

902

903

904

905

906

907

908

909

910

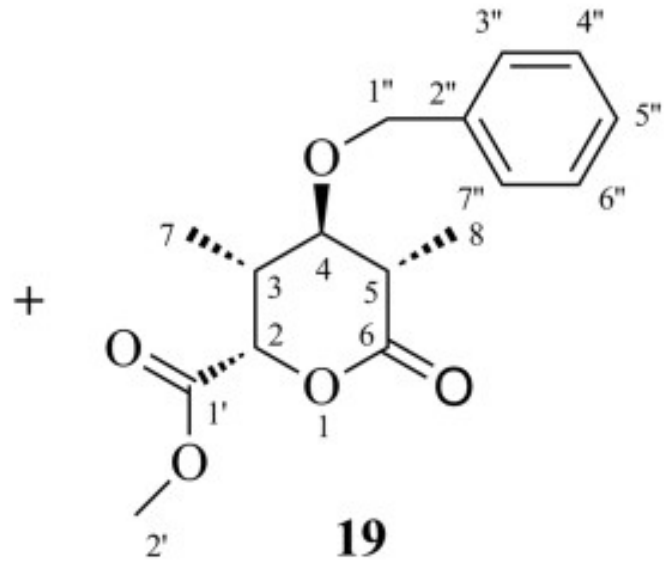

In a two neck round-bottomed flask, equipped with a Dimroth condenser and a magnetic stirring system, cycloadduct 8 (40.1 mg, $0.15 \mathrm{mmol}), \mathrm{NaHCO} 3(60 \mathrm{mg}, 0.71 \mathrm{mmol})$ and anhydrous $\mathrm{CH} 2 \mathrm{Cl} 2(2.5 \mathrm{~mL})$ were placed. The mixture was cooled with a solid $\mathrm{CO} 2 /$ acetone bath at $-78{ }^{\circ} \mathrm{C}$. Then, $\mathrm{O} 3$ was bubbled inside the solution through a diffusor for $20 \mathrm{~min}$, until the reaction mixture was saturated by ozone acquiring a blue colour. After reaction completion (as determined by TLC), the system was purged with N2, in order to remove the excess of ozone. Then, the Dimroth condenser was removed and two septa were fitted on the two necks of the flask. Afterwards, SMe2 $(25 \mu \mathrm{L}, 0.34 \mathrm{mmol})$ was added at $-78{ }^{\circ} \mathrm{C}$ and the mixture was stirred for $15 \mathrm{~min}$. Then, the solution was filtered via cannula in order to separate $\mathrm{NaHCO} 3$ excess, and the solvent was evaporated. The resulting crude was placed in a round-bottomed flask equipped with a stirring bar under nitrogen atmosphere. Then, PDC (232.1 mg, $0.61 \mathrm{mmol})$, dissolved in DMF $(0.6 \mathrm{~mL})$ was added and the mixture was stirred for $4 \mathrm{~h}$. Afterwards, a diazomethane solution in diethyl ether $(15 \mathrm{~mL}, 4.6 \mathrm{mmol})$ and methanol $(5 \mathrm{~mL})$ were added and the mixture was stirred for $30 \mathrm{~min}$ in the dark. Once the reaction was complete (as determined by TLC), the solvent was evaporated in vacuo. The resulting residue was submitted to flash column chromatography on silica gel, 


46

47

49

eluting with mixtures of hexane and EtOAc of increasing polarity. The elution with hexane/ EtOAc, 7:3 afforded the final products as colourless oils: $18(6.1 \mathrm{mg}, 11 \%)$ and $19(3.1 \mathrm{mg}, 7 \%)$.

\section{Dimethyl $\left(2 R^{*}, 3 S^{*}, 4 R^{*}, 5 R^{*}, 6 S^{*}\right)-4-B e n z y l o x y-2-m e t h o x y-3,5-d i m e t h y l t e t r a h y d r o p y r a n-2,6-$}

dicarboxylate (18): $\mathrm{TLC}: \mathrm{Rf}=0.57$ ( $\mathrm{SiO} 2$, hexane/EtOAc, $1: 1$, developed with anisaldehyde reagent). IR (film): $v^{\sim}=2952(\mathrm{H}-\mathrm{Csp} 3, \mathrm{st}), 1759(\mathrm{C}=\mathrm{O}), 1652(\mathrm{C}=\mathrm{C}), 1559,1457,1378,1274,1214(\mathrm{C}-\mathrm{O})$, 1117, $1065 \mathrm{~cm}-1$. 1H NMR (500 MHz, CDCl3): $\delta=0.97$ (d, J = $7.5 \mathrm{~Hz}, 3 \mathrm{H}, \mathrm{H} 7), 1.06$ (d, J = $7.5 \mathrm{~Hz}, 3$ H, H8), 2.26-2.30 (m, 1 H, H3), 2.30-2.38 (m, 1 H, H5), 3.28 (s, 3 H, H9), 3.30-3.34 (m, 1 H, H4), 3.77 (s, $3 \mathrm{H}, \mathrm{H} 2^{\prime}$ or H2"), 3.79 (s, $3 \mathrm{H}, \mathrm{H} 2^{\prime}$ or H2"), 4.57 (d, J = 6.0 Hz, $\left.2 \mathrm{H}, \mathrm{H} 1^{\prime \prime \prime}\right), 4.78$ (d, J = 4.0 Hz, $1 \mathrm{H}$, H6), 7.20-7.35 (m, 5 H, H3"', H4"', H5'"', H6"', H7"') ppm. 13C NMR (75 MHz, CDCl3): $\delta=8.91$ (C7), 10.42 (C8), 36.01 (C5), 40.42 (C3), 51.37 (C9), 52.29 (C2' or C2"), 52.53 (C2' or C2"), 67.43 (C4 or C6), 69.54 (C1"'), 71.38 (C4 or C6), 103.57 (C2), 127.21 (C3"'), 127.40 (C7"'), 128.32 (C4"'), 129.55 (C5"'), 138.50 (C2"'), 168.20 (C1' or C1"'), 170.15 (C1' or C1" ) ppm. MS (DIP-CI, NH3, 70 eV, 150 $\left.{ }^{\circ} \mathrm{C}\right): \mathrm{m} / \mathrm{z}(\%)=383(100)[\mathrm{M}+\mathrm{NH} 4-1], 384(20)[\mathrm{M}+\mathrm{NH} 4], 385(4)[\mathrm{M}+\mathrm{NH} 4+\mathrm{H}], 335$ (2) [M OMe], 227 (1) [M - BnO - MeO]. C19H26O7 (366.41 g mol-1): calcd. C 62.28, H 7.15; found C 62.31, H 7.23.

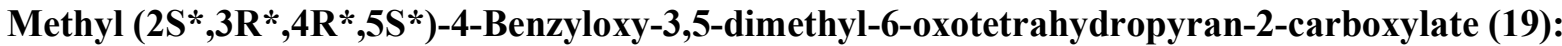
TLC: $\mathrm{Rf}=0.79\left(\mathrm{SiO} 2\right.$, hexane/EtOAc, 1:1, anisaldehyde reagent). IR (film): $v^{\sim}=2927$ (H-Csp3, st), 1800, 1737, $1700(\mathrm{C}=\mathrm{O}), 1652(\mathrm{C}=\mathrm{C}), 1559,1542,1509,1459$ (CH3 def asym), $1191(\mathrm{C}-\mathrm{O}), 1096(\mathrm{C}-$ O-C asym st, C-O st) cm-1. 1H NMR (500 MHz, CDCl3): $\delta=1.15$ (d, J = 7.0 Hz, $3 \mathrm{H}, \mathrm{H} 7), 1.16$ (d, J $=7.0 \mathrm{~Hz}, 3 \mathrm{H}, \mathrm{H} 8), 2.05-2.15(\mathrm{~m}, \mathrm{~J} 1=1.5, \mathrm{~J} 2=7.0 \mathrm{~Hz}, 1 \mathrm{H}, \mathrm{H} 3), 2.15-2-20$ (m, J1 = 3.0, J2 = 7.0 Hz, 1 H, H5), 3.05 (dd, J1 = 9.5, J2 = 18.5 Hz, 1 H, H4), 3.44 (s, 3 H, H2'), 4.62 (q, J1 = 5.0 Hz, 2 H, H1"), 5.59 (d, J = 1.5 Hz, 1 H, H2), 7.28-7.35 (m, 5 H, H3", H4", H5", H6", H7" ) ppm. 13C NMR (50 MHz, CDCl3): $\delta=9.4$ (C7), 13.6 (C8), 31.6 (C3), 40.7 (C5), 53.1 (OMe), 73.2 (C1"), 77.8 (C2), 82.3 (C4), 127.3 (C2", C7" ), 127.9 (C5"), 128.9 (C4", C6"), 137.4 (C2"), 171.3 (C1'), 173.6 (C6) ppm. MS (DIP$\left.\mathrm{CI}, \mathrm{NH} 3,70 \mathrm{eV}, 150{ }^{\circ} \mathrm{C}\right): \mathrm{m} / \mathrm{z}(\%)=310(100)[\mathrm{M}+\mathrm{NH} 4], 311(18)[\mathrm{M}+\mathrm{NH} 4+\mathrm{H}], 312(26)[\mathrm{M}+$ $\mathrm{NH} 4+2 \mathrm{H}], 292$ (1) [M], 293 (1) [M + H], 295 (5) [M + 3 H, ó M + NH4 - CH3], 260 (1) [M - MeO], 185 (1) [M - BnO]. C16H20O5 (292.33 g mol-1): calcd. C 65.74, H 6.90; found C 65.81, H 6.97. 

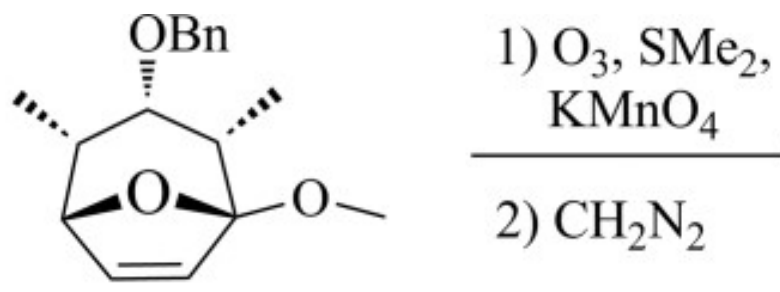

\section{2) $\mathrm{CH}_{2} \mathrm{~N}_{2}$}

\section{0}

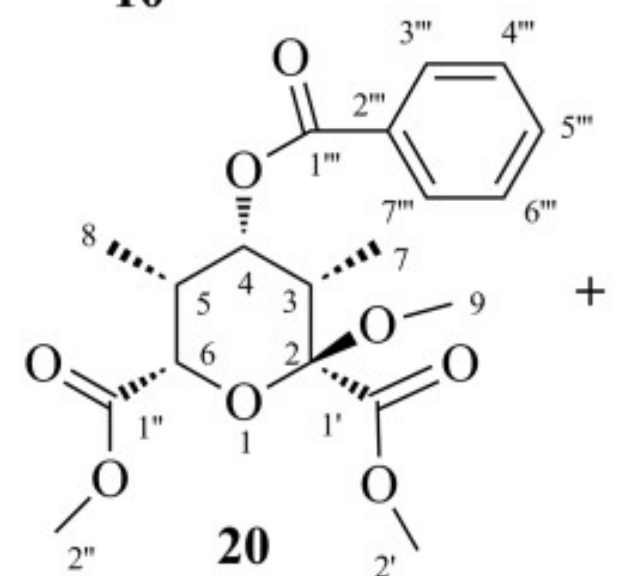

In a two-necked round-bottomed flask, equipped with magnetic stirring and a Dimroth condenser connected to a $\mathrm{CaCl} 2$ trap, substrate $10(146.4 \mathrm{mg}, 0.53 \mathrm{mmol}), \mathrm{NaHCO} 3(164 \mathrm{mg}, 1.99 \mathrm{mmol})$, anhydrous $\mathrm{CH} 2 \mathrm{Cl} 2(7 \mathrm{~mL})$ and anhydrous $\mathrm{MeOH}(1.7 \mathrm{~mL})$ were placed. The mixture was cooled with a solid CO2/acetone bath to $-78{ }^{\circ} \mathrm{C}$. Then, $\mathrm{O} 3$ was bubbled inside the solution for 20 min through a diffusor, until the reaction mixture was saturated by ozone adopting a blue colour. After reaction completion (as determined by TLC), the system was purged with N2, in order to remove the excess of ozone. Then, the Dimroth condenser was removed and two septa were fitted to the flask necks. Afterwards, $\mathrm{SMe} 2(25 \mu \mathrm{L}, 0.34 \mathrm{mmol})$ was added at $-78^{\circ} \mathrm{C}$ and the mixture was stirred for $15 \mathrm{~min}$. Then, the solution was filtered via cannula in order to separate $\mathrm{NaHCO} 3$ excess, and the solvent was evaporated in vacuo to dryness. The resulting crude was placed in a round-bottomed flask equipped with magnetic stirring, under nitrogen atmosphere. $\mathrm{tBuOH}(2.1 \mathrm{~mL}, 22.0 \mathrm{mmol})$, a buffer solution of $\mathrm{NaH} 2 \mathrm{PO} 4(5 \% \mathrm{w} / \mathrm{w}, 4 \mathrm{~mL}, \mathrm{pH}=4.4)$, and $\mathrm{KMnO} 4$ (1 M, $6.3 \mathrm{~mL}, 6.4 \mathrm{mmol})$ were added. The reaction mixture was stirred at room temperature for $15 \mathrm{~min}$ (and monitored by TLC). An aqueous saturated solution of $\mathrm{Na} 2 \mathrm{SO} 3(10 \mathrm{~mL})$ was added until the purple colour disappeared in order to quench $\mathrm{KMnO} 4$ excess. Afterwards, $\mathrm{HCl}(1 \mathrm{M})(20 \mathrm{~mL})$ was added to dissolve the $\mathrm{MnO} 2$ generated and then mixture was then extracted with chloroform $(10 \mathrm{~mL} \times 8)$. The organic phases were combined, washed with 
diazomethane solution in diethyl ether $(15 \mathrm{~mL}, 4.6 \mathrm{mmol})$ and anhydrous methanol $(5 \mathrm{~mL})$ were added to the resulting crude. The reaction solution was stirred for $30 \mathrm{~min}$ in the dark and after reaction completion (as determined by TLC), the solvent was evaporated. The resulting residue was submitted to flash column chromatography on silica gel, eluting with mixtures of hexane and EtOAc of increasing polarity. The elution with hexane/EtOAc, 7:3 afforded product 20, as a colourless oil (36.3 $\mathrm{mg}, 17 \%)$ and the elution with hexane/EtOAc, 6:4 afforded product 21 also as a colourless oil (22.0 $\mathrm{mg}, 15 \%)$.

\section{Dimethyl $\left(2 \mathrm{R}^{*}, 3 \mathrm{~S}^{*}, 4 \mathrm{~S}^{*}, 5 \mathrm{R}^{*}, 6 \mathrm{~S}^{*}\right)-4-$-Benzoyloxy-2-methoxy-3,5-dimethyl-tetrahydropyran-2,6-} dicarboxylate (20): TLC: $\mathrm{Rf}=0.54$ ( $\mathrm{SiO} 2$, hexane/EtOAc, 1:1, developed with anisaldehyde reagent). IR (film): $v^{\sim}=2954(\mathrm{H}-\mathrm{Csp} 3, \mathrm{st}), 1766(\mathrm{C}=\mathrm{O}), 1723$ (C=O), 1453 (CH3 def asym), 1391, 1272, 1194 (C-O), 1117, 1075, 1027, 988, 922, 789, $714 \mathrm{~cm}-1$. 1H NMR (500 MHz, CDCl3): $\delta=1.06$ (d, J = 3.5 Hz, $3 \mathrm{H}, \mathrm{H7}$ or H8), 1.07 (d, J = 3.5 Hz, $3 \mathrm{H}, \mathrm{H} 7$ or H8), 2.56 (dq, J1 = 1.0, J2 = 7.5 Hz, 1 H, H3), 2.70 (ddq, J1 = 2.0, J2 = $3.0 \mathrm{~Hz}, \mathrm{~J} 3=7.0 \mathrm{~Hz}, 1 \mathrm{H}, \mathrm{H} 5$ ), 3.23 (s, $3 \mathrm{H}, \mathrm{H} 9$ ), 3.78 (s, $3 \mathrm{H}, \mathrm{H} 2^{\prime}$ or H2"), 3.82 (s, 3 H, H2' or H2"), 4.55 (d, J = 3.5 Hz, 1 H, H6), 5.65 (dd, J1 = 5.5, J2 = 11.5 Hz, 1 H, H4), 7.44 (dd, J1 = 8, J2 = 15.5 Hz, 2 H, H4"', H6"'), 7.56 (dd, J1 = 7.5, J2 = 15.0 Hz, 1 H, H5"'), 8.04 (d, J = 7.0 Hz, 2 H, H3"' and H7"' ) ppm. 13C NMR (50 MHz, CDCl3): $\delta=9.69$ (C7), 11.26 (C8), 33.33 (C5), 37.79 (C3), 51.36 (C9), 52.16 (C2' or C2"), 52.47 (C2' or C2"), 70.24 (C4), 71.11 (C6), 103.12 (C2), 128.46, 128.80, 129.38, 129.54, 133.18, 133.46 (C2"', C 3"', C4"', C5'"', C6"', C7"'), 164.50 (C1"'), 167.57 (C1' or $\left.\mathrm{C} 1^{\prime \prime}\right), 169.49$ (C1' or C1") ppm. MS (DIP-CI, NH3, $\left.70 \mathrm{eV}, 150{ }^{\circ} \mathrm{C}\right): \mathrm{m} / \mathrm{z}(\%)=397(100)[\mathrm{M}+\mathrm{NH} 4$ - 1], 398 (20) [M + NH4], 383 (17) [M + 3 H], 381 (2) [M + H], 348 (5) [M - OMe], 260 (4) [M $\mathrm{C} 7 \mathrm{H} 5 \mathrm{O} 2+\mathrm{H}$ or $\mathrm{M}-(\mathrm{C} 2 \mathrm{H} 4 \mathrm{O} 2) 2]$. C19H24O8 (380.39 g mol-1): calcd. C 59.99, H 6.36; found C 60.02, H 6.40 .

Dimethyl (2R*,3S*,4S*,5R*,6S*)-4-Hydroxy-2-methoxy-3,5-dimethyltetrahydropyran-2,6-

dicarboxylate, (21): Colourless oil. TLC: $\mathrm{Rf}=0.22$ ( $\mathrm{SiO} 2$, hexane/EtOAc, 1:1, developed by anisaldehyde reagent). IR (film): $v^{\sim}=3525(\mathrm{O}-\mathrm{H}$ st), $2952(\mathrm{H}-\mathrm{Csp} 3$, st), $1740(\mathrm{C}=\mathrm{O}), 1654(\mathrm{C}=\mathrm{O})$, 1559, 1542, 1439 (CH3 def asym), 1370 (CH3 def sym), 1274, 1162 (C-O), 1127, 1077, 1036 (C-O-C 1001 asym st, $\mathrm{C}-\mathrm{O}$ st) $\mathrm{cm}-1$. 1H NMR (500 MHz, CDCl3): $\delta=0.93$ (d, J = 7.5 Hz, $3 \mathrm{H}, \mathrm{H} 7$ or H8), 0.96 (d, J $=7.0 \mathrm{~Hz}, 3 \mathrm{H}, \mathrm{H} 7$ or H8), 2.25 (dq, J1 = 3.0, J2 = 7.5 Hz, $1 \mathrm{H}, \mathrm{H} 3$ ), 2.36 (ddq, J1 = 1.0, J2 = 3.5 Hz, J3 $=7.5 \mathrm{~Hz}, 1 \mathrm{H}, \mathrm{H} 5), 3.19$ (s, $3 \mathrm{H}, \mathrm{H} 9), 3.78$ (s, $3 \mathrm{H}, \mathrm{H} 2^{\prime}$ or H2"), 3.82 (s, $3 \mathrm{H}, \mathrm{H} 2^{\prime}$ or H2"), 4.29 (dd, J1 = $5.5, \mathrm{~J} 2=11.0 \mathrm{~Hz}, 1 \mathrm{H}, \mathrm{H} 4), 4.41(\mathrm{~d}, \mathrm{~J}=3.5 \mathrm{~Hz}, 1 \mathrm{H}, \mathrm{H} 6)$ ppm. 13C NMR (75 MHz, CDCl3): $\delta=8.89$ (C7), 10.39 (C8), 35.99 (C5), 40.33 (C3), 51.34 (C9), 52.35 (C2' or C2"), 52.49 (C2' or C2"), 67.44 (C4 1006 or C6), 71.44 (C4 or C6), 103.32 (C2), 168.15 (C1' or $\left.\mathrm{C} 1{ }^{\prime \prime}\right), 170.10$ (C1' or $\left.\mathrm{Cl}^{\prime \prime}\right)$ ppm. MS (DIP-CI, $\left.\mathrm{NH} 3,70 \mathrm{eV}, 150{ }^{\circ} \mathrm{C}\right): \mathrm{m} / \mathrm{z}(\%)=294(100)[\mathrm{M}+\mathrm{NH} 4], 295(13)[\mathrm{M}+\mathrm{NH} 4+\mathrm{H}], 277$ (4) [M + H], 278 (2) $[\mathrm{M}+2 \mathrm{H}], 262(8)[\mathrm{M}-\mathrm{MeOH}+\mathrm{NH} 4], 245(15)[\mathrm{M}-\mathrm{MeOH}+\mathrm{H}], 218(6)[\mathrm{M}-\mathrm{C} 2 \mathrm{H} 3 \mathrm{O} 2+\mathrm{H}]$. 

THP Products 22 and 24: In a two-necked round-bottomed flask, equipped with magnetic stirring and

1013 a Dimroth condenser connected to a $\mathrm{CaCl} 2$ trap, the corresponding cycloadduct (8 or 10, independently) 1014 (261 mg, $0.97 \mathrm{mmol}$ ), anhydrous NaHCO3 (136 mg, $1.62 \mathrm{mmol}$ ), and anhydrous CH2Cl2 (10.8 mL) 1015 were placed. The mixture was cooled with a solid $\mathrm{CO} 2 /$ acetone bath down to $-78^{\circ} \mathrm{C}$. Then, $\mathrm{O} 3$ was 1016 1017 bubbled inside the solution for $20 \mathrm{~min}$ through a diffusor, until the reaction mixture was saturated by ozone adopting a blue colour. After reaction completion (as determined by TLC), the system was purged with N2, in order to remove the excess of ozone. The Dimroth condenser was removed and two septa were fitted to the necks of the flask. SMe2 $(0.16 \mathrm{~mL}, 2.23 \mathrm{mmol})$ was added at $-78{ }^{\circ} \mathrm{C}$ and the mixture was stirred for $20 \mathrm{~min}$. Then, the mixture was warmed to room temperature, anhydrous $\mathrm{MeOH}(2.2 \mathrm{~mL})$ and NaBH4 (88 mg, $2.33 \mathrm{mmol}$ ) were added and the reaction system was stirred for $2.5 \mathrm{~h}$. After reaction completion (as determined by TLC), the $\mathrm{NaBH} 4$ excess was quenched with water $(0.3 \mathrm{~mL})$ and $\mathrm{MeOH}$ $(10 \mathrm{~mL})$ was added to dissolve the formed boronated byproducts and intermediates and the mixture was stirred for $15 \mathrm{~min}$. The solvent was then evaporated under vacuum to complete dryness. The obtained crude was lixiviated with EtOAc $(8 \times 10 \mathrm{~mL})$, the organic phases were combined together and the solvent was evaporated. The resulting residue was submitted to flash column chromatography on silica gel, eluting with mixtures of hexane and EtOAc of increasing polarity to afford final respective THP products 22 or 24 (see below). In the case of starting from substrate 8 a minor product $23(1 \%)$ was obtained together with the major product $22(91 \%)$.

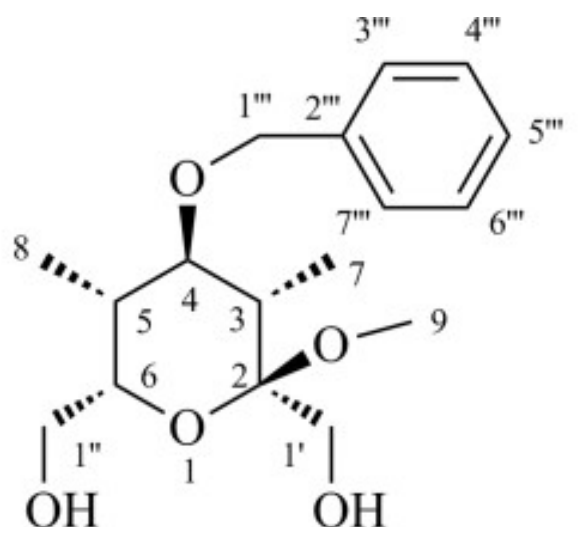
$=3749,3426(\mathrm{O}-\mathrm{H}), 2940$ (H-Csp3, st), 1700, 1455, 1360, 1210, 1156 (C-O), 1063, 947, 861, $739 \mathrm{~cm}-$ 1. 1H NMR (500 MHz, CDCl3): $\delta=0.95$ (d, J = 7.0 Hz, 3 H, H8), 1.09 (d, J = 7.0 Hz, 3 H, H7), $1.92-$ $1.98(\mathrm{dd}, \mathrm{J} 1=4.0, \mathrm{~J} 2=7.5 \mathrm{~Hz}, 1 \mathrm{H}, \mathrm{H} 5), 2.20-2-26$ (dd, J1 = 7.0, J2 = 14.5 Hz, 1 H, H3), 3.21 (dd, J1 = 
3.5, J2 = 6.0 Hz, 1 H, H4), 3.29 (s, 3 H, H9), 3.54 (d, J = $12.0 \mathrm{~Hz}, 1 \mathrm{H}, \mathrm{H} 1^{\prime}$ ), 3.55 (d, J = 11.5 Hz, 1 H, H1"), 3.64 (d, J = 11.5 Hz, 1 H, H1'), 3.69 (dd, J1 = 12.0, J2 = 3.0 Hz, 1 H, H1"), 4.22 (m, 1 H, H6), 4.54 (q, J1 = 12.0, J2 = 3.0 Hz, 2 H, H1"'), 7.25-7.32 (m, 5 H, H3"', H4'", H5"', H6"', H7"') ppm. 13C

1044 1045 1046 1047 1048 1049 1050 1051 1052

1053

1054

1055

1056

1057

1058

1059

1060

1061

1062

1063

1064

1065

1066

1067

1068

1069 NMR (50 MHz, CDC13): $\delta=13.6$ (C7), 14.3 (C8), 35.6 (C5), 37.5 (C3), 48.3 (C9), 62.1 (C1' or C1'), 63.3 (C1' or C1"'), 70.9 (C6), 71.6 (C1"'), 83.7 (C4), 101.2 (C2), 127.5 (C3'"', C5'", C7"'), 128.3 (C4"', C6"'), 138.5 (C2 $\left.{ }^{\prime \prime \prime}\right)$ ppm. MS (DIP-CI, NH3, $\left.70 \mathrm{eV}, 150^{\circ} \mathrm{C}\right): \mathrm{m} / \mathrm{z}(\%)=296(100)[\mathrm{M}-\mathrm{MeOH}+\mathrm{NH} 4]$, 297 (16) [M - MeO + NH4], 188 (24) [M - BnOH - MeOH + NH4]. C17H26O5 (310.18 g mol-1): calcd. C 65.78, H 8.44; found C 65.83, H 8.31.

\section{[(2R,3S,4S,5R,6S)-4-(Benzyloxy)-2-methoxy-3,5-dimethyltetrahydro-2H-pyran-2,6-} diyl]dimethanol (24)

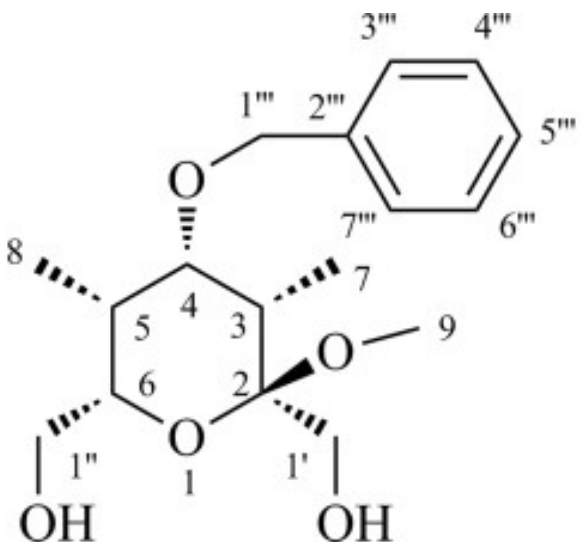

Colourless oil, $264.8 \mathrm{mg}, 88 \%$ yield. TLC: $\mathrm{Rf}=0.45$ (SiO2, EtOAc, developed by anisaldehyde reagent). IR (film): $v^{\sim}=3408(\mathrm{O}-\mathrm{H}), 2929$ (H-Csp3, st), 1719, 1455, 1357, 1277, 1137, 1073, 1027, 903, 863, 789, 764, 699 cm-1. 1H NMR (500 MHz, CDCl3): $\delta=0.95$ (d, J = 9.0 Hz, 3 H, H8), 1.09 (d, $\mathrm{J}=9.0 \mathrm{~Hz}, 3 \mathrm{H}, \mathrm{H} 7), 2.10-2.20$ (m, 1 H, H5), 2.30-2.45 (m, 1 H, H3), 3.27 (s, 3 H, H9), 3.57 (d, J = 13.8 Hz, 1 H, H1'), 3.58 (d, J = 12.6 Hz, 1 H, H1"), 3.75 (d, J = 14.7 Hz, 1 H, H1'), 3.76 (m, 1 H, H1"), 3.85 (m, 1 H, H6), 4.00 (dd, J1 = 6.9, J2 = 13.2 Hz, 1 H, H4), 4.54 (q, J = 1.2 Hz, 2 H, H1'") 7.37 (m, 5 H, H3"', H4'", H5"', H6"', H7"') ppm. 13C NMR (75 MHz, CDCl3): $\delta=8.6$ (C7), 10.9 (C8), 33.3 (C5), 36.2 (C3), 47.7 (C9), 59.9 (C1' or $\left.\mathrm{C} 1^{\prime \prime}\right), 63.6\left(\mathrm{C1}^{\prime}\right.$ or $\left.\mathrm{C} 1^{\prime \prime}\right), 69.5$ (C1"'), $72.6(\mathrm{C} 6), 74.9(\mathrm{C} 4), 102.5(\mathrm{C} 2)$, 127.1 (C5"'), 127.3 (C3"' , C7"'), 128.2 (C4"', C6"'), 138.8 (C2"') ppm. MS (DIP-CI, NH3, 70 eV, 150 $\left.{ }^{\circ} \mathrm{C}\right): \mathrm{m} / \mathrm{z}(\%)=296(100)[\mathrm{M}-\mathrm{MeOH}+\mathrm{NH} 4], 297$ (17) [M - MeO + NH4], 328 (47) [M + NH4], 329 (7) $[\mathrm{M}+\mathrm{H}+\mathrm{NH} 4], 327$ (13) $[\mathrm{M}+\mathrm{NH} 3], 279$ (30) [M - MeO], 171 (10) [M - BnOH - MeO]. C17H26O5 (310.18 g mol-1): calcd. C 65.78, H 8.44; found C 65.75, H 8.47. 
1073

1074

1075

1076

1077

1078

1079

1080

1081

1082

1083

1084

1085

1086

1087

1088

1089

1090

1091

1092

1093

1094

1095

1096

1097

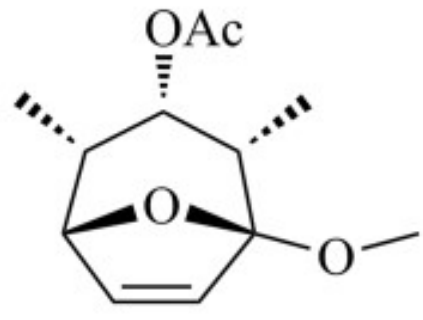

9

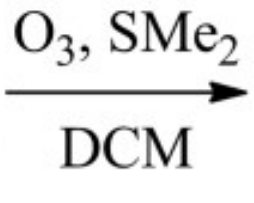

$\mathrm{H}$

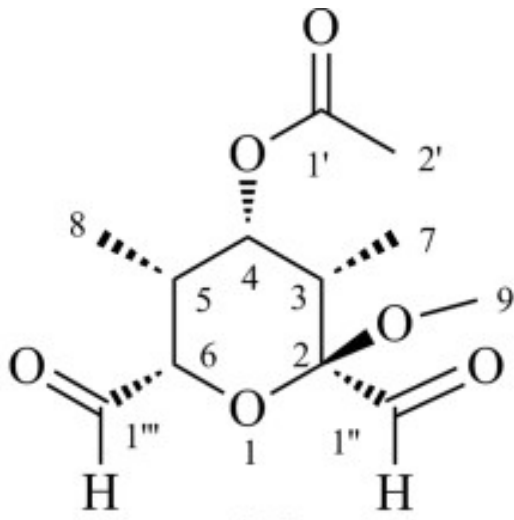

25

In a two-necked round-bottomed flask, equipped with magnetic stirring and a Dimroth condenser, substrate $9(50 \mathrm{mg}, 0.22 \mathrm{mmol})$ and anhydrous DCM $(5 \mathrm{~mL})$ were placed, under nitrogen atmosphere. The mixture was cooled with a solid $\mathrm{CO} 2 /$ acetone bath at $-78^{\circ} \mathrm{C}$. Then, $\mathrm{O} 3$ was bubbled inside the solution for $20 \mathrm{~min}$ through a diffusor, until the reaction mixture was saturated by ozone getting a blue colour. After reaction completion (as determined by TLC), the system was purged with N2, in order to remove the excess of ozone. Then, the Dimroth condenser was removed, two septa were fitted to the flask necks and the system was warmed to room temperature for $15 \mathrm{~min}$. Afterwards, $\mathrm{SMe} 2(32 \mu \mathrm{L}, 0.44$ mmol) was added and the mixture was stirred for $16.5 \mathrm{~h}$. After reaction completion (as determined by TLC), the solvent was evaporated and the resulting residue was submitted to flash column chromatography on silica gel, eluting with mixtures of hexane and EtOAc of increasing polarity. The elution with hexane/EtOAc, 8:2 afforded final product 25 as a colourless oil (31 $\mathrm{mg}, 54 \%$ ). IR (film): $v^{\sim}=3471(\mathrm{C}-\mathrm{O}), 2979,2946,2842$ (H-Csp3), 1744 (C=O), 1456, 1375, 1239, 1162, 1140, 1084, 1034, 995, 917 cm-1. 1H NMR (300 MHz, CDCl3): $\delta=0.99$ (d, J = 7.5 Hz, $3 \mathrm{H}, \mathrm{H} 7$ or H8), 1.00 (d, J = 7.2 Hz, 3 H, H7 or H8), 2.11 (s, 3 H, H2"), 2.1 (m, 1 H, H3), 2.41 (ddq, J1 = 7.5, J2 = 5.4 Hz, J3 $=7.5 \mathrm{~Hz}, 1 \mathrm{H}, \mathrm{H} 5), 3.24$ (s, $3 \mathrm{H}, \mathrm{H} 9), 4.31$ (d, J = 5.4 Hz, $1 \mathrm{H}, \mathrm{H6}$ ), 5.35 (dd, J1 = 7.5, J2 = 7.5 Hz, 1 H, H4), 9.55 (s, 1 H, H1" or H1"'), 9.77 (s, $1 \mathrm{H}, \mathrm{H} 1^{\prime \prime}$ or H1"') ppm. 13C NMR (75 MHz, CDCl3): $\delta=8.34$ (C7), 9.30 (C8), 20.88 (C2'), 33.10 (C5), 37.61 (C3), 51.36 (C9), 69.66 (C4), 73.04 (C6), 102.11 (C2), 167.48 (C1'), 200.71 (C1"), 200.85 (C1'") ppm. MS (DIP-CI, NH3, $\left.70 \mathrm{eV}, 150{ }^{\circ} \mathrm{C}\right): \mathrm{m} / \mathrm{z}(\%)=276$ (100) [M + NH4], 258 (2) [M], 227 (10) [M - CH3O], 199 (40) [M - AcO], 229 (60) [M - CHO]. C12H18O6 (258.27 g mol-1): calcd. C 55.81, H 7.03; found C 55.78, H 6.97. 

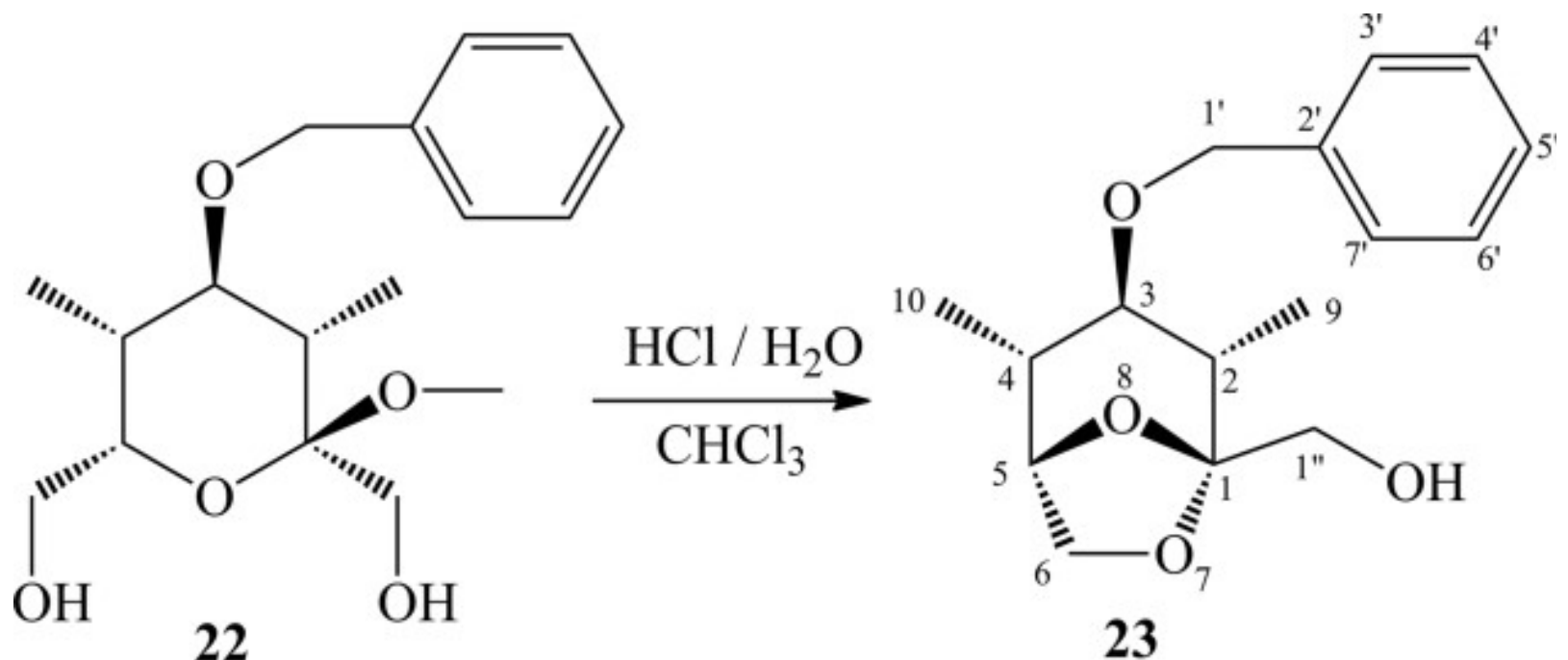

1103

The intramolecular cyclization of tetrahydropyran 22 was carried out by dissolving $47.8 \mathrm{mg}$ of this substrate in $\mathrm{CHCl}_{3}(1 \mathrm{~mL})$ containing catalytic amounts of aqueous $\mathrm{HCl}(10 \mu \mathrm{L})$. The solution was kept whilst stirring at room temp. for $3 \mathrm{~d}$. The TLC analysis showed the presence of two compounds: the unchanged starting material and a new product with higher Rf. The reaction mixture was concentrated to dryness, obtaining a crude oil that was submitted to flash column chromatography on silica gel $(100 \mathrm{~g} / \mathrm{g}$ of crude material), eluting with mixtures of hexane and ethyl acetate of increasing polarity. Pure product 23 was isolated as a white solid ( $20.5 \mathrm{mg}, 83 \%$ conversion, $70 \%$ yield).

M.p. $98-99^{\circ} \mathrm{C}$ (ethyl acetate). $\mathrm{TLC} \mathrm{Rf}=0.57(\mathrm{SiO} 2$, hexane/EtOAc, $2: 8) ; \mathrm{Rf}=0.70(\mathrm{SiO} 2, \mathrm{EtOAc})$, developed with anisaldehyde reagent. IR (film): $v^{\sim}=3460(\mathrm{O}-\mathrm{H}), 2966$ (H-Csp3, st), 1652, 1455, 1351, 1223 (C-O), 1175, 1140, 1061, 1013, 897, 849, 739, 699 cm-1. 1H NMR (500 MHz, CDCl3): $\delta=1.02$ (d, J = 1.5 Hz, 3 H, H9 or H10), 1.03 (d, J = 1.5 Hz, 3 H, H9 or H10), 1.92-1.99 (m, 1 H, H2), 2.12-2.19 (m, 1 H, H4), 3.12 (dd, J1 = 9.5, J2 = 19.5 Hz, 1 H, H3), 3.70 (d, J = 5 Hz, 1 H, H1"), 3.72 (m, 2 H, H6), $3.90(\mathrm{~d}, \mathrm{~J}=7.5 \mathrm{~Hz}, 1 \mathrm{H}, \mathrm{H11}), 4.33$ (dd, J1 = 4.5, J2 = 8.5 Hz, 1 H, H5), 4.59 (s, 2 H, H1'), 7.26-7.30 (m, $2 \mathrm{H}, \mathrm{H} 4^{\prime}$ and $\mathrm{H6}^{\prime}$ ), 7.33 (d, J = $4 \mathrm{~Hz}, 3 \mathrm{H}, \mathrm{H}^{\prime}$, $\mathrm{H}^{\prime}$ and $\mathrm{H}^{\prime}$ ) ppm. 13C NMR (50 MHz, CDCl3): $\delta=$ 12.3 (C9), 14.1 (C10), 39.8 (C4), 43.1 (C2), 62.8 (C6), 66.0 (C1"), 74.0 (C1'), 78.8 (C3), 83.9 (C5), 109.3 (C1), 127.6 (C3' and C7'), 127.7 (C4' and C6'), 128.4 (C5'), 138.3 (C2') ppm. MS (DIPCI, NH3, $\left.70 \mathrm{eV}, 150{ }^{\circ} \mathrm{C}\right): \mathrm{m} / \mathrm{z}(\%)=296(100)[\mathrm{M}+\mathrm{NH} 4], 297$ (17) [M + H + NH4], 279 (10) [M + H], 171 (18) [M - BnO], $172(18)[\mathrm{M}-\mathrm{BnO}+\mathrm{H}], 188\{\mathrm{M}-\mathrm{BnOH}+\mathrm{NH} 4\}$. C16H22O4 (278.35 g mol-1): calcd. C 


\section{ACKNOWLEDGMENTS}

1128

1129 The authors thank the Spanish Ministry of Economics and Competitiveness (MINECO) for financial 1130 support (grant number CTQ2015-65040-P). In addition, financial support from the University of 1131 Barcelona (grant number UB-VRR-2012/AR000126) and from the Generalitat de Catalunya (grant 1132 number AGAUR 2014-SGR-1658) is also gratefully acknowledged. 
1134 Keywords: Cycloaddition $\cdot$ Ozonolysis $\cdot$ Oxygen heterocycles $\cdot$ Synthesis design $\cdot$ Stereoselectivity 1135 
[2] Y. Kobayashi, Carbohydr. Res. 1999, 315, 3-15.

1138 [3] A. Berecibar, C. Grandjean, A. Siriwardena, Chem. Rev. 1999, 99, 779-844.

[4] P. A. Horton, F. E. Koehn, R. E. Longley, O. J. McConnell, J. Am. Chem. Soc. 1994, 116, 6015-6016.

[5] M. Ball, M. J. Gaunt, D. F. Hook, A. S. Jessiman, S. Kawahara, P. Orsini, A. Scolaro, A. C. Talbot, H. R. Tanner, S. Yamanoi, S. V. Ley, Angew. Chem. Int. Ed. 2005, 44, 5433-5438; Angew. Chem. 2005, 117, 5569.

S. Hanessian, T. Focken, X. Mi, R. Oza, B. Chen, D. Ritson, R. Beaudegnies, J. Org. Chem. $2010,75,5601-5618$.

M. T. Crimmins, A. C. DeBaillie, J. Am. Chem. Soc. 2006, 128, 4936-4937. Darst, EMBO J. 2005, 24, 674-682.

[9] R. E. Ireland, J. D. Armstrong III, J. Lebreton, R. S. Meissner, M. A. Rizzacasa, J. Am. Chem. Soc. $1993,115,7152-7165$.

[10] L. David, M. Chapel, J. Gandreuil, G. Jeminet, R. Durand, Experientia 1979, 35, 1562-1563.

[11] J. F. Blount, R. H. Evans, C. Liu, T. Hermann, J. W. Westley, J. Chem. Soc., Chem. Commun. $1975,20,853-855$.

[12] For an interesting review see: P. A. Clarke, S. Santos, Eur. J. Org. Chem. 2006, 2045-2053.

[13] D. J. Kopecky, S. D. Rychnovsky, J. Am. Chem. Soc. 2001, 123, 8420-8421. [14] S. B.

[15] B. A. Smith III, P. K. Minbiole, R. P. Verhoest, M. Schelhaas, J. Am. Chem. Soc. 2001, 123, Huang, R. Hong, Angew. Chem. Int. Ed. 2016, 55, 6280-6284; Angew. Chem. 2016, 128, 6388.

[17] a) H. M. R. Hoffmann, Angew. Chem. Int. Ed. 1973, 12, 819-835; Angew. Chem. 1973, 20, 877; b) R. Noyori, Y. Hayakawa, Org. React. 1983, 29, 163-344; c) N. N. Joshi, H. M. R. Hoffmann, Angew. Chem. Int. Ed. Engl. 1984, 23, 1-19; Angew. Chem. 1984, 96, 29; d) J. Mann, Tetrahedron 1986, 42, 4611-4659; e) A. Pavzda, A. Schoffstall, Adv. Cycloaddit. 1990, 2, 1-89; f) A. Hosomi, Y. Tominaga, Comprehen. Org. Chem. 1995, 5, 593-615; g) F. G. West, Adv. Cycloaddit. 1995, 4, 1-40; h) M. Harmata, Tetrahedron 1997, 53, 6235-6280; i) J. H. Rigby, F. C. Pigge, Org. React. 1997, 51, 351-478; j) M. Harmata, Recent Res. Dev. Org. Chem. 1997, 1, 523-535; k) M. Harmata, Adv. Cycloaddit. 1997, 4, 41-86; 1) J. K. Cha, J. Oh, Curr. Org. Chem. 1998, 2, 217-232; m) A. El-Wareth, A. A. O. Sarhan, Curr. Org. Chem. 2001, 5, 827-844; n) M. Harmata, Acc. Chem. Res. 2001, 34, 595-605; o) A. Schall, O. Reiser, Chemtracts 2004, 17, 436-441; p) J. Huang, R. P. Hsung, Chemtracts 2005, 18, 207-214; q) M. Harmata, Adv. Synth. Catal. 2006, 348, 2297-2306; r) M. Harmata, Chem. Commun. 2010, 46, 
8886-8903; s) A. G. Lohse, R. P. Hsung, Chem. Eur. J. 2011, 17, 3812-3822; t) S. Roth, C. B. Stark, Angew. Chem. Int. Ed. 2006, 45, 6218-6221; Angew. Chem. 2006, 118, 6364.

[18] a) A. M. Montaña, S. Ribes, P. M. Grima, F. Garcia, Acta Chem. Scand. 1998, 54, 453-460; b) A. M. Montaña, S. Ribes, P. M. Grima, F. Garcia, Chem. Lett. 1997, 9, 847-848; c) A. M. Montaña, P. M. Grima, Tetrahedron 2002, 58, 4769-4786; d) A. M. Montaña, P. M. Grima, Tetrahedron Lett. 2001, 42, 7809-7813; e) A. M. Montaña, F. J. Bernal, J. Lorenzo, C. Farnos, C. Batalla, M. J. Prieto, V. Moreno, F. X. Avilés, J. M. Mesas, M. T. Alegre, Bioorg. Med. Chem. 2008, 16, 1721-1737; f) A. M. Montaña, P. M. Grima, Tetrahedron Lett. 2002, 43, 2017 2021; g) A. M. Montaña, C. Batalla, J. A. Barcia, Curr. Org. Chem. 2009, 13, 919-938; h) A. M. Montaña, A. Moyano, M. A. Pericas, F. Serratosa, Ann. Chem. Quim. Ser. C 1988, 84, 82-88; i) A. M. Montaña, J. A. Barcia, Tetrahedron Lett. 2005, 46, 8475-8478; j) A. M. Montaña, S. Ribes, P. M. Grima, F. García, X. Solans, M. Font-Bardia, Tetrahedron 1997, 53, 11669-11684; k) A. M. Montaña, F. García, P. M. Grima, Tetrahedron Lett. 1999, 40, 1375-1378; 1) A. M. Montaña, F. García, P. M. Grima, Tetrahedron 1999, 55, 5483-5504; m) A. M. Montaña, F. García, C. Batalla, Tetrahedron Lett. 2004, 45, 8549-8552; n) A. M. Montaña, F. García, C. Batalla, Lett. Org. Chem. 2005, 2, 475-479; o) A. M. Montaña, F. García, C. Batalla, Lett. Org. Chem. 2005, 2, 480-484; p) A. M. Montaña, J. A. Barcia, Tetrahedron Lett. 2005, 46, 84758478; q) A. M. Montaña, J. A. Barcia, Helv. Chim. Acta 2008, 91, 187-208; r) A. M. Montaña, J. A. Barcia, G. Kociok-Köhn, M. Font-Bardia, Tetrahedron 2009, 65, 5308-5321.

[19] For a review, see: I. V. Hartung, H. M. R. Hoffmann, Angew. Chem. Int. Ed. 2004, 43, 1934 1949; Angew. Chem. 2004, 116, 1968.

[20] a) M. Candy, G. Audran, H. Bienaymé, C. Bressy, J. M. Pons, Org. Lett. 2009, 11, 4950-4953; b) M. Candy, G. Audran, H. Bienaymé, C. Bressy, J. M. Pons, J. Org. Chem. 2010, 75, 1354 1359.

[21] a) V. Varghese, M. Saha, K. M. Nicholas, T. V. Rajanbabu, L. G. Upchurch, B. E. Smart, Org. Synth. 1989, 67, 141-146; b) G. Tester, V. Varghese, A. M. Montaña, M. A. Kahn, K. M. Nicholas, J. Org. Chem. 1990, 55, 1569-1578.

[22] a) A. M. Montaña, P. M. Grima, M. Castellví, C. Batalla, M. Font-Bardia, Tetrahedron 2012, 68, 9982-9998; b) A. M. Montaña, P. M. Grima, C. Batalla, F. Sanz, G. Kociok-Köhn, Eur. J. Org. Chem. 2014, 13, 2726-2746; c) A. M. Montaña, P. M. Grima, C. Batalla, G. Kociok-Köhn, Tetrahedron: Asymmetry 2014, 25, 677-689.

[23] a) M. R. Ashcroft, H. M. R. Hoffman, Org. Synth. 1978, 58, 17-23; b) J. G. Vinter, H. M. R. Hoffman, J. Am. Chem. Soc. 1973, 95, 3051-3052; c) H. M. R. Hoffman, D. Wagner, R. Wartchow, Chem. Ber. 1990, 123, 2131-2139; d) T. Schttelius, H. M. R. Hoffman, Chem. Ber. 1991, 124, 1673-1675.

[24] H. Kim, H. M. R. Hoffmann, Eur. J. Org. Chem. 2000, 12, 2195-2201.

[25] a) A. M. Montaña, S. Ribes, P. M. Grima, F. García, Magn. Reson. Chem. 1998, 36, 174-180;

b) A. M. Montaña, S. Ribes, P. M. Grima, F. García, Magn. Reson. Chem. 1999, 37, 507-511;

c) A. M. Montaña, M. Cano, Magn. Reson. Chem. 2002, 40, 261-272.

[26] C. Lu, E. W. Hughes, P. A. Giguere, J. Am. Chem. Soc. 1941, 53, 1507.

[27] a) S. Kyasa, T. J. Fisher, P. H. Dussault, Synthesis 2011, 2475-2481; b) P. S. Baily, Chem. Rev. 1958, 58, 925-1010; c) P. S. Bailey, Ozonation, in: Organic Chemistry, Academic Press, New 
York, 1978, vol. 1; 1982, vol. 2; d) W. H. Bunnelle, Chem. Rev. 1991, 91, 335-362; e) K. J. McCullough, M. Nojima, in: Organic Peroxides (Ed.: W. Ando), John Wiley, New York, 1992; f) C. C. Lin, H. J. Wu, Tetrahedron Lett. 1995, 36, 9353-9356.

[28] a) S. Kawamura, H. Yamakoshi, M. Nojima, J. Org. Chem. 1996, 61, 5953-5958; b) S. A. Testero, M. I. Mangione, A. G. Suárez, R. A. Spanevello, Eur. J. Org. Chem. 2013, 24, 52365245 .

[29] a) W. H. Bunnelle, S. G. Lee, J. Am. Chem. Soc. 1992, 114, 7577-7578; b), K. Griesbaum, G. Kiesel, Chem. Ber. 1989, 122, 145-149; c) S. Fliszar, C. Belzecki, J. B. Chylinska, Can. J. Chem. 1967, 45, 221-224.

[30] a) W. H. Bunnelle, T. A. Isbell, J. Org. Chem. 1992, 57, 729-740; b) H. Hayes, T. W. Wallace, Tetrahedron Lett. 1990, 31, 3355-3358.

[31] a) K. Teshima, S. Kawamura, Y. Ushigoe, M. Nojima, K. J. McCullough, J. Org. Chem. 1995, 60, 4755-4763; b) H. Mayr, J. Baran, E. Will, H. Yamakoshi, K. Teshima, M. Nojima, J. Org. Chem. 1994, 59, 5055-5058; c) K. Griesbaum, W. Volpp, Chem. Ber. 1988, 121, 1795-1799; d) R. Criegee, Chem. Ber. 1975, 108, 743-748.

[32] a) S. Flish, J. Renard, Can. J. Chem. 1970, 48, 3002-3009; b) S. Fliszar, M. Granger, J. Am. Chem. Soc. 1970, 92, 3361-3369.

[33] a) K. Griesbaum, R. Greinert, Chem. Ber. 1989, 123, 391-397; b) K. Griesbaum, A. R. Bandopuadhyay, Can. J. Chem. 1987, 65, 487-490; c) M. Meister, G. Zwick, K. Greisbaum, Can. J. Chem. 1983, 61, 2385-2388; d) H. Ked, K. Griesbaum, Can. J. Chem. 1980, 58, 20492054.

[34] a) R. Criegee, Angew. Chem. Int. Ed. Engl. 1975, 14, 745-751; Angew. Chem. 1975, 87, 765; b) C. Geletneky, S. Berger, Eur. J. Org. Chem. 1998, 1625-1627.

[35] a) C. A. Taatjes, O. Welz, A. J. Eskola, J. D. Savee, A. M. Scheer, D. E. Shallcross, B. Rotavera, E. P. F. Lee, J. M. Dyke, D. K. W. Mok, D. L. Osborn, C. J. Percival, Science 2013, 340, 177-180; b) K. J. McCullough, N. Nakamura, T. Fujisaka, M. Nojima, S. Kusubayashi, J. Am. Chem. Soc. 1991, 113, 1786-1791.

[36] a) T. J. De Boer, H. J. Backer, Org. Synth. 1963, 4, 250-254; b) J. A. Moore, D. E. Reed, Org. Synth. 1961, 41, 16.

[37] A. M. Montaña, Química Orgánica Estructural, vol. I: Enlace Químico y Constitución Molecular, Pearson Prentice-Hall, Madrid, 2014, 3rd edition, p. 71-268.; A. M. Montaña, Química Orgánica Estructural, vol. II: Estereoquímica y Propiedades Moleculares, Pearson Prentice-Hall, Madrid, 2014, 3rd edition, p. 845-1000 and 1263-1340.

[38] a) P. Neeb, S. Frank, O. Horie, G. K. Moortgat, Atmos. Environ. 1997, 31, 1417-1423; b) B. Bonn, G. Schuster, G. K. Moortgat, J. Phys. Chem. A 2002, 106, 2869-2881; c) X. Zhang, Z. Chen, H. Wang, S. He, G. Huang, Atmos. Environ. 2009, 43, 4465-4471; d) A. S. Hasson, A. W. Ho, K. T. Kuwata, S. E. Paulson, J. Geophys. Res. 2001, 106, 34131-34142; e) S. Richters, H. Herrmann, T. Berndt, Environ. Sci. Technol. 2016, 50, 2354-2362; f) L. Vereecken, A. R. Rickard, M. J. Newland, W. J. Bloss, Phys. Chem. Chem. Phys. 2015, 17, 23847-23858; g) L. Yao, Y. Ma, L. Wang, J. Zheng, A. Khalizov, M. Chen, Y. Zhou, L. Qi, F. Cui, Atmos. Environ. 2014, 94, 448-457. 
[39] a) Q. E. Thomson, J. Org. Chem. 1962, 27, 4498-4502; b) S. L. Schreiber, R. E. Claus, J. Reagan, Tetrahedron Lett. 1982, 23, 3867-3870; c) J. A. Marshall, A. W. Garofalo, J. Org. Chem. 1993, 58, 3675-3680; d) S. L. Schreiber, W. F. Liew, Tetrahedron Lett. 1983, 24, $2363-$ 2367; e) T. J. Fisher, P. H. Dussault, Tetrahedron Lett. 2010, 51, 5615-5619; f) J. Mulzer, T. Schulze, A. Strecker, W. Denzer, J. Org. Chem. 1988, 53, 4098-40103; g) D. Gupta, R. Soman, S. Dev, Tetrahedron 1982, 38, 3013-3018; h) G. S. Nandra, M. J. Porter, J. M. Elliott, Synthesis 2005, 475-479; i) K. A. Pollart, R. Miller, J. Org. Chem. 1962, 27, 2392-2394; j) W. White, S. W. King, J. O. O'Brien, Tetrahedron Lett. 1971, 12, 3591-3595; k) D. M. Laventine, M. Davies, E. L. Evinson, P. R. Jenkins, P. M. Cullis, J. Fawcett, Tetrahedron 2005, 46, 307-310; 1) K. Namba, Y. Murata, M. Horikawa, T. Iwashita, S. Kusumoto, Angew. Chem. Int. Ed. 2007, 46, 7060-7063; Angew. Chem. 2007, 119, 7190; m) T. T. Shawe, C. J. Sheils, S. M. Gray, J. L. Conard, J. Org. Chem. 1994, 59, 5841-5842; n) D. H. Hua, S. Venkataraman, J. Org. Chem. 1988, 53, 1095-1097; o) R. Willand-Charnley, T. J. Fisher, B. M. Johnson, P. H. Dussault, Org. Lett. 2012, 14, 2242-2245; p) C. E. Schiaffo, P. H. Dussault, J. Org. Chem. 2008, 73, 46884690; q) D. F. Taber, K. Nakajima, J. Org. Chem. 2001, 70, 2515-2517; r) K. M. Miller, W. S. Huang, T. F. Jamison, J. Am. Chem. Soc. 2003, 125, 3442-3443; s) H. Lu, C. Li, Org. Lett. $2006,8,5365-5367$.

[40] E. J. Corey, G. Schmidt, Tetrahedron Lett. 1979, 5, 399-402.

[41] a) A. Atsushi, S. Masamune, Tetrahedron Lett. 1986, 27, 4537-4540; b) W. R. Roush, J. Am. Chem. Soc. 1989, 109, 7575-7577.

[42] a) H. Kropf, Houben Weyl Methoden Der Organische Chemie (Ed.: H. Kropf), Thieme, Stuttgart, Germany, 1988, vol. E13/2, p. 1111; b) K. Griesbaum, G. Kiesel, Chem. Ber. 1989, 122, 145-149; c) D. L. J. Clive, M. H. D. Postema, J. Chem. Soc., Chem. Commun. 1994, 235 236; d) L. A. Flippin, D. W. Gallagher, K. Jalali-Araghi, J. Org. Chem. 1989, 54, 1430-1432; e) F. L. Greenwood, J. Org. Chem. 1955, 20, 803; f) B. Witkop, J. B. Patrick, J. Am. Chem. Soc. 1952, 74, 3855; g) P. Dai, P. H. Dussault, T. K. Trullinger, J. Org. Chem. 2004, 69, 2851-2852; h) L. Chen, D. F. Wiemer, J. Org. Chem. 2002, 67, 7561-7564; i) P. Lavallée, G. Bouthillier, J. Org. Chem. 1986, 51, 1362-1365; j) C. Schwartz, J. Raible, K. Mott, P. H. Dussault, Tetrahedron 2006, 62, 10747-10752.

[43] F. Carrel, P. Vogel, Tetrahedron: Asymmetry 2000, 11, 4661-4680.

[44] CCDC 1476717 (for 12), and 1476716 (for 23) contain the supplementary crystallographic data for this paper. These data can be obtained free of charge from The Cambridge Crystallographic Data Centre

[45] a) P. Dobes, J. Rezac, J. Fanfrlík, M. Otyepka, P. Hobza, J. Phys. Chem. B 2011, 115, 85818589; b) J. J. P. Stewart, J. Comput.-Aided Mol. Des. 1990, 4, 1-105; c) J. J. P. Stewart, J. Mol. Model. 2007, 13, 1173-1213.

[46] a) J. J. P. Stewart, MOPAC-2016 Computational Chemistry, Version 16.146W: http://OpenMOPAC.net; b) J. D. C. Maia, G. A. U. Carvalho, C. P. Mangueira, S. R. Santana, L. A. F. Cabral, G. B. Rocha, J. Chem. Theory Comput. 2012, 8, 3072-3081.

[47] C. Lee, W. Yang, R. G. Parr, Phys. Rev. B 1988, 37, 785-789.

[48] a) A. D. Becke, J. Chem. Phys. 1993, 98, 5648-5652; b) A. Bakalova, R. Buyukliev, G. Momekov, J. Mol. Struct. 2015, 1091, 118-124. 
[49] M. J. Frisch, G. W. Trucks, H. B. Schlegel G. E. Scuseria, M. A. Robb, J. R. Cheeseman, V. G. Zakrzewski, J. A. Montgomery Jr., E. Stratmann, J. C. Burant, S. Dapprich, J. M. Millam, A. D. Daniels, K. N. Kudin, M. C. Strain, O. Farkas, J. Tomasi, V. Barone, M. Cossi, R. Cammi, B. Mennucci, C. Pomelli, C. Adamo, S. Clifford, J. Ochterski, G. A. Petersson, P. Y. Ayala, Q. Cui, K. Morokuma, A. D. Malick, K. D. Rabuck, K. Raghavachari, J. B. Foresman, J. Cioslowski, J. V. Ortiz, A. G. Baboul, B. B. Stefanov, G. Liu, A. Liashenko, P. Piskorz, I. Komaromi, R. Gomperts, R. L. Martin, D. J. Fox, T. Keith, M. A. Al-Laham, C. Y. Peng, A. Nanayakkara, M. Challacombe, P. M. W. Gill, B. Johnson, W. Chen, M. W. Wong, J. L. Andrés, C. González, M. Head-Gordon, E. S. Replogle, J. A. Pople, Gaussian 03, revision E.01SMP, Gaussian, Inc., Wallingford, CT, 2004.

[50] a) W. J. Hehre, R. Ditchfield, J. Pople, J. Chem. Phys. 1972, 56, 2257-2261; b) P. N. V. Pavankumar, P. Seetharamulu, S. Yao, J. D. Saxe, G. Dasharatha, G. Reddy, F. H. Hausheer, J. Comput. Chem. 1999, 20, 365-382.

[51] J. Tomasi, B. Mennucci, R. Cammi, Chem. Rev. 2005, 105, 2999-3093.

[52] G. M. Sheldrick, Acta Crystallogr., Sect. A 2008, 64, 112-221.

[53] International Tables of X-ray Crystallography, Kynoch Press, 1974, vol. IV, p. 99-100 and 149. 


\section{Legends to figures}

1316

1317

1318

1319

1320

1321

1322

1323

1324

1325

1326

1327

1328

1329

1330

1331

1332

1333

1334

1335

1336

1337

1338

1339

1340

1341

1342

1343

1344

1345

1346

1347

1348

1349

Figure 1. Examples of natural products containing acetallic THP subunits.

Scheme 1. (a) Generation of oxyallyl cation II. (b) [4+3] cycloaddition. (c) Reduction of the carbonyl group at C3. (d) Protection of alcohol group on C3. (e) Reductive ozonolysis. (f) Oxidative ozonolysis.

Scheme 2. Generation of C1-functionalized 8-oxabicyclo[3.2.1] oct-6-en-3-one products via the $[4 \mathrm{C}(4 \pi)$ $+3 \mathrm{C}(2 \pi)$ ] cycloaddition. Theoretically possible diastereoisomeric products are so indicated.

Figure 2. Mechanism proposed for the formation of the 8-oxabicyclo[3.2.1] oct-6-en-3-one products.

Figure 3. Diastereoselectivity observed in the reduction of carbonyl group in substrates $2 \mathrm{a}$ and $2 \mathrm{c}$. In these cases, the major diastereoisomer resulted from the attack at the Si and Re faces, respectively.

Scheme 3. Cleavage of the oxygen bridge of intermediate 9 .

Scheme 4. Proposed mechanism for the oxidative ozonolysis using UHP with polyfunctionalized oxabicycles.

Figure 4. A) Regioselectivity in the rearrangement of ozonide 9a: formation of 9b. Electrostatic potential map (EPM) of Criegee intermediate 9b, calculated by Gaussian-03 and mapped on an isodensity surface of $0.004 \mathrm{e} \cdot \mathrm{Bohr}-3$, in the potential interval of $+9 \times 10-3$ and $-9 \times 10-3$. The intense positive electrostatic potential (dark blue) at the level of the electrophilic site of carbonyl oxide is particularly noteworthy. B) Minimum energy conformation for Criegee intermediate 9b. Accessibility of the Re face of the carbonyl oxide subunit. C) Minimum energy conformation of 9c, in which it is possible to observe the hydrogen bond of the hydroperoxide group and also the higher accessibility of the Si face of the formyl group.

Scheme 5. Proposed mechanism for the formation of products 18 and 19 during oxidative ozonolysis using PDC.

Scheme 6. Products 20 and 21 obtained from the oxidative ozonolysis with $\mathrm{KMnO} 4$ as an oxidizing agent. 
1350 Scheme 7. Proposed mechanism for the formation of THP products by reductive ozonolysis. Generation 1351 of 23 by an independent trans-acetallization process under acidic conditions.

1352

1353

1354

1355

1356

1357

1358

1359

1360 


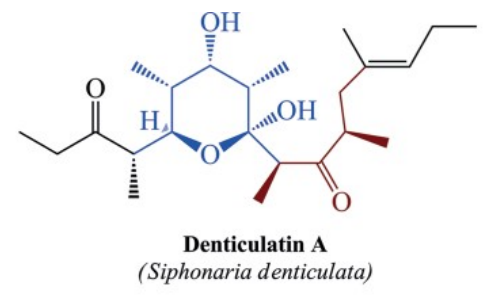<smiles>[R]c1oc([C@@H](C)[C@]2(O)O[C@]3(O[C@H]([C@@H](C)C(=O)CC)[C@@H](C)C(=O)[C@H]3C)[C@@H](C)[C@@H](O)[C@@H]2C)c(C)c(=O)c1C</smiles>

Siphonarin $\mathbf{A}, \mathrm{R}=\mathrm{Me}$

Siphonarin B, R $=$ Et $\quad$ (Siphonaria australis)

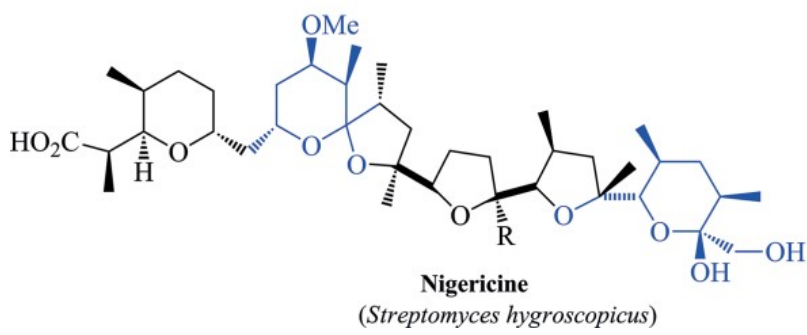

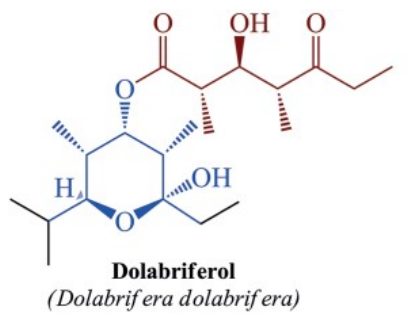

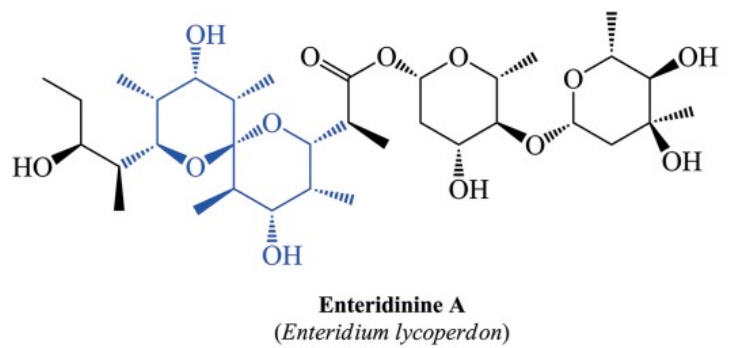

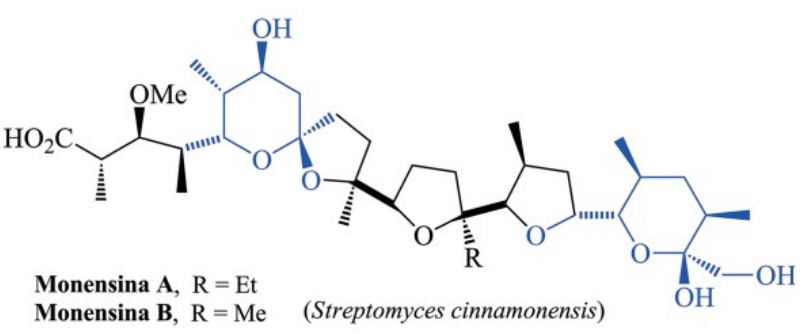




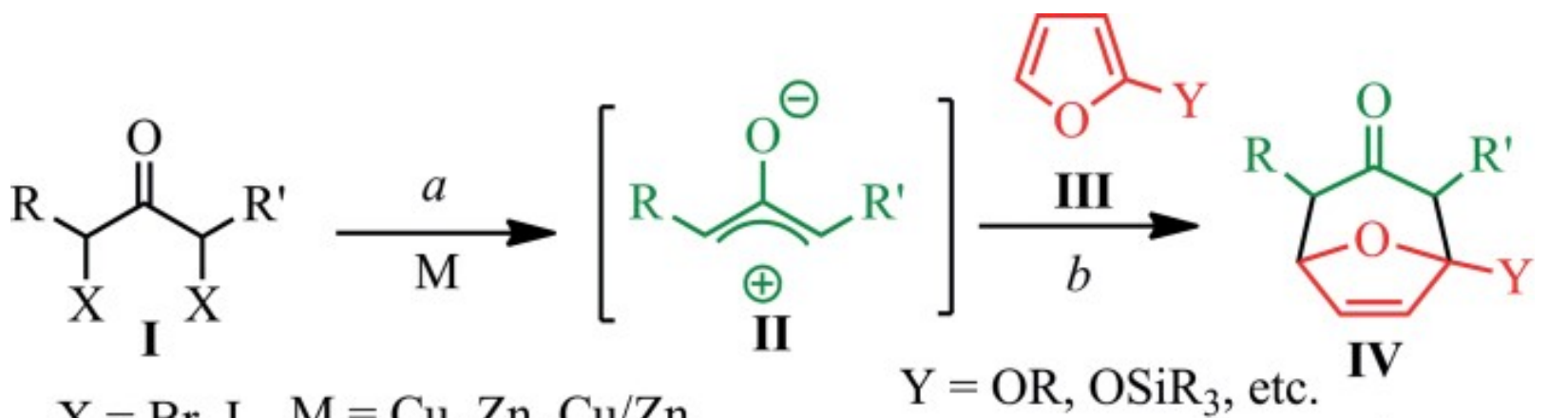
$\mathrm{X}=\mathrm{Br}, \mathrm{I} \quad \mathrm{M}=\mathrm{Cu}, \mathrm{Zn}, \mathrm{Cu} / \mathrm{Zn}$, $\mathrm{Ag}, \mathrm{Zn} / \mathrm{Ag}, \mathrm{Cu} / \mathrm{NaI}$, $\mathrm{Fe}_{2}(\mathrm{CO})_{9}$ $\mathrm{R}, \mathrm{R}^{\prime}=\mathrm{H}, \mathrm{Br}, \mathrm{CH}_{3}$, etc.
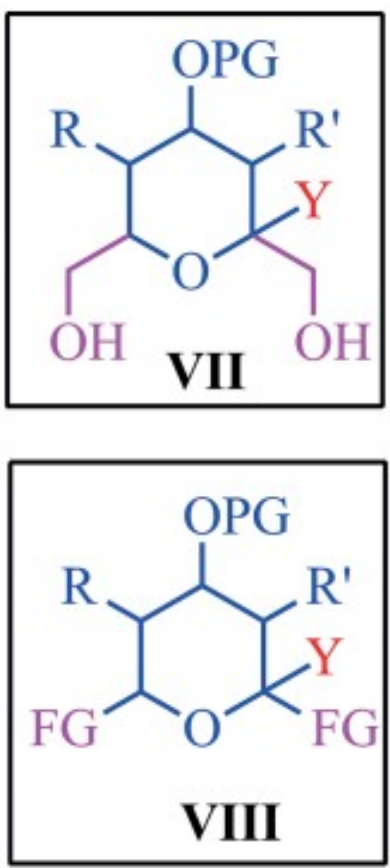

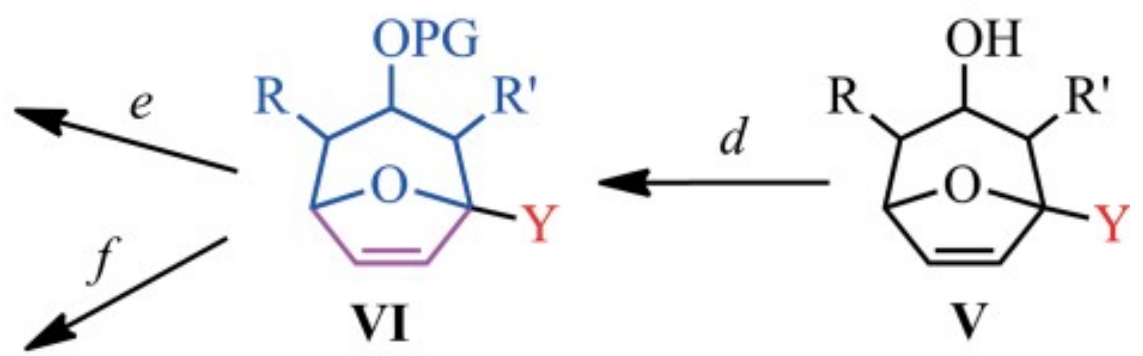

$P G=B n, A c$ 


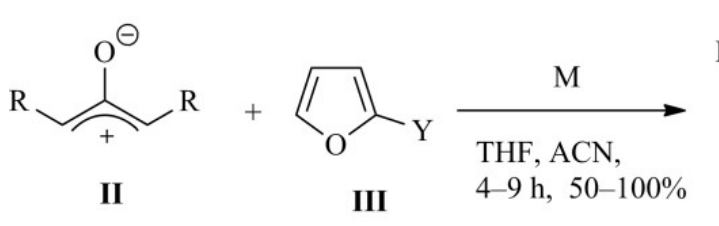<smiles>[R]C1C(=O)C([R])[C@@]2([Y])C=C[C@@H]1O2</smiles>

IVa

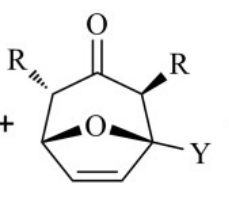

IVb

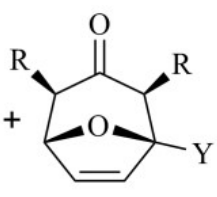

IVe

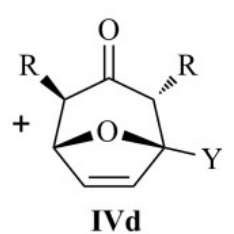

$\mathrm{R}=\mathrm{Me}$, Akyl, $\quad \mathrm{Y}=\mathrm{OR}, \quad \mathrm{M}=\mathrm{Cu}, \mathrm{Zn}, \mathrm{Cu} / \mathrm{Zn}$,

$\mathrm{H}$, Hal, Chex., etc $\mathrm{OSiR}_{3}$, etc. $\mathrm{Ag}, \mathrm{Zn} / \mathrm{Ag}, \mathrm{Cu} / \mathrm{NaI}$, $\mathrm{Fe}_{2}(\mathrm{CO})_{9}$<smiles>C/C=C(/[O-])C=C[C+]1C=CC=C1OC</smiles>

1

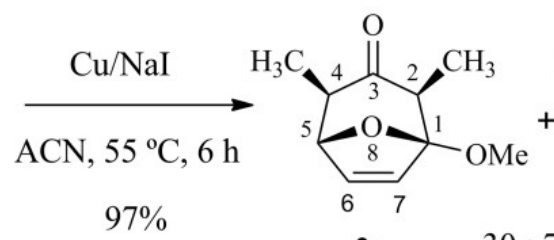

2a $30: 70$

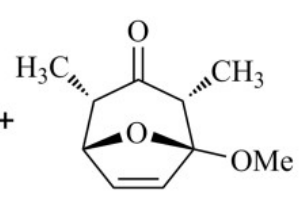

2c 


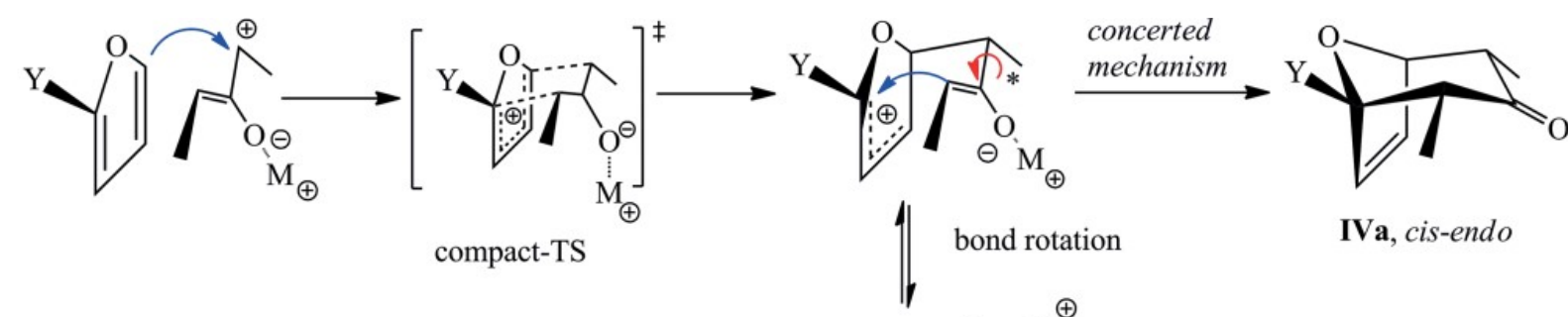

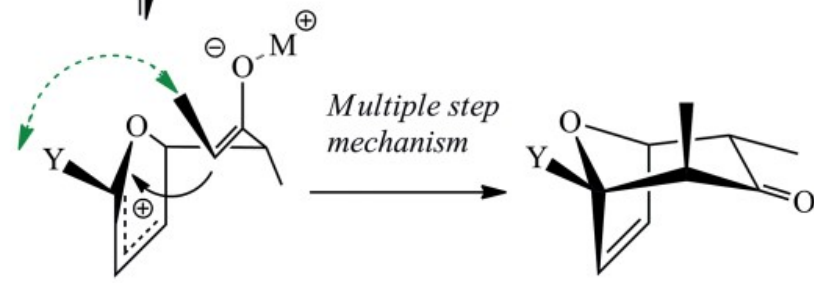

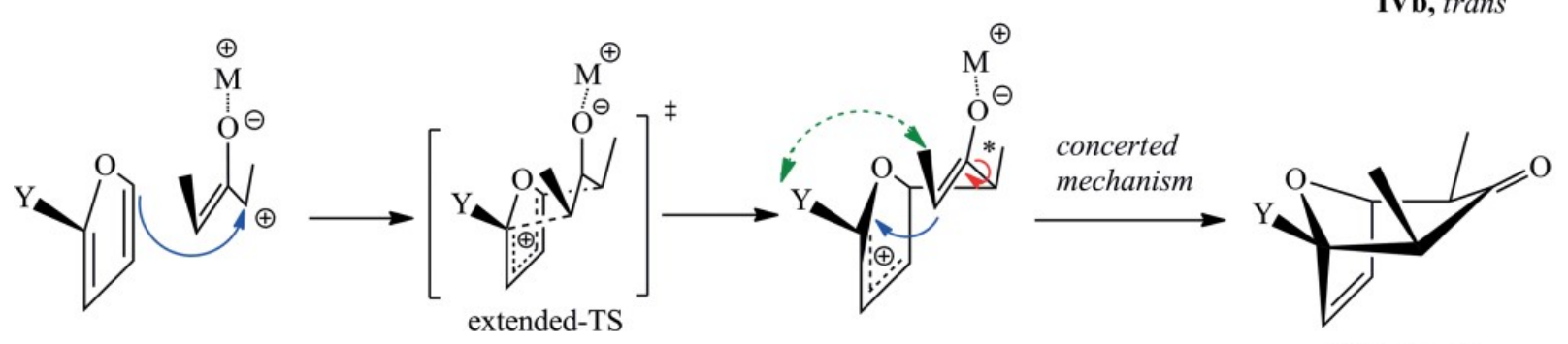
IVc, cis-exo bond rotation 


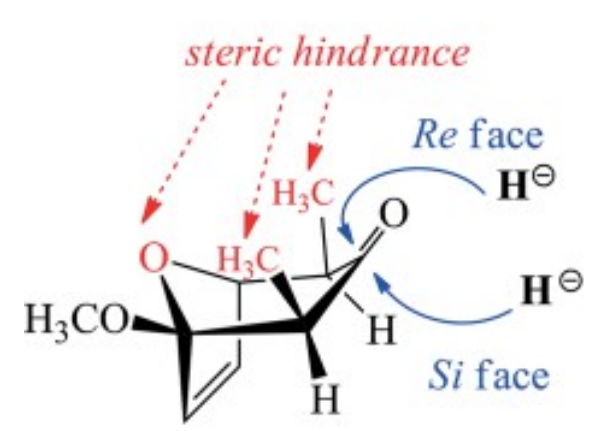

2a

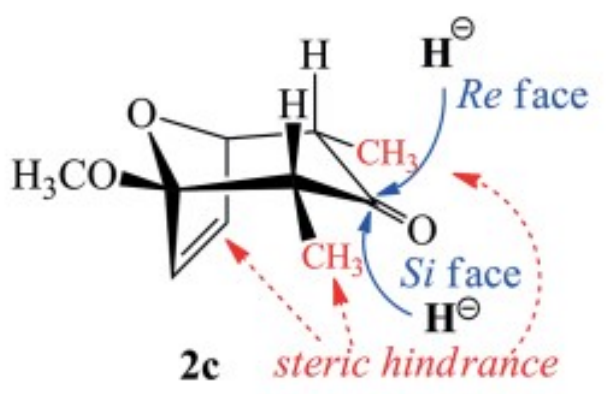

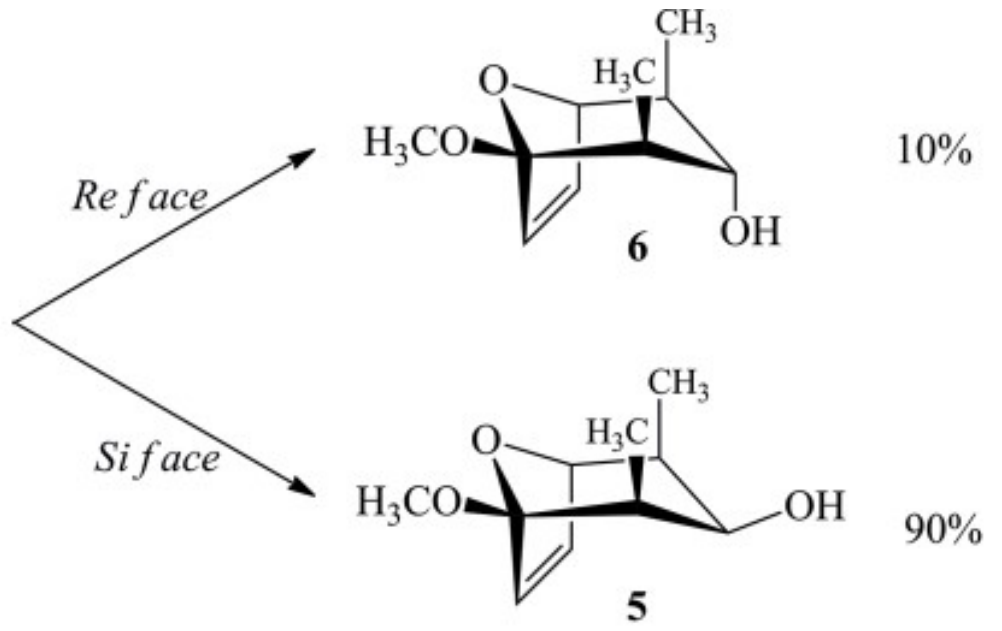

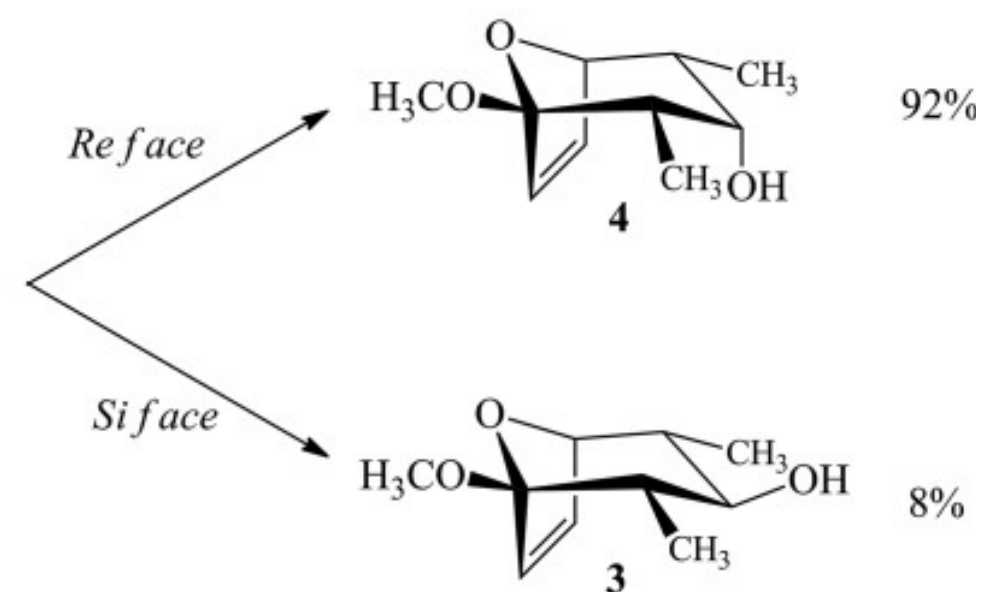




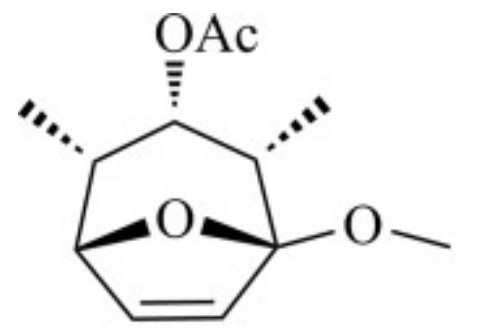

9

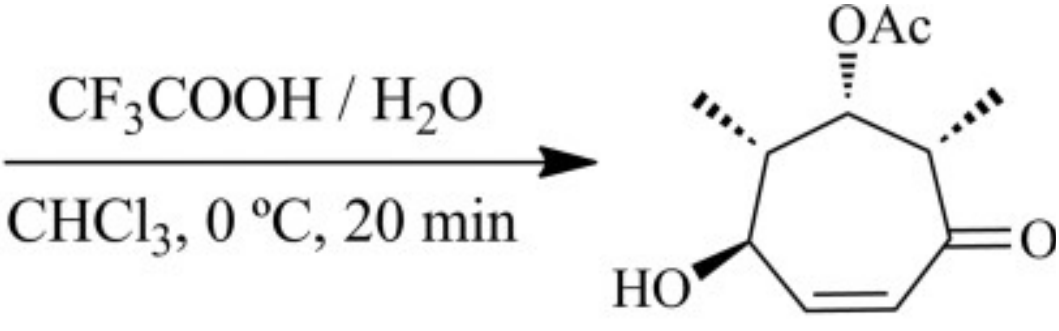

$1190 \%$ 
<smiles>CO[C@]12C=C[C@@H](O1)[C@@H](C)[C@@H](OC(C)=O)[C@@H]2C</smiles>

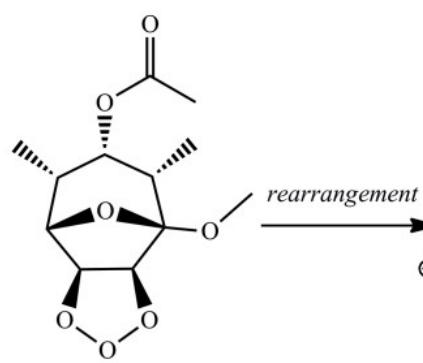

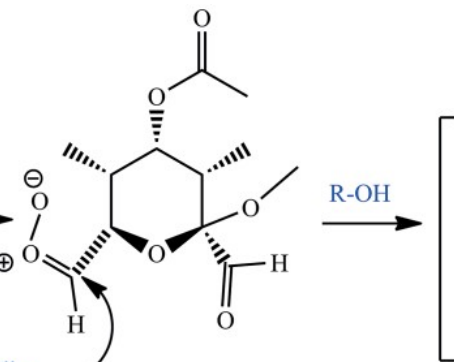
ozonide 9a $R e$ face R-ÖH (exo) $\begin{gathered}\text { more accessible site } \\ \text { (stereoselective attack) }\end{gathered}$ b

Criegee intermediate<smiles>[2H][C@H](OO)[C@H]1O[C@@](C=O)(OC)[C@H](OC(C)=O)[C@@H]1C</smiles>

9c

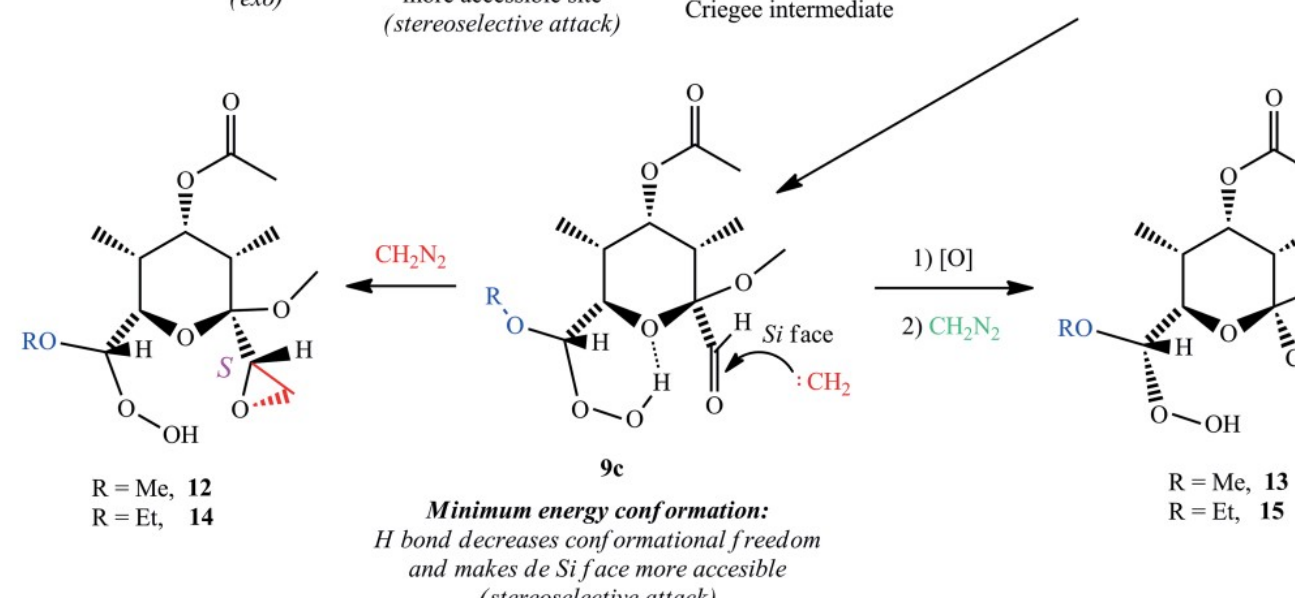




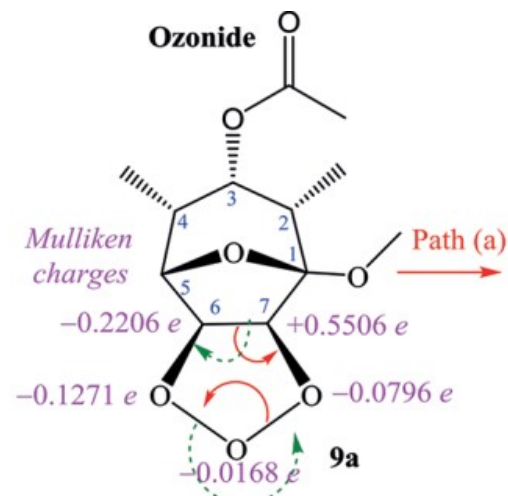

$\Delta H_{f}=-185.42 \mathrm{Kcal} \cdot \mathrm{mol}^{-1}(\mathrm{PM} 7)$

Total steric energy $=54.59 \mathrm{Kcal} \cdot \mathrm{mol}^{-1}(\mathrm{MM} 2)$<smiles>CO[C@]1([C@@H](O)O[O-])O[C@H](C=O)[C@@H](C)[C@H](OC(C)=O)[C@@H]1C</smiles>

Criegee intermediate II, 9b

$\Delta H_{f}=-189.53 \mathrm{Kcal} \cdot \mathrm{mol}^{-1}$

Total steric energy $=18.85 \mathrm{Kcal} \cdot \mathrm{mol}^{-1}$<smiles>CO[C@]1(C=O)O[C@H](C=O)[C@@H](O)[C@H](OC(C)=O)[C@@H]1C</smiles><smiles>CO[C@@H](O[O-])[C@H]1O[C@@](C=O)(OC)[C@@H](C)[C@H](OC(C)=O)[C@H]1C</smiles>

Criegee intermediate I, 9b $\Delta H_{f}=-191.46 \mathrm{Kcal} \cdot \mathrm{mol}^{-1}$ Total steric energy $=13.64 \mathrm{Kcal} \cdot \mathrm{mol}^{-1}$

(A) Regioselectivity in the rearrangement of ozonide 9a: formation of $9 \mathbf{b}$

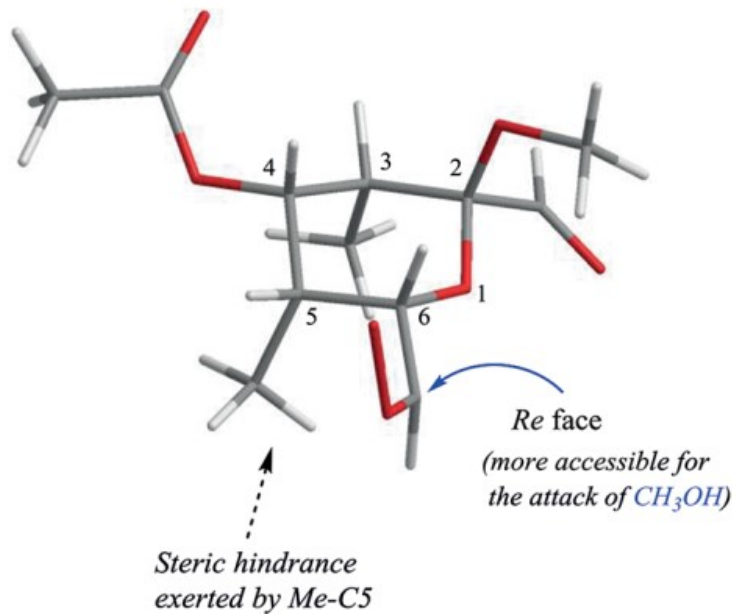

(B) Minimum energy conformation for Criegee intermediate

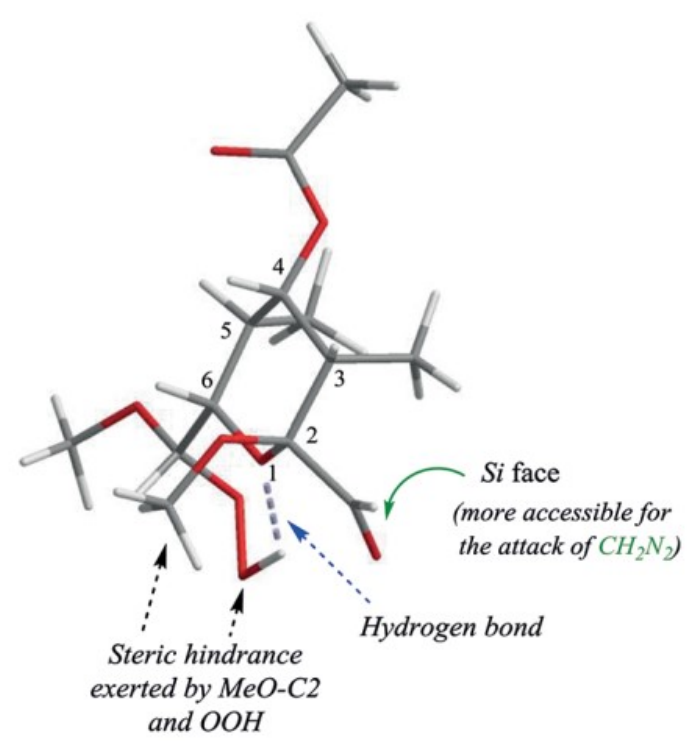

(C) Minimum energy conformation for the acetallic hydroperoxide intermediate 9c 


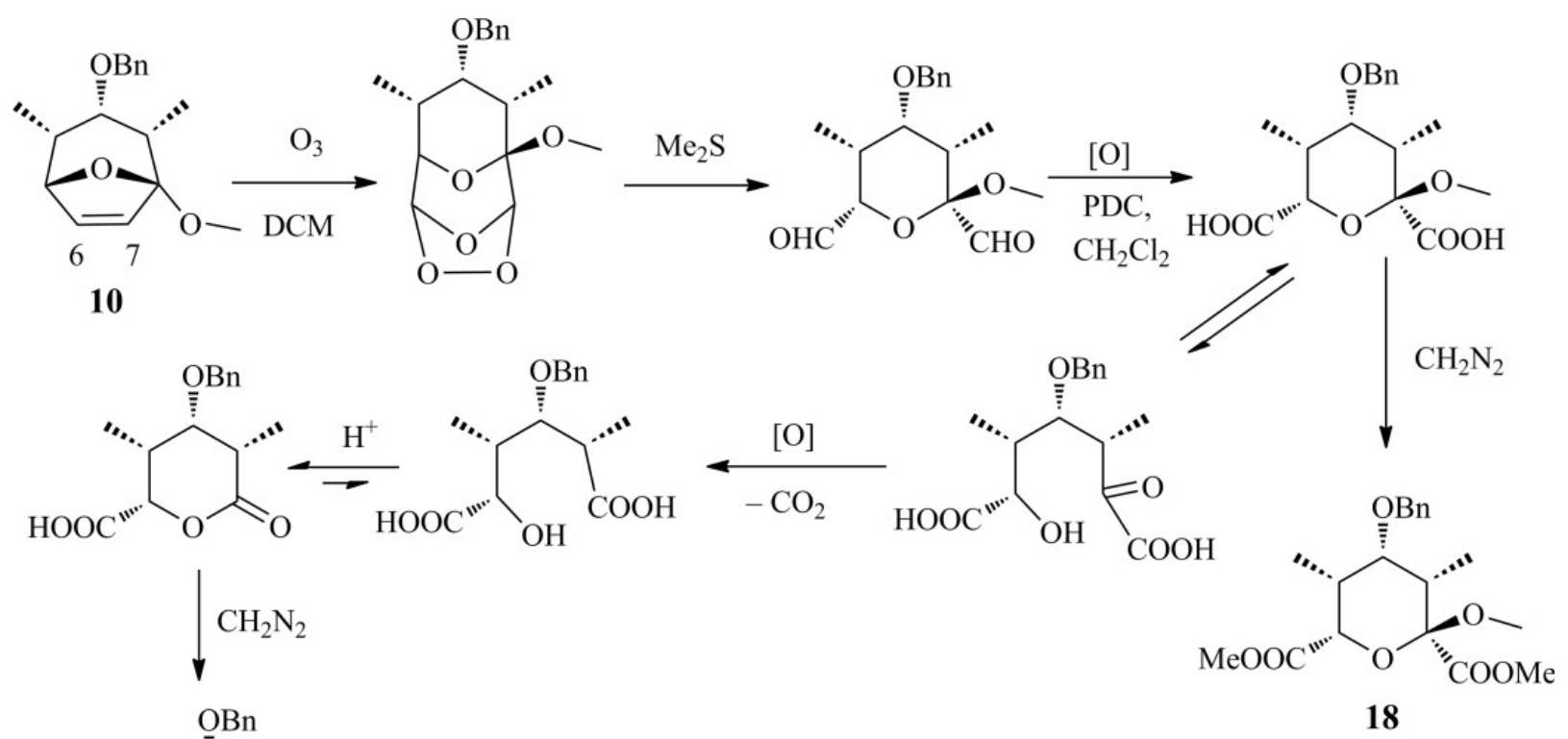<smiles>CC(=O)[C@H]1OC(=O)[C@H](C)[C@H]2O[C@@H](c3ccccc3)[C@@H]1[C@H]2C</smiles> 
<smiles>CO[C@]1(C(=O)O)O[C@H](C(=O)O)[C@@H](C)[C@H](OCc2ccccc2)[C@@H]1C</smiles><smiles>CO[C@H]1C[C@@](OC)(C(=O)O)O[C@H](C(=O)O)[C@@H](C)[C@@H]1OC(=O)c1ccccc1</smiles><smiles>CO[C@]1(C(=O)O)O[C@H](C(=O)O)[C@@H](C)[C@H](O)[C@H]1C</smiles><smiles>COC(=O)[C@]1(OC)O[C@H](C(C)=O)[C@@H](C)[C@H](OC(=O)c2ccccc2)[C@@H]1C</smiles>
$\downarrow \mathrm{CH}_{2} \mathrm{~N}_{2}$<smiles>COC(=O)[C@H]1O[C@@](OC)(C(=O)OC)[C@H](C)[C@H](O)[C@H]1C</smiles> 


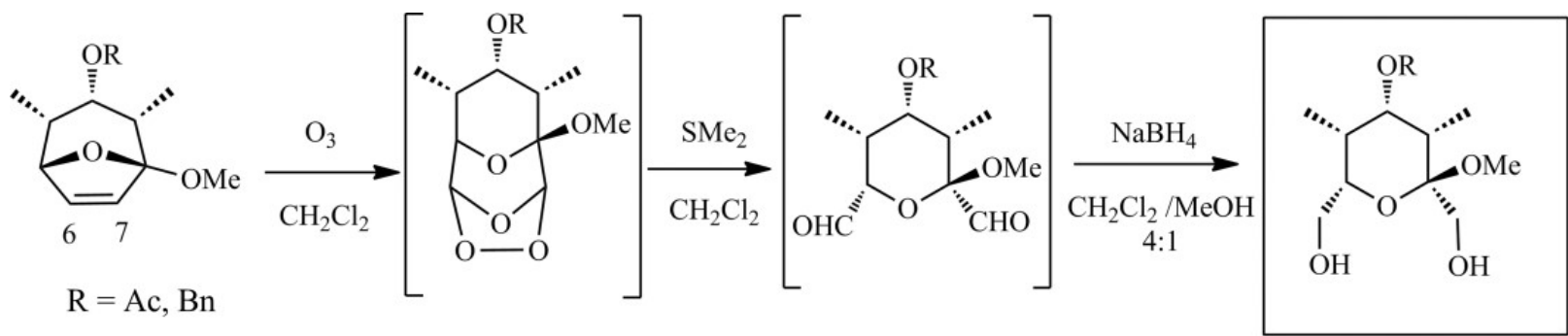

$\mathrm{R}=\mathrm{Ac}, \mathrm{Bn}$

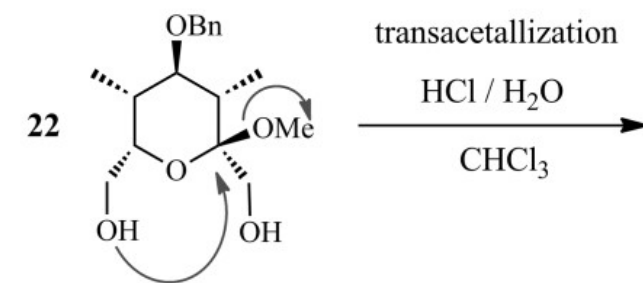

major product 
1423 Table 1 Alcohols resulting from the reduction of 1-methoxy-2,4-dimethyl-8-oxabicyclo[3.2.1]oct-6-en1424 3-ones.

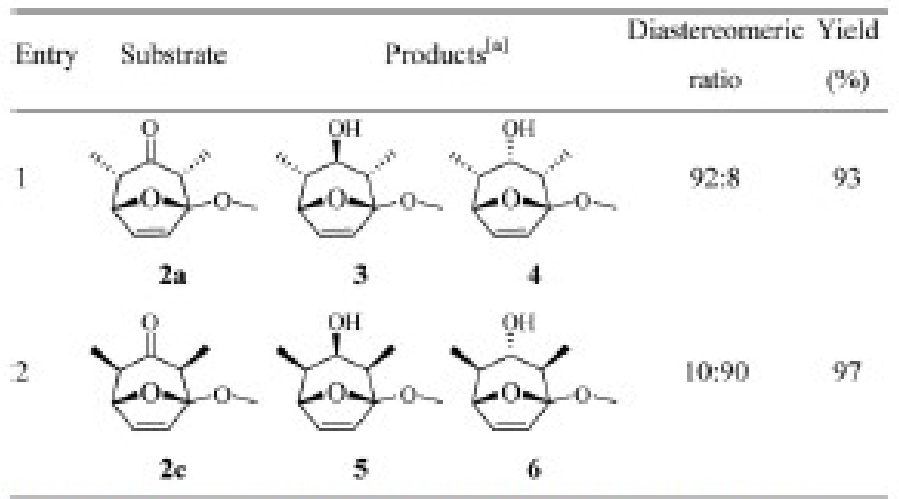

[a] The optimal results were obtained using $\mathrm{NaBH}_{4} \mathrm{MeOH}, 0^{\circ} \mathrm{C}, 7 \mathrm{~h}$. 
1432 Table 2. Protection of 8-oxabicyclo[3.2.1]oct-6-en-3-ols to afford 7-10.

Entry Substratc Conditions Products Yield

1 AcclMeli, THF,

3

7

2

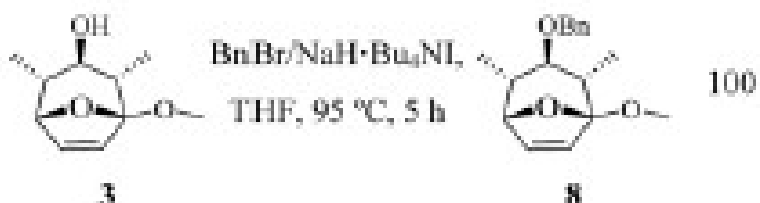

3

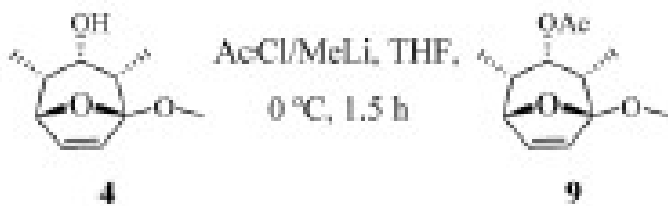
77
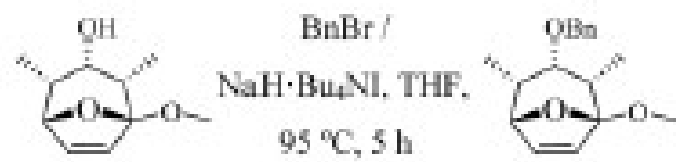

96 
1438 Table 3. Results from the oxidative ozonolysis reaction for the generation of THP final products.

\begin{tabular}{ll} 
Entry & \multicolumn{1}{c}{ Conditions } \\
\hline 9 & 1) $\mathrm{O}_{7},-78^{\circ} \mathrm{C}$ \\
& 3) $\mathrm{CH}_{2} \mathrm{~N}_{2}$ r.t. $0.5 \mathrm{~h}(4$ equiv. $)$,
\end{tabular}

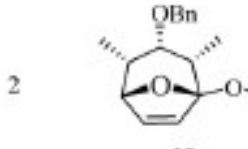

10

1) $\mathrm{O}_{3},-78^{\circ} \mathrm{C}$

2) UHP ( 8 equiv.),

$-60^{\circ} \mathrm{C}, 1.5 \mathrm{~h}$

3) $\mathrm{CH}_{2} \mathrm{~N}_{2}$, r.t., $0.5 \mathrm{~h}$

ЕtOH<smiles>CO[C@H](O)[C@H]1O[C@](O)(C2(C)CO2)[C@H](C)[C@@H](C)[C@@H]1C</smiles>

12

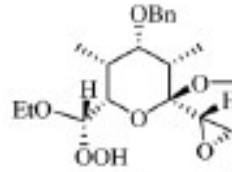

14

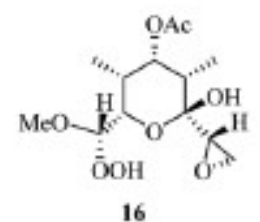<smiles>CO[C@]1(C(C)=O)O[C@H](C(C)=O)[C@@H](C)[C@H](OC(C)=O)[C@@H]1C</smiles>

17

$\mathrm{QA}$

13

9 3) $\mathrm{CH}_{2} \mathrm{~N}_{3}$, r.t $0.5 \mathrm{~h}$<smiles>COC(=O)[C@@]1(OC)O[C@@H]([C@@H](C)OC)[C@H](C)C[C@@H]1C</smiles>

$46: 34$

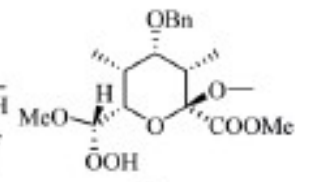

$30: 45$<smiles>COC(=O)[C@H]1O[C@](OC)(C(=O)OC)[C@H](C)[C@H](O)[C@@H]1Cc1ccccc1</smiles><smiles>CC(=O)[C@H]1OC(=O)[C@H](C)[C@H](C(=O)c2ccccc2)[C@@H]1C</smiles>

8 3) PDC, r.t., $4 \mathrm{~h}$ $\mathrm{CH}_{2} \mathrm{Cl}_{2}$ 4) $\mathrm{CH}_{2} \mathrm{~N}_{3}$, r.t., $0.5 \mathrm{~h}$

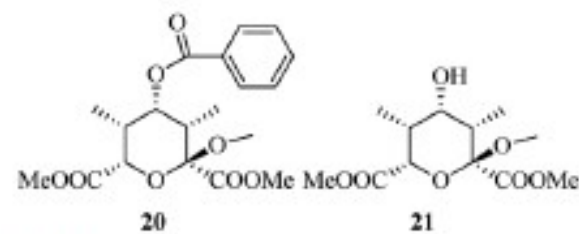


1443 Table 4. Results from the reductive ozonolysis reaction for the formation of THP final products.

Eniry Subiran Condibns solwer Products

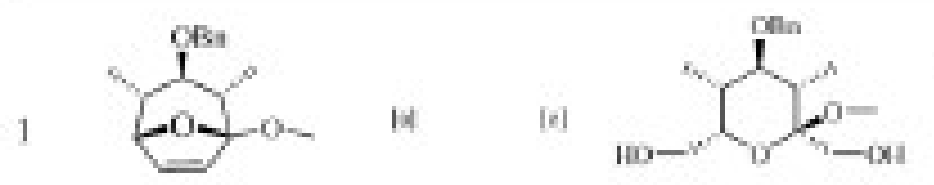

is<smiles>COC12C=CC(O1)C(C)C(C)C2(C)C</smiles>

10<smiles>COC12C=CC(O1)[C@@H](C)[C@H](C)[C@H]2C</smiles>

9

22

24<smiles>CC1[C@@H](C)[C@H](C)[C@@H](C)[C@@]2(C[Hg])OC[C@H]12</smiles>

23

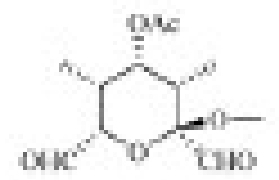

34 
1448 Table 5. Crystal data and structure refinement for 12 and 23.[44]

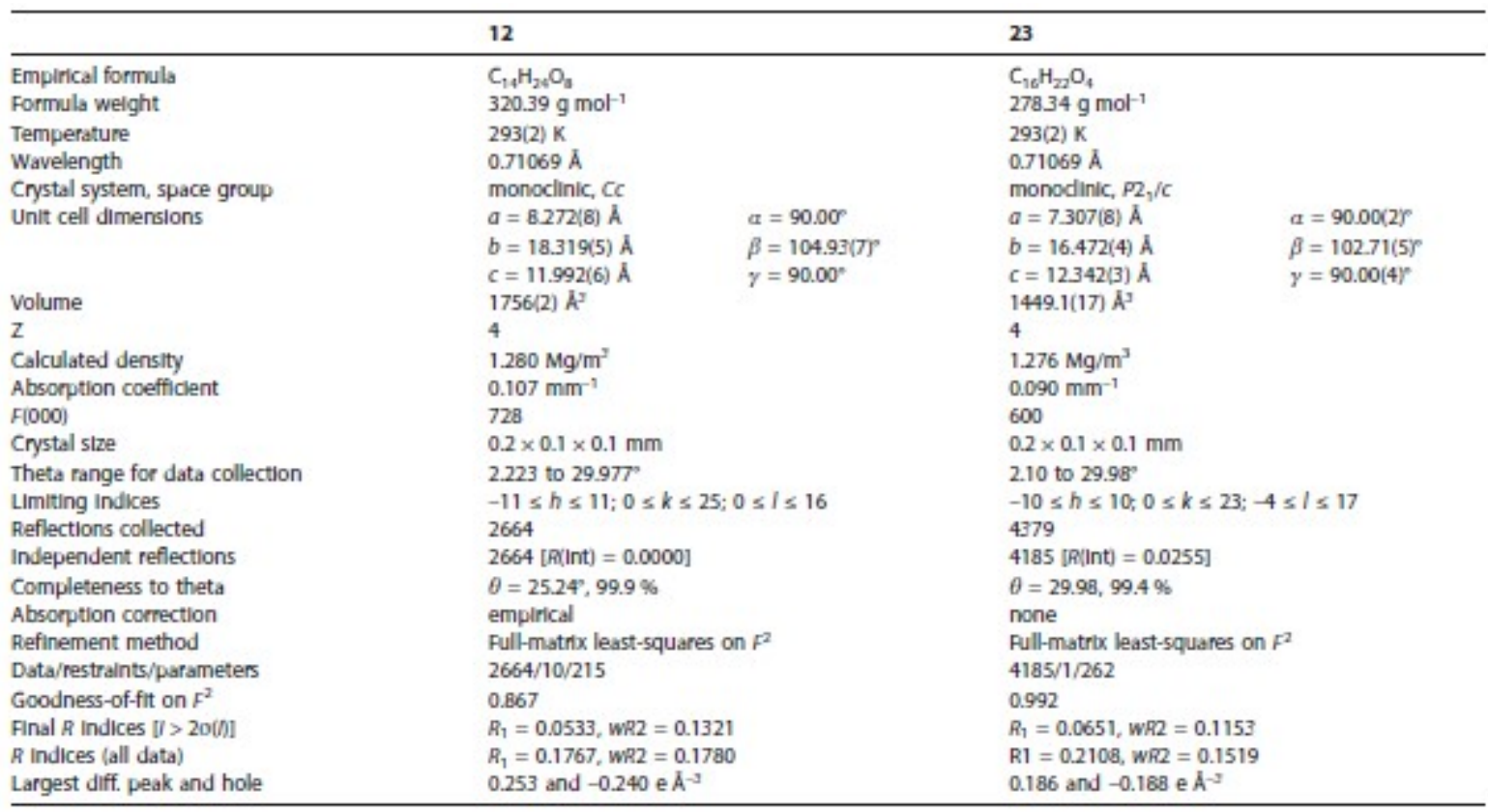

